\title{
Section 6
}

Tracking of specific microbes in the environment 


\title{
Lac as a marker gene to track microbes in the environment
}

\author{
FRANS DE LEIJ and NIGEL BAINTON \\ School of Bio-medical and Life Sciences, University of Surrey, Guildford, Surrey, GU2 7XH, \\ United Kingdom.
}

\section{Introduction}

The environmental use of microorganisms as a means to combat pests and diseases, to remediate contaminated land and act as bio-fertilisers and plant growth promoters has been a focus for research for many years. However, the successful application of living microbial inocula is dependent on a thorough understanding of the behaviour of the organisms involved in relation to the environment into which they are released [8]. In order to gain this type of understanding, a large variety of selective and semi-selective media have been developed that allow selective recovery of organisms from environmental samples. Such media make use of specific characteristics that are inherent to the organism under study. Such characteristics include, growth conditions (temperature, $\mathrm{pH}$, etc), resistance to antibiotics and heavy metals, tolerance to osmotic pressure and/or expression of phenotypic characteristics such as fluorescent pigments, coloration and morphology. In this way, media have been designed for the isolation and quantification of many ecologically important bacteria [27]

Recent advances in recombinant technology have allowed the identification, characterisation and isolation of genes that encode for useful characteristics in relation to environmental applications. After isolation, and introduction into suitable vector systems, such genes can subsequently be introduced into a single recipient organism, allowing the creation of a genetically modified microorganism (GMM) with potentially 'improved' characteristics for environmental use. However, public concerns over the possible (negative) consequences of releasing functionally 'improved' organisms into the environment has increased the need for the development of sensitive detection techniques for microorganisms in environmental samples. The need to detect GMMs in the environment has created an impetus for the development of detection methods employing molecular techniques. Besides genes that encode for functional characteristics that are aimed to improve the environmental performance of a GMM, a variety of genes have been isolated from several organisms to facilitate detection of a particular GMM in the environment. Depending on the type of genetic marker employed, a GMM may be tracked phenotypically, relying on the expression of the marker gene by the GMM. Alternatively, 
the presence of a marker gene can be identified by methods that do not rely on its expression [19]. In general, maker genes can be divided into three groups:

1. Short but unique oligonucleotide sequences that act as a genetic signature.

2. Genes that provide a selectable characteristic, such as resistance to an antibiotic, a heavy metal or ability to metabolise an unusual chemical.

3. Chromogenic markers that provide a colour change.

Chromogenic markers contain one or more genes whose presence in a microbial cell may be detected by an ability to produce a colour change in a substrate. Isolation of microorganisms on media supplemented with substrates that are capable of being transformed into coloured products has been used successfully to distinguish bacteria expressing the $x y l E$ gene, which encodes for catechol 2,3-dioxygenase [30] and those that carry the lacZY genes from Escherichia coli. The latter encode B-galactosidase (lacZ) and lactose permease (lacY) [14]. Other systems in this category are GUS (expression of B-glucoronidase), the lux operon from Vibrio fischeri, in which organisms are identified by their ability to bio-luminesce [28] and accumulation of GFP (Green Fluorescent protein) within cells that express the GFP genes from the jelly fish Aequorea victoria [5].

\section{The lac operon}

The lac operon of $E$. coli spans approximately 5300 base pairs and includes the $l a c Z$, lac $Y$ and $l a c A$ genes in addition to the operator, promoter and transcription terminator regions. Since its description [18], the lactose operon has been a model system of great usefulness in biology. Study of this operon has touched on some significant questions in biology. For example, fundamental questions of the mechanisms involved in expressing genes were first studied in this system [18]. The discovery of the lac repressor and its binding to an operon site on the DNA was one of the first problems concerning protein-DNA interactions to be examined [25]. Studies of B-galactosidase in relation to lac $Z$ mutants have been important in defining many aspects of gene-protein relationships. Studies with fragments of B-galactosidase also have served as a model system for investigating proteinprotein interactions. The lactose permease, the product of the second structural gene, lac $Y$, was the first membrane transport protein that was studied extensively. Many fundamental concepts of the transport of molecules into the cell were derived from these studies. It is therefore not surprising that structures of the lactose operon have been investigated intensively [3]. For example, Fowler and Zabin [15] reported the amino-acid sequence of B-galactosidase in 1978. When methods for determining DNA sequences became available, the DNA sequence of both the lac repressor and the control elements of the lactose operon was determined [3,16]. After the DNA sequence of $l a c Y$ was confirmed [4], the DNA sequence of lac $Z$ was determined [20] with the amino acid sequence of B-galactosidase as confirmation. The third component of the lac operon, lacA, was sequenced in 1985 and its amino-acid sequence determined [17]. The lacA gene encodes for 
thiogalactosidetransacetylase and is thought to be involved in detoxification of thiogalactosides by the cell.

\section{Procedures}

Genetic marking of fluorescent Pseudomonas with lacZY

To be of use for tracking microbes in the environment, marker genes need to be rare in the release environment to allow distinction between the marked organism and indigenous populations on non-selective media. Alternatively, the isolation medium should be selective, not allowing growth of indigenous bacteria that express the phenotypic features encoded by the marker gene. All fluorescent pseudomonads isolated from the environment are unable to use lactose as a carbon source. This feature makes the genes that make up the lac operon ideal as genetic markers for this group of bacteria. Not only do these genes enable a recipient organism to utilise lactose as the sole carbon source, but the lac $Z$ gene, which encodes for B-galactosidase, allows cleavage of the substrate X-gal (5-chloro4-bromo-3-indolyl-B-D-galactopyranoside) into a bright blue product that is easily recognised [14]. To determine whether lac $Z$ alone was sufficient for lactose utilisation, lacY was eliminated on broad hostrange plasmids (pMON5002 and pMON5013) which were constructed to carry genes into recipient bacteria. Plasmid pMON5002 was restricted with $\mathrm{EcoRI}$ at the unique site in the lac $Z$ coding sequence and with Bglll, which cuts uniquely down stream from lacY. The incorporation of the lacZ gene alone did not confer the ability of transformed Pseudomonas cells to efficiently utilise lactose as a sole carbon source. The inclusion of lacY (lactose permease) enabled growth at a rate comparable to that observed on glucose. This implies that in Pseudomonas, as in E.coli, B-galactosidase remains a cytoplasmic protein, which does not gain access to sufficient lactose, without an active lactose transport mechanism. The lacY product, lactose permease, provides this transport mechanism [14].

Although different strategies can be employed to generate lacZY marked bacteria, the following might serve as an example of procedures employed by Barry [2] to obtain a lacZY marked P. aureofaciens that was used for release in the field [12]. Although the E. coli lacZY 
genes expressed from different promoters on broad host-range plasmids are highly effective selectable markers for Pseudomonas [14], these genes are equally effective when delivered by a transposon Tn7-lac element into the bacterial chromosome. The advantage of $\mathrm{Tn} 7$ is that the transposition gene products function in trans and only 160 base pairs at each terminus are required to allow this transposition to occur. In addition, $\mathrm{Tn} 7$ inserts with high specificity integrate at high frequency into the chromosomes of many Gram-negative bacteria. Tn 7 typically has only one insertion site per bacterial chromosome and is relatively rare in the environment [24]. Therefore, using the Tn 7 based delivery system eliminates the need for screening through unwanted transposon mutants [22]. Originally the Tn7-lac element was composed of two unstable plasmids of different incompatibilities. Although the method is useful for generating lac-marked Pseudomonas, features that make this method unsuitable for common use are that any manipulation of the $\mathrm{Tn} 7$ element has to be done on a low copy plasmid not amenable to fast multiplication [2]. Also the Tn7-lac element itself contains a number of unknown regions of DNA that might originate from $E$. coli or from $\varphi 80$ or $\lambda$ at the end of the lacA gene. The first improvement involved the use of the smaller IncO plasmids in the cloning and delivery system. Because of the decrease in size and the apparent broader host-range of IncO plasmids, the double IncO system can be used effectively in the cloning of genes and in the introduction of Tn7-lac elements into Pseudomonas. To further facilitate the cloning steps, and in particular the construction of more versatile and more widely applicable Tn7-lac elements, a small replicon was made by making a deletion of pUC8. A $500 \mathrm{bp}$ fragment was cloned in this from into the $E$. colichromosome containing the $T n 7$ insertion site. Into this E. colistrain the Tn7-lac element had been transposed and the bacterium contained a helper plasmid. From the progeny of this bacterium, a replicon of $2 \mathrm{~kb}$ with an $11 \mathrm{~kb}$ transposon was isolated. In this form the Tn7-lac element was easier to manipulate. Smaller cloning Tn7-lac elements were then constructed and their effectiveness for the expression of the lac genes determined. Mono-component Tn7-lac delivery systems were developed to expand the range of bacteria that may be marked with the lac genes. These 'suicide' delivery vectors, based on unstable IncQ replicons or on pBRS22, eliminate the need for antibiotic sensitivities in the target bacteria and for the replication 
of the delivery replicon. The IncQ-based mono-component delivery system was used to mark a fluorescent pseudomonad (Ps. 3732RN) to create Ps 3732RNL11. The Tn7-lac element in Ps 3732RNL11 is composed of around $1700 \mathrm{bp}$ of the termini of $\mathrm{Tn} 7$ and the lacZY genes (and a truncated lacA gene) promoted by the iuc operon promoter. The element used ( $\mathrm{Tn} 7-\mathrm{lac7117)}$ contains a number of restriction sites to allow ease of cloning of additional genes, promoter replacements or substitution of lac with other selectable markers.

For applications in the environment, clearly stable integration of recombinant materials into the genome is desirable. Bailey et al. [1] successfully inserted two gene marker cassettes into the chromosome of a $P$. fluorescens isolate (SBW25). Given the potential for random and deleterious insertion, a strategy was adopted to facilitate detection whilst minimising the possibility of gene exchange and metabolic disruption. Two distinct chromosomal sites were therefore selected, approximately $1 \mathrm{Mb}$ apart on the chromosome, namely sites Ee and site -6-.

Site Ee was isolated from an EcoRI fragment from SBW25. The marker lacZY genes were inserted into a unique Bglll site within the $\mathrm{Ee}$ site under the control of the iucA promoter isolated from pMON7117 [2]. This fragment was transferred onto a mobilisable suicide delivery plasmid and integrated into the chromosome of SBW25 at the Ee site by homologous recombination. Site -6- was also isolated on an EcoRI chromosomal fragment. A marker gene cassette containing KanR and $X Y I E$ genes were inserted into the unique Bglll site within the -6- site, with the integrating fragment being delivered by electroporation.

The transformation of Pseudomonas spp. using mobilisable suicide vectors as above or electroporation as in our laboratories using pMC1871 (Pharmacia) is often difficult and inefficient, requiring large quantities of transforming DNA and much subsequent screening. Pseudomonas fluorescens SBW25 appears to be more difficult in this regard than most other fluorescent Pseudomonas but even here methodologies have been developed for successful integration of genes.

The following might serve as a guide:

1. To provide biomass suitable for transformation, careful growth of bacteria to mid exponential phase is required, using cells at $O D=$ $0.6(550 \mathrm{~nm})$. 
2. After chilling on ice for $\mathbf{3 0}$ minutes, cells are pelleted by centrifugation in Falcon tubes (3K rpm for 3 minutes) followed by resuspension in $15 \%$ glycerol (V/V).

3. Cells from an initial culture volume of $250 \mathrm{ml}$ are finally resuspended in 250|l of glycerol solution and stored on ice.

4. Purified plasmid DNA is obtained at a concentration of $1 \mathrm{mg} / \mathrm{ml}$. Forty five $\mathrm{ml}$ of chilled SBW25 suspension is mixed with $5 \mathrm{ml}(5 \mathrm{mg})$ of plasmid DNA in a pre-chilled microfuge tube and stored on ice for 1 minute before being transferred to a pre-chilled electroporation cuvette ( $2 \mathrm{~mm}$ gap, Biorad).

5. Electroporation is carried out using a Biorad Gene Pulsar apparatus (settings: 2.5KV, $200(25(\mathrm{~F})$ ).

6. Within one minute of applying the potential, the cell suspension is mixed with $500 \mathrm{ml}$ of SOB broth and gently mixed.

7. The contents of the cuvette is incubated at $30^{\circ} \mathrm{C}$ for 4 hours before plating onto tetracycline-containing LB plates followed by incubation at $30{ }^{\circ} \mathrm{C}$ for 48 hours.

8. An initial screen of recombinants is made by selecting for a TetR, $K a n R, l a c Z+$ phenotypes. Recombinants carrying the newly introduced DNA are identified by using PCR analysis of DNA from isolates using primers homologous to regions of DNA that should be present within the newly inserted DNA.

9. After genotypic identification, functional assays for insertion of desired sequences are normally carried out. For example, using hplc or bioassay plates where the inserted genes are responsible antibiotic biosynthesis.

Integration of DNA of up to $7 \mathrm{~kb}$ in length has been successfully achieved using this method, with predicted genotype and functionality observed.

\section{Recovery of fluorescent pseudomonads expressing lac $Z Y$ from environmental samples}

Selective agar based media

Bacteria expressing the lacZY marker genes will be able to grow on mineral media such as $M 9$ [26] amended with $1 \%(w / v)$ lactose [14]. 
Intrinsic resistance to antibiotics, such as rifampicin, might achieve further selection from the native microbial populations. This approach allows sensitive selection of up to 1-10 colony forming units (cfu) per $\mathrm{g}$ of non-sterile soil [13]. Problems arise when the natural soil populations have a significant proportion of bacteria that can use lactose as a carbon source and/or is resistant to the antibiotics used to select for the recombinant strain. For example, $1 \%$ of the culturable microbial community in a silty-loam field soil (Hamble series) taken from Littlehampton (W. Sussex, UK) was able to utilise lactose as the sole carbon source. A further $3.5 \%$ of the community was resistant to kanamycin incorporated at a level of $100 \mathrm{mg} / \mathrm{l}$, while $0.03 \%$ of the culturable bacterial community could utilise lactose and expressed resistance to kanamycin [11]. Clearly, minimal media such as M9 [26], amended with lactose and/or antibiotics are of little use for the selective recovery of recombinants in such situations. In this case, it was estimated that the detection limit of a triple marked $P$. fluorescens strain (SBW25EeZY-6KX, expressing the lacZY genes for lactose utilisation, the aph1 gene for kanamycin resistance and the $x y l E$ gene encoding for catechol 2,3 dioxygenase), on minimal medium [26] amended with $1 \%(\mathrm{w} / \mathrm{v})$ lactose, $50 \mathrm{mg} / \mathrm{l} \mathrm{X-gal} \mathrm{and} 100 \mathrm{mg} / \mathrm{l}$ kanamycin, was around $10^{3} \mathrm{cfu} / \mathrm{g}$ soil [11]. On roots, where bacterial numbers are one to two log units higher than in soil, detection would only be possible if the recombinant was present in concentrations $>10^{4} \mathrm{cfu} / \mathrm{g}$ rhizosphere soil. Consequently, a more sensitive method was required to isolate lacZY marked Pseudomonas cells from environmental samples. A growth medium, called P-1, developed for the selective recovery of Pseudomonas strains producing fluorescent pigment [21] provided the solution. This medium is made up as follows:

$\begin{array}{ll}\mathrm{KH}_{2} \mathrm{PO}_{4} & 1.0 \mathrm{~g} \\ \mathrm{MgSO}_{4} .7 \mathrm{H}_{2} \mathrm{O} & 0.5 \mathrm{~g} \\ \mathrm{KCl} & 0.2 \mathrm{~g} \\ \mathrm{NaNO}_{3} & 5.0 \mathrm{~g} \\ \text { Desoxycholate } & 1.0 \mathrm{~g} \\ \text { Betaine } & 5.0 \mathrm{~g} \\ \text { Agar } & 15 \mathrm{~g} \\ \text { Distilled water } & 1 \text { litre } \\ \text { pH } & 7.2-7.4\end{array}$


To obtain a clear medium, the ingredients are mixed thoroughly in a dry flask, before water is added. After mixing with water, the $\mathrm{pH}$ is adjusted using $1 \mathrm{~N} \mathrm{NaOH}$. In our case, per flask, $5 \mathrm{ml} 1 \mathrm{~N} \mathrm{NaOH}$ is pipetted into a litre of medium to obtain the required $\mathrm{pH}$. The medium is then autoclaved. When the medium has cooled sufficiently (40$\left.45^{\circ} \mathrm{C}\right), 50 \mathrm{mg} \mathrm{Xgal}$ is added $(1 \mathrm{ml}$ stock solution of $50 \mathrm{mg}$ Xgal per $\mathrm{ml}$ DSMO). This medium will allow growth of both lacZY positive fluorescent Pseudomonas and indigenous lacZY deficient fluorescent $P$ seudomonas. The former will produce dark blue fluorescent colonies, while the latter will form white fluorescent colonies when viewed under long wave UV light. However, it has to be noted that the production of the blue pigment that results from the cleavage of $X$-gal will to some extent mask the fluorescence of the lacZY positive bacteria on agar media. The medium thus created enables phenotypic selection of the genetically marked Pseudomonas, from a background of indigenous fluorescent Pseudomonas. As indigenous fluorescent Pseudomonas are common (typically between $10^{5}-10^{6} \mathrm{cfu} / \mathrm{g}$ soil), further selective agents have to be added to obtain a medium that is more selective. In the case of the triple marked $P$. fluorescens described before, addition of $100 \mathrm{mg}$ kanamycin per litre medium, will only allow recombinants to grow. No doubt the same result can be obtained using other antibiotics to which the strain under investigation is resistant.

Surprisingly, good selective recovery can be obtained using P-1 medium from mashed root and leaf material that is colonised by fluorescent Pseudomonas, even though this material contains relative large quantities of carbohydrates and other substances that can be utilised by a variety of microorganisms. This indicates that the betaine used in the medium as a carbon source is probably not crucial for the observed selectivity for fluorescent pseudomonads. The more likely chemical in the medium that is responsible for Pseudomonas selectivity is desoxycholate. In fact, incorporation of desoxycholate into TSA (triptic soy agar) at a rate of $1 \mathrm{~g} / \mathrm{l}$ seems to induce selectivity for Pseudomonas (De Leij, unpublished results). Therefore, the use of selective media that obtain their selectivity independent of the carbon source allows recovery of recombinant cells from environmental samples that are relatively rich in nutrients. Examples include compost, sewage sludge, plant material and foodstuff. This also means that selective media for lacZY marked bacteria that are based on the 
incorporation of lactose as the sole carbon source are unlikely to remain selective when recovery is attempted from samples that contain alternative carbon sources.

Most Probable Number techniques involving lacZY

The extreme selectivity of P-1 medium amended with antibiotics also allows the use of enrichment methods involving larger quantities of soil. Instead of using a selective agar medium, a broth can be created using the same recipe without the agar. A $0.1 \%$ soil suspension in $\mathrm{P}-1$ broth amended with kanamycin $(100 \mathrm{mg} / \mathrm{l})$ and X-gal $(50 \mathrm{mg} / \mathrm{l})$ will provide a clear medium, that will turn blue after 3-7 days incubation in shake culture at $25^{\circ} \mathrm{C}$ when at least 1 recombinant cell is present [9]. In theory, recombinant cells can be detected in this medium up to any required sensitivity (for example, using one litre broth, 1 cell/10g of soil can be detected). In practice, dilution series are prepared in $10 \mathrm{ml}$ selective broth and after incubation in shake culture those dilutions that turn blue are scored [9]. Whereas it is difficult to see fluorescence of lacZY positive colonies on agar, exposure of broth that contains lacZY positive fluorescent Pseudomonas will fluoresce intensely when exposed to long wave UV light. Most probable number estimates are subsequently used to estimate the number of cells in the original sample. Most probable number estimates, however, are inherently variable (unless large numbers of replicates and small dilution steps are used). So unless the number of recombinants in the sample are below the detection limit of agar plating (ca $50 \mathrm{cfu} / \mathrm{g}$ sample) dilution plating will be the method of choice to estimate the number of recombinant cells in a sample. In the case of qualitative detection of recombinant cells in environmental samples, enrichment is the more sensitive approach.

\section{Application of lacZY marker genes in ecological studies}

\section{Environmental fitness of LacZY marked organism}

The use of marker genes, such as lacZY, offers clear advantages in providing an extra tool allowing selective recovery of marked organisms from environmental samples. However, marker genes offer no 
advantage to the modified organism in terms of its competitive ability. It seems therefore logical to assume that the extra metabolic load of expressing these genes will put the organism at a distinct disadvantage compared to the non-modified parental strain. For example, Compeau et al. [7] found that rifampicin resistant mutants of $P$. putida were recovered from soil at lower rates compared to their non-modified parents. After only two days in soil there was more than a 10 -fold difference in recovery of the two strains. This problem is claimed not to occur with fluorescent Pseudomonas that are marked using the Tn7-lac system [23]. Co-inoculation of the rhizosphere of maize with a Tn7-lac modified $P$. aureofaciens (strain L11) and its nonmodified parent (strain RN) at different ratios did not give an significant difference in recovery of the two strains $2,3,4,8$ or 11 days later [23]. Similarly, Bailey et al. [1] found that no difference in the competitive ability of the triple marked $P$. fluorescens SBW25EeZY-6KX and its non-modified parent in the phytosphere of sugar beet. However, recent investigations indicate that effects on environmental fitness of lacZY modified strains depend on the environmental conditions into which the recombinant is released. Environments, such as the rhizoshere of pea, provide enough nutrients to mask any difference in metabolic load. In environments with a certain degree of nutrient stress, such as in soil and the rhizosphere of wheat, the extra metabolic load conferred by expressing lac $Z Y$ reduces the environmental fitness of the marked strain significantly [10]. Other factors, such as disruption of existing genes due to insertion of the marker genes seem to play no significant role [10]. In summary it can be stated that the use of lacZY as a marker gene, is likely to result in a lower recovery rate compared with the parental strain when conditions are adverse. In situations where there is little nutrient stress, it is unlikely that detectable differences between parental and the recombinant strain will occur.

\section{Relevance of cfu counts}

The use of the lacZY marker lies in the fact that these genes allow easy identification of microbial colonies that express $B$-galactosidase activity on selective media into which X-gal is incorporated. This method of estimating viable recombinant cells in an environmental sample assumes therefore that: 
- All recombinant cells present in a sample can be extracted

- Each viable cell that is extracted will result in a distinct blue colony

- Incubation conditions, determined by nutrients, time and temperature, will activate all the recombinant cells in a given sample to multiply and form a colony.

Clearly none of these assumptions can be taken for granted. For example, when microbial cells are incorporated into soil, invariably only $10 \%$ of the cells added to the soil can be recovered. This phenomenon is difficult to explain, as there are several factors that influence recovery. First of all it is possible that a large proportion of the cells added to a soil system will die and are therefore lost. Secondly, some cells might become firmly absorbed to soil particles. Thirdly, it is possible that the extraction procedure (soil mixing, whirly-mixing, etc.) will damage cells beyond recovery. And fourthly, cells might clump together, forming apparently a single colony, while in fact this colony has originated from more than one cell. The last factor touches on the second assumption that each viable cell will form a distinct blue colony. Clearly, a colony might originate from several cells, in which case the estimate of the recombinant population in soil will be an underestimation. Furthermore, cfu counts on agar media rely on the ability of cells to multiply. However, this might not always the case. It is now generally accepted that many bacteria can enter a viable but non-culturable state [6]. Cells that have entered this state are not recoverable using traditional plating techniques. There is some evidence that Pseudomonas cells could enter such a state [29]. It was found that one year after introduction into agricultural drainage water $P$. fluorescens counts were consistently higher using immuno fluorescens (IF) than using cfu counts on agar. This indicated that a proportion of the $P$. fluorescens added became non-culturable. It was however not clear if these cell cells were simply not viable or that they were viable but non-culturable as the IF technique can not distinguish between the two states. Our own investigations with the triple marked $P$. fluorescens described above, indicate that colonies formed on P-1 medium amended with kanamycin and X-gal can be phenotypically very different. During times of environmental stress, instead of forming loosely packed colonies after approx. 2-3 days incubation at $25{ }^{\circ} \mathrm{C}$, colonies appeared after more than 10 days incubation. The morphology of those colonies was entirely different from those formed by 
non-stressed cells. The colonies were small, very dark blue and the cells in the colony were very tightly packed (De Leij, unpublished observations). These observations indicate that prevailing environmental conditions can induce physiological changes in Pseudomonas cells that will affect their recovery on agar media.

\section{Conclusions}

In summary it can be stated that:

1. LacZY provides a convenient, safe, well-described marker system for bacterial species that do not posses these genes.

2. Incorporation of lac $Z Y$ into the bacterial genome might lead to a slight reduction of environmental fitness when cells are moderately stressed.

3. Because members of the indigenous microbial community commonly express lacZY themselves, selection procedures based on the lacZY should be combined with suitable selective media.

4. Results obtained from cfu estimates almost certainly under-estimates the true viable recombinant population in the environment.

\section{References}

1. Bailey MJ. Lilley AK. Thompson IP. Rainey PB. Ellis RJ (1995) Site directed chromosomal marking for a fluorescent pseudomonad isolated from the phytosphere of sugar beet: marker gene transfer and pre-release evaluation. Mol Ecol 4: 755-764.

2. Barry GF (1988) A broad-host range shuttle system for gene insertion into chromosomes of Gram-negative bacteria. Gene 71: 75-84.

3. Bereuther K. Adler K. Geisler N. Klemm A (1973) The amino-acid sequence of lac repressor. Proc Natl Acad Sci USA 70: 3576-3580.

4. Büchel DE. Gronenberg B. Müller-Mill B (1980) Sequence of the lactose permease gene. Nature 283: 541-545.

5. Chalfie M Tu Y. Euskirchen G. Ward WW. Prasher DC (1994) Green fluorescent protein as a marker for gene expression. Science 263: 802-805.

6. Colwell RR. Brayton PR. Grimes DJ. Roszak DB. Huq SA. Palmer LM (1985) Viable but nonculturable vibrio cholerae and related pathogens in the environment: implications of release of genetically engineered microorganisms. Bio/Tech 3: 817-820.

7. Compeau G. Al-Achi BJ. Platsouka E. Levi SB (1988) Survival of rifampicin-resistant mutants of Pseudomonas fluorescens and Pseudomonas putida in soil systems. Appl Environ Microbiol 54: 2432-2438.

8. Deacon JW (1991) Significance of ecology in the development of biological control agents against soil-borne pathogens. Biocontrol Science and Technology 1: 5-20.

9. De Leij FAAM. Bailey MJ. Whipps JM. Lynch JM (1993) A simple most probable number technique for the sensitive recovery of a genetically modified Pseudomonas aureofaciens from soil. Lett Appl Microbiol 16: 307-310. 
10. De Leij FAAM. Thomas CE. Bailey MJ. Whipps JM. Lynch JM (1998) Effect of insertion site and metabolic load on the environmental fitness of a genetically modified Pseudomonas fluorescens isolate. Appl Environ Microbiol 64: 2634-2638.

11. De Leij FAAM. Whipps JM Lynch JM (1995) Traditional methods of detecting and selecting functionally important microorganisms from the soil and rhizoshere. In: Allsopp D. Colwell RR. Hawksworth DL (eds) Microbial Diversity and Ecosystem Function, pp 321-336. CAB International, Wallingford.

12. Drahos DJ. Barry GF. Hemming BC (1988) Pre release testing procedures: US field test of a lacZY-engineered bacterium. In: Sussman M. Collins GM. Skinner FA. Steward-Tull (eds) The Release of Genetically Engineered Micro-organisms, pp 181-192. Academic Press, San Diego.

13. Drahos DJ. Barry GF. Hemming BC. Brandt EJ. Kline EL. Skipper HD Kluepfel DA (1992) Use of lacZY chromosomal marker system to study spread and survival of genetically engineered bacteria in soil. In: Fry JC. Day MJ (eds) Release of Genetically Engineered and other Microorganisms, pp 147-159. Cambridge University Press.

14. Drahos DJ. Hemming BC. McPherson S (1986) Tracking recombinant organisms in the environment: B-galactosidase as a selectable marker for fluorescent pseudomonads. Bio/Tech 4: 439-444.

15. Fowler AV.Zabin I (1978) Amino-acid sequence of ß-galactosidase. J Biol Chem 253: 5521-5525.

16. Gilbert W. Maxam A (1973) The nucleotide sequence of the lac operon. Proc Natl Acad Sci USA 70: 3581-3584.

17. Hediger MA. Johnson DF. Nierlich DP. Zabin I (1985) DNA-sequence of lactose operon - the lacA gene and the transcriptional termination region. Proc Natl Acad Sci USA 82: 6414-6418.

18. Jacob F. Monod J (1961) Genetic regulatory mechanisms in the synthesis of proteins. J Mol Biol 3: $318-356$.

19. Jain RK. Burlage RS. Sayler GS (1988) Methods for detecting recombinant DNA in the environment. Crit Rev Biotech 8: 33-84.

20. Kalnins A. Otto K. Rüther U. Müller-Mill B (1983) Sequence of the lacZ gene of Escherichia coli. EMBO 2: 593-597.

21. Katoh K. Itoh K (1983) New selective media for Pseudomonas strains producing fluorescent pigment. Soil Sci Plant Nutr 19: 525-532.

22. Kluepfel DA. Kline EL. Skipper HD. Hughes TA. Gooden DT. Drahos DJ. Barry GF. Brandt EJ (1991) The release and tracking of genetically engineered bacteria in the environment. Phytopathol 81: 348-352.

23. Kluepfel DA. Tonkyn DW (1992) The ecology of genetically altered bacteria in the rhizosphere. In: Tjamos ES (ed) Biological Control of Plant Diseases, pp 407-413. Plenum Press, New York.

24. Lichtenstein C. Brenner S (1982) Unique insertion site of $\mathrm{Tn} 7$ in E. coli chromosome. Nature 297: 601-603.

25. Pardee AB. Jacob F. Monod J (1959) The genetic control and cytoplasmic expression of "inducibility" in the synthesis of ß-galactosidase by E. coli. J Mol Biol 1: 165-178.

26. Sambrook J. Fritsch EF. Maniatis T (1989) Molecular Cloning. A Laboratory Manual. Second Edition. New York: Cold Spring Harbor.

27. Schneider J. Reinheimer G (1988) Isolation methods. In: Austin B (ed) Methods in Aquatic Bacteriology. pp 73-94. John Wiley, London.

28. Shaw JJ. Kado CI (1986) Development of a Vibrio bioluminescence gene-set to monitor phytopathogenic bacteria during the ongoing disease process in a non-disruptive manner. Bio/Tech 4: $560-564$.

29. Van Overbeek LS. Van Elsas JD. Trevors JT. Starodus ME (1990) Long-term survival of and plasmid stability in Pseudomonas and Klebsiella species and appearance of non-culturable cells in agricultural drainage water. Microb Ecol 14: 239-249.

30. Winstanley C. Morgan JAW. Pickup RW. Jones JG. Saunders JR (1989) Differential regulation of lambda $p_{\mathrm{L}}$ and $p_{\mathrm{R}}$ by a cI repressor in a broad host range thermoregulated plasmid marker system. Appl Environ Microbiol 55: 771-777. 


\title{
$X y l E$ as a marker gene for microorganisms
}

\author{
ROGER W. PICKUP ${ }^{1 *}$, JON R. SAUNDERS ${ }^{2}$, J. ALUN \\ MORGAN $^{3}$, CRAIG WINSTANLEY ${ }^{4}$ and VENETIA A. \\ SAUNDERS $^{5}$ \\ ${ }^{1}$ Centre for Ecology and Hydrology, Ambleside, Cumbria, LA22 OLP, UK; ${ }^{2}$ School of \\ Biological Sciences, University of Liverpool, Liverpool, L69 7ZB, UK; ${ }^{3} H R I$ Wellesbourne, \\ Wellsbourne, Warwick.CV35 9EF ${ }^{4}$ Department of Medical Microbiology and Genitourinary \\ Medicine, University of Liverpool, L69 3BX, Liverpool, ${ }^{5}$ Biomolecular Sciences, Liverpool \\ John Moores University, Liverpool, L3 3AF, UK:
}

\section{Introduction}

The $x y l E$ gene encodes catechol 2, 3 dioxygenase (C230) (E.C. 1.13.1.2), a critical enzyme in the dissimilation of toluenes, benzoates and their methyl derivatives via the meta pathway [35]. The enzyme breaks down catechol to the yellow-coloured product 2-hydroxymuconic semialdehyde. The presence of C230 in bacteria or protein preparations is thus evident from the formation of the resulting yellow product. The $x y l E$ system does not require specific or selective media in order to detect positive colonies [39]. Bacteria can be grown on any appropriate growth substrate or medium, if necessary replicated on to separate plates and the original sprayed with catechol to detect $\mathrm{C} 230^{+}$colonies [23]. C230 is inactivated in the presence of oxygen and is therefore rapidly destroyed outside the bacterial cell unless protected by acetone or ethanol [24]. The detection of active C230 should therefore be indicative of intact and therefore probably viable host cells [23]. As with other indicator genes, there may be problems with the presence of indigenous bacteria bearing $x y l E$ or related genes. However, these have been estimated to constitute a very small fraction of the microbial population in most environments and are completely absent from others [5]. Any problem with background can be overcome by the use of additional genetic markers and/or the characteristic induction of $x y l E$ when coupled to inducible promoters and/or molecular methods (see section 'Application of method'). The presence of yellow-pigmented bacteria in test systems does not seem to be a problem, since yellow haloes around colonies and changes in intensity of yellow-colouration on induction of $x y l E$ distinguish positive colonies from other bacteria.

The $x y l E$ gene(s) used as a marker has been derived from a variety of TOL plasmids. The region bearing the TOL genes has been shown to be transposable 
and derivatives of plasmids bearing the TOL genes, including $x y l E$, have been constructed in vivo [12]. More valuable marker systems however, have been constructs derived from the TOL plasmid pWWO where the $x y l E$ gene has been coupled to inducible promoters [37-39]. This reduces the load on the host of expressing the gene, allows the gene to be expressed at will to higher levels than found under normal induction conditions, and assists in the distinction of engineered organisms from any naturally occurring $\mathrm{XylE}^{+}$bacteria. Most constructs have involved placing $x y l E$ under the control of the leftward $\left(\lambda p_{\mathrm{L}}\right)$ or rightward $\left(\lambda p_{\mathrm{R}}\right)$ promoters of bacteriophage lambda [26]. Expression from these promoters is controlled by use of the $\mathrm{cI}_{857}$ allele which encodes a temperature-sensitive lambda immunity repressor. Thus the gene is essentially switched off at $28^{\circ} \mathrm{C}$ and below but at higher temperatures thermal inactivation of the repressor leads to expression. In the majority of Gram-negative bacteria this control is very tight and no expression is observed at lower growth temperatures. However, endogenous promoters and/or illicit initiation of transcription can lead to low level expression of $x y l E$ even at non-inducing temperatures in some bacterial species. Use of a temperature expression control is particularly valuable in an environmental context. Bacteria growing under natural or microcosm conditions in temperate climates will not reach sufficient temperatures to induce expression of the indicator gene. This only occurs after sampling, when the temperature can be shifted artificially to allow expression. The use of a thermally controlled promoter thus may prevent the imposition of the biochemical load of expressing the gene under environmental conditions. In addition, $x y l E$-marked environmental isolates may be used since low recovery temperatures are permissible. In our experience there is no reduction in recovery after colonies have been subjected to a two hour induction period prior to further re-culture. This may be especially important when assessing whether the $x y l E$ marker has been transferred to indigenous organisms that may not grow at temperatures tolerated by the released host.

This review will describe the use of xylE as a marker gene and its detection through expression within bacterial colonies, by immunological and molecular techniques and will comment on its versatility through expression in a range of bacterial hosts, under different promoters in a variety of environments. For reviews on a wider range of markers available for environmental biotechnology see Shepherd [29].

\section{Procedures}

The activity of the $x y I E$ product catechol-2, 3-dioxygenase (C230) is readily measured by its ability to break down catechol to the yellowcoloured product 2-hydroxymuconic semialdehyde. The presence of the $x y I E$ gene may be detected by the presence of enzymic activity, detection of the $\mathrm{C} 230$ protein by immunological means, or detection 
of nucleic acid sequences representing all or part of the gene. All these approaches may be applied at the level of individual colonies growing on agar plates or on larger samples, including crude environmental samples.

\section{Detection of xylE expressing colonies}

Colonies expressing $x y I E\left(\mathrm{C}_{230^{+}}\right)$are readily identified using a catechol spray test. There may be problems associated with bacteria that naturally produce yellow-pigmented colonies. These can be overcome by careful before and after comparisons and by observing the characteristic yellow halo of 2-hydroxymuconic semialdehyde that appears around colonies of $\mathrm{C} 230^{+}$bacteria.

\section{Steps in the procedure}

1. Grow the bacteria on suitable agar and under appropriate conditions for the host organism(s). Dilutions that will produce $30-300$ colonies per plate are ideal.

2. Plates containing colonies of host bacteria carrying $\mathrm{Cl}_{857}$-regulated $x y I E$ marker systems are first incubated at $42^{\circ} \mathrm{C}$ for 2 hours to allow the induction of the marker gene. This is unnecessary for unregulated $x y I E$ systems.

3. Spray the plates using an atomiser with catechol solution. $\mathrm{C} 230^{+}$ colonies and the immediately surrounding area become coloured bright yellow within a few minutes.

\section{Solutions}

- Catechol spray solution $1 \%(\mathrm{w} / \mathrm{v})$ catechol in distilled water or 50 $\mathrm{mM}$ Tris-acetate buffer, $\mathrm{pH} 7.5$

\section{Enzymatic assay of C230 activity in environmental samples}

The presence of catechol 2,3 dioxygenase can be assayed directly by lysis of target cells. However, C230 is inactivated by oxygen when in the absence of acetone or ethanol. As a result the activity of this enzyme declines rapidly outside the confines of bacterial cells under normal environmental conditions. It can safely be assumed that any enzyme activity detected results from the presence of C230 inside 
intact, and probably living, cells. The method given is essentially that of Sala-Trepat and Evans [27].

Steps in the procedure

1. Grow the host organism under appropriate culture conditions.

2. Harvest the cells by centrifugation $(10,000 \times \mathrm{g}$ for 15 minutes at $\left.4{ }^{\circ} \mathrm{C}\right)$.

3. Wash the cells in an equal volume of phosphate buffer $(0.1 \mathrm{M}, \mathrm{pH}$ 7.4).

4. Suspend in acetone-phosphate buffer.

5. Sonicate on ice for 10 periods of 30 seconds with 30 seconds intervals at an amplitude of $15 \mu \mathrm{m}$ peak to peak.

6. Centrifuge the sonicate at $15,000 \times g$ for 15 minutes, decant the supernatant and retain at $4{ }^{\circ} \mathrm{C}$ for no longer than 1 hour before assay.

7. Add $100 \mu \mathrm{l}$ sample to $900 \mu \mathrm{l}$ catechol assay buffer and measure the appearance of 2 hydroxymuconic semialdehyde at $375 \mathrm{~nm}$ for 3-5 minutes. If necessary, repeat using suitable dilutions of the sample.

8. Activity is expressed as: $\mathrm{C} 230$ activity = (absorbance change. $\mathrm{min}^{-1} \cdot \mathrm{ml}^{-1}$ sample $\left.\times 1000 / 12\right) / \mathrm{mg} \mathrm{ml}^{-1}$ protein

9. Protein concentration is assayed by standard methods.

\section{Solutions}

- Phosphate buffer (0.1 M, pH 7.4)

- Acetone-phosphate buffer $(0.1 \mathrm{M}$ phosphate buffer, $10 \% \mathrm{v} / \mathrm{v}$ acetone, $\mathrm{pH}$ 7.4)

- Catechol assay buffer ( $10 \mathrm{mM}$ catechol in acetone-phosphate buffer $\mathrm{pH} 7.4)$

\section{Purification of C230 for antibody production}

\section{Steps in the procedure}

1. Grow 10 times $1 \mathrm{~L}$ cultures of E. coli HB101(pFBA10-2) $n$ nutrient broth containing $50 \mu \mathrm{g} / \mathrm{ml}$ kanamycin at $28^{\circ} \mathrm{C}$ for 16 hours.

2. Induce expression of $x y I E$ by raising the growth temperature to $42^{\circ} \mathrm{C}$ for 8 hours.

3. Harvest the bacteria by centrifugation at $3,000 \times \mathrm{g}$ for 30 minutes at $4^{\circ} \mathrm{C}$. 
4. Wash in Tris-acetate buffer $\mathrm{pH} 7.5$ and harvest by centrifugation as in (3).

5. Resuspend in $50 \mathrm{mM}$ Tris-acetate buffer $\mathrm{pH} 7.5$ containing $10 \%$ acetone and cool on ice.

6. Sonicate on ice for 10 periods of 30 seconds with 30 seconds intervals at an amplitude of 15 um peak to peak.

7. Centrifuge the sonicate at $15,000 \times g$ for 15 minutes, decant the supernatant and retain at $4{ }^{\circ} \mathrm{C}$.

8. Incubate the supernatant at room temperature with $1 \mu \mathrm{g} / \mathrm{ml}$ deoxyribonuclease for 10 minutes.

9. Add $0.8 \mathrm{ml}$ cold $\left(-20^{\circ} \mathrm{C}\right)$ acetone, and then immediately centrifuge the mixture at $10,000 \times \mathrm{g}$ for 15 minutes at $4^{\circ} \mathrm{C}$. Decant the supernatant and add 0.5 volumes of ice-cold acetone and leave on ice for 10 minutes. Recentrifuge as previously and carefully decant the supernatant, retaining the pellet.

10. Resuspend the pellet in $5 \mathrm{ml}$ Tris-acetone buffer and pass through a 0.22 um filter.

11. Apply the crude enzyme preparation in 50 ug aliquots to a MonoO HR 5/5 anionic column (Pharmacia) previously equilibrated in Trisacetone buffer on a Pharmacia FPLC apparatus.

12. Elute with a $30 \mathrm{ml}$ gradient in Tris-acetone buffer containing 0 to 1 $\mathrm{M} \mathrm{NaCl}$ at a flow rate of $0.75 \mathrm{ml} /$ minute and collect $1 \mathrm{ml}$ fractions.

13. Determine the activity of each fraction by removing $1 \mu \mathrm{l}$ subsamples and adding to $50 \mu \mathrm{l} 1 \% \mathrm{w} / \mathrm{v}$ catechol in Tris-acetate buffer in a microtitre plate. Active samples are identified by the formation of a yellow colouration in the wells.

14. Pool active fractions and precipitate the enzyme by adding 1.8 volumes of cold $\left(-20^{\circ} \mathrm{C}\right)$ acetone and centrifuging at $10,000 \times \mathrm{g}$ for 15 minutes at $4{ }^{\circ} \mathrm{C}$.

15. Resuspend the pellet in the original volume of Tris-ethanol buffer and dialyse against this buffer for 5 hours.

16. Apply to a Superose 12 gel filtration column (Pharmacia), equilibrate and run at a flow rate of $0.4 \mathrm{ml} /$ minute in Tris-ethanol buffer.

17. Collect $1 \mathrm{ml}$ fractions, assay for $\mathrm{C} 230$ activity in microtitre plates as above and pool fractions showing activity. Store purified enzyme preparations at $-70^{\circ} \mathrm{C}$ in Tris-ethanol buffer.

Notes

1. Other strains carrying $x y l E$ can also be used for this purpose. 


\section{Solutions}

- Tris-acetate buffer (50 mM Tris-acetate, $\mathrm{pH} 7.5$ )

- Tris-acetone buffer (50 mM Tris-acetate, $10 \% \mathrm{v} / \mathrm{v}$ acetone, $\mathrm{pH} 7.5$ )

- Tris-acetone- $\mathrm{NaCl}$ buffer (50 mM Tris-acetate, $10 \% \mathrm{v} / \mathrm{v}$ acetone, $1 \mathrm{M}$ $\mathrm{NaCl}, \mathrm{pH} 7.5)$

- C230 assay buffer ( $1 \% \mathrm{w} / \mathrm{v}$ catechol in $50 \mathrm{mM}$ Tris-acetone buffer, $\mathrm{pH} 7.5)$

- Tris-ethanol buffer (50 mM Tris-acetate, $10 \% \mathrm{v} / \mathrm{v}$ ethanol, $\mathrm{pH} 7.5$ )

\section{Preparation of antibodies to $C 230$}

\section{Steps in the procedure}

1. Dialyse purified $\mathrm{C} 230$ preparation extensively against $0.1 \mathrm{M}$ phosphate-buffered saline (PBS).

2. Inject 500 ug of purified C230 intramuscularly into a New Zealand White Rabbit.

3. Give booster injections at 2 and 6 weeks.

4. After 6 weeks collect $10 \mathrm{ml}$ blood from the marginal ear vein, allow to clot at room temperature for 1 hour.

5. Centrifuge at $15,000 \times \mathrm{g}$ for 15 minutes, remove the serum and store it in aliquots at $-20^{\circ} \mathrm{C}$.

\section{ELISA of $C 230$}

Steps in the procedure

1. Coat samples in $0.1 \mathrm{M}$ carbonate buffer ( $100 \mu \mathrm{l}$ per well) on to the inside of a Nunc Immuno-plate (Maxi Sorb F96) for 1 hour.

2. Block each well for 1 hour with PBS-Tween-BSA.

3. Wash plates three times with PBS-Tween.

4. Add $100 \mu$ l diluted antiserum and incubate at room temperature for 1 hour.

5. Add $100 \mu$ ldiluted horse-radish peroxidase (HRP) conjugated antirabbit serum and incubate at room temperature for 1.5 hour.

6. Wash the plates thoroughly six times with PBS-Tween.

7. Add 100 pi substrate buffer.

8. Stop the reaction by adding $100 \mu \mathrm{l}$ of $2.5 \mathrm{M} \mathrm{1-04}$ and read the absorbance in a microtitre ELISA reader at $490 \mathrm{~nm}$. 


\section{Solutions}

- $0.1 \mathrm{M}$ carbonate buffer $\mathrm{pH} 9.6$

- PBS-Tween

- $0.05 \% \mathrm{v} / \mathrm{v}$ Tween-20 in $0.1 \mathrm{M}$ phosphate-buffered saline

- PBS-Tween-BSA

- $0.05 \% \mathrm{v} / \mathrm{v}$ Tween-20 and $1 \% \mathrm{w} / \mathrm{v}$ bovine serum albumin in $0.1 \mathrm{M}$ phosphate-buffered saline

- 1/500 dilution of rabbit anti-C230 antiserum in PBS-TweenBSA

- 1/500 dilution of horse-radish peroxidase (HRP) conjugated antirabbit serum in PBS-Tween

- substrate buffer

- 2 mMO-phenylenediamine, $50 \mathrm{mM} \mathrm{Na}_{2} \mathrm{HPO}_{4}, 20 \mathrm{mM}$ citric acid plus a $1 / 600$ dilution of 20 vol hydrogen peroxide, $\mathrm{pH} 4.4$

- $2.5 \mathrm{M} \mathrm{H}_{2} \mathrm{SO}_{4}$

Direct sampling and probing of $x y I E$ genes from aquatic samples

DNA extracted from cultured cells or directly from environmental samples can be probed for the presence of $x y I E$-specific sequences. The probes may be specific oligonucleotides of 17-35 bases complementary to the $x y l E$ gene sequence (oligonucleotide probes) (see below) or a restriction fragment embracing all or part of the gene per se (whole gene probe). The whole gene probe we use routinely is an $822 \mathrm{bp} \mathrm{FWI}$ restriction fragment of the plasmid pFBA10-2 [14] extracted from low melting point agarose gels.

Probes are labelled either radioactively or non-isotopically by standard procedures for $5^{\prime}$-end labelling for oligonucleotide probes or random hexanucleotide priming for whole gene probes.

Steps in the procedure

1. Filter $100 \mathrm{ml}$ lakewater or other water sample through 0.22 um cellulose nitrate filters (Whatman $25 \mathrm{~mm}$ diameter).

2. Lyse the cells by placing the filters in each of the following solutions for 5 minutes:

$0.5 \mathrm{MNaOH} ; 1.5 \mathrm{M} \mathrm{NaCl}$

$1 \mathrm{M}$ Tris (pH 7.5); $1.5 \mathrm{M} \mathrm{NaCl}$

4 times strength SET buffer 
3. Bind the DNA to the filters in a vacuum oven at $80^{\circ} \mathrm{C}$ for at least 2 hours.

4. Pre-hybridize the filters for 18 hours at $68^{\circ} \mathrm{C}$ in 10 times strength Denhardt's solution, 6 times strength saline sodium citrate (SSC) and $200 \mathrm{ug} / \mathrm{ml}$ denatured calf thymus DNA.

5. Hybridize for 18 hours at $68^{\circ} \mathrm{C}$ in the same solution containing ${ }^{32} \mathrm{P}$ labelled $x y I E$ probe.

6. After hybridization wash the filters once for 20 minutes at $68^{\circ} \mathrm{C}$ with each of the following solutions: 2 times strength SSC containing $0.1 \%$ sodium dodecyl sulphate (SDS):

0.5 times strength SSC containing $0.1 \%$ SDS;

0.1 times strength SSC containing $0.1 \%$ SDS.

7. Dry the filters and expose to X-ray film (Kodak X-Omat or similar) at $-70^{\circ} \mathrm{C}$ for up to 4 days.

Notes

3. Essentially the same hybridization procedures can be used to detect xylE sequences in Southern blots of restriction fragments or whole plasmids.

Solutions

- $0.5 \mathrm{M} \mathrm{NaOH} ; 1.5 \mathrm{M} \mathrm{NaCl}$

- $1 \mathrm{MTris}(\mathrm{pH} 7.5) ; 1.5 \mathrm{M} \mathrm{NaCl}$

- 4 times strength SET buffer $(1 \times$ SET is $0.1 \mathrm{M} \mathrm{NaCl} ; 0.001 \mathrm{M}$ EDTA; $0.1 \mathrm{M}$ Tris $\mathrm{pH} 7.5$ )

- Prehybridization solution

- 10 times strength Denhardt's solution $1 \times$ Denhardt's solution is $0.02 \%$ Ficoll; $0.02 \%$ Polyvinylpyrrolidone; $0.02 \%$ Bovine serum albumen)

- 6 times strength SSC $(1 \times$ SSC is $0.15 \mathrm{M} \mathrm{NaCl} ; 0.165 \mathrm{M}$ Sodium citrate)

- $200 \mathrm{ug} / \mathrm{ml}$ denatured calf thymus DNA

- Hybridization solution

- Prehybridization solution containing labelled probe (whole gene probes are boiled to denature the strands for 5 minutes followed by 5 minutes on ice before adding to the solution 2 times strength SSC containing $0.1 \%$ SDS 0.5 times strength SSC containing $0.1 \%$ SDS 0.1 times strength SSC containing $0.1 \%$ SDS 
A variety of different sequences within the gene can be used to prime PCR amplification of $x y / E$. We have used forward ( $5^{\prime}$ end) amplimers representing bases 71-92 or 465-481 and reverse ( $3^{\prime}$ end) primers complementary to bases $764-748$ or $861-841$ with equal success. Successful amplification can be determined both on the basis of production of an amplification product of expected size on polyacrylamide or agarose gels, or by specific hybridization to a $x y I E$ probe or an oligonucleotide probe specific to the central portion of the gene (for example 5'-CGTCGCCCAGTTTCTCAGTC-3', which represents bases 561-580 of the $x y I E$ sequence).

\section{Steps in the procedure}

1. Mix 2-4 $\mu \mathrm{l}$ (0.01-10 ug DNA) sample with $2 \mu \mathrm{l}$ of each primer (1forward and 1reverse), $10 \mu \mathrm{l}$ reaction buffer, $15 \mu \mathrm{l} \mathrm{MgCl}$ solution, $1 \mu \mathrm{l}$ Taq polymerase, $5 \mu \mathrm{lBSA}$ solution and make up to $100 \mu \mathrm{l}$ with sterile distilled water.

2. Overlay all samples with sterile liquid paraffin.

3. Transfer to thermal cycler and subject to $95^{\circ} \mathrm{C}$ for 2 minutes to denature the DNA followed by 30 cycles of the following program:

$95^{\circ} \mathrm{C}$ for 1 minute (denaturation);

$60^{\circ} \mathrm{C}$ for 1 minute (primer annealing);

$72^{\circ} \mathrm{C}$ for 1 minute (primer extension).

4. Analyse amplified products by gel electrophoresis and hybridization.

\section{Note}

4. The conditions shown are for the pair of primers JCxylE1 (forward) and JCxylE2 (reverse) which should give an amplification product of $790 \mathrm{bp}$. For primers AWxylE1 (forward) and AWxylE2 (reverse) which give a product of 299 bp the DNA should be subjected to a denaturation period of $94^{\circ} \mathrm{C}$ for 5 minutes followed by 27 cycles of $94^{\circ} \mathrm{C}$ for 1 minute, $55^{\circ} \mathrm{C}$ for 10 seconds, and $72^{\circ} \mathrm{C}$ for 30 seconds with an additional 3 cycles utilising an extended polymerisation time of 1 minute.

\section{Solutions}

- dNTP solution

- a solution containing $10 \mathrm{mM}$ each of dATP, dCTP, dGTP and dTTP in sterile distilled water 
- Primers (all at $100 \mathrm{ng} / \mathrm{ml}$ in sterile distilled water)

- JCXyIE (forward)

5'-AGCGGGCCATGTGCAGCTGCGT-3' (bases 71-92 of xyIE;

$$
\left.\mathrm{T}_{\mathrm{m}}=74^{\circ} \mathrm{C}\right)
$$

- JCXyIE2 (reverse)

5'-CGAAGTGTTCTGCGGGGGGA-3' (inverse complement of bases $841-861$ of $x y l E ; T_{m}=66^{\circ} \mathrm{C}$ )

- AWxyIE 1 (forward)

5'-CATGTATGGCGACGAAT-3' (bases 465-481 of $x y / E ; \mathrm{T}_{\mathrm{m}}=$ $\left.50^{\circ} \mathrm{C}\right)$

- AWxylE2 (reverse)

5'-CACGGCAAGACCATCTA-3' (inverse complement of bases $748-764$ of $x y / E ; 7 m=52^{\circ} \mathrm{C}$ )

- reaction buffer

- 67 mM Tris- $\mathrm{HCl}, \mathrm{pH} 8.8$

- $\mathrm{MgCl}_{2}$ solution

- $10 \mathrm{mM}$

- BSA solution

- $1 \%$ in sterile distilled water

\section{Application of the method}

The $x y I E$ gene can be detected directly by assaying for enzyme activity in colonies or protein extracts [25]. The gene itself can be detected by DNA/DNA hybridisation using either whole gene probes consisting of the gene itself or with oligonucleotide probes derived from the $x y I E$ sequence [25]. PCR amplification primers and identification probes have been produced that are highly specific for both strands of the $x y \mid E$ gene and are effective for the identification and quantification of $x y I E$ bacteria in both laboratory cultures and microcosms $[25,40]$. The probes discriminate release hosts from background bacteria, but, as with all PCR .procedures cannot distinguish between live, 'dead' and nonculturable but viable (NCBV) cells. PCR detection of $x y l E$ has been achieved from bacteria in both environmental water and soil [13, 21, 23, 31].

Cassettes composed of $x y I E$ under the control of lambda promoters and the $\mathrm{cl}_{857}$ repressor have been inserted into broad host range nonconjugative plasmids derived from RSF1010 (IncO group) [38] and 
conjugative plasmids derived from RP4 (IncP group) [39] for use in a wide range of Gram negative bacteria. The same cassettes have been inserted into the transposons $\operatorname{Tn} 5$ and $\operatorname{Tn} 7$ for delivery into the bacterial chromosome [37]. As might be expected, the stability of the $x y I E$ gene and/or its vehicle varies greatly depending on the host concerned and the details of the genetic constructions used. Stable and unstable chromosomal $x y I E$ marker cassettes, imposing differing metabolic burdens on the host have been used to determine the fate of genetically-manipulated Pseudomonas putida isolates released into freshwater or soil microcosms $[22,23,37,39]$. The number of colonies recovered expressing $x y / E$ was found to decline at a rate that was not significantly different between any of the marker systems, despite differences in the metabolic burden that they imposed on the cells and their stabilities in pure culture. In soil microcosms the effect of the water content of the soil was dominant in determining recovery of $x y I E^{+}$ cells over the different metabolic burdens imposed by the marker cassettes used. Since instability of either plasmid or chromosomallylocated markers is only normally apparent if growth has occurred, unstable markers such as those based on $x y l E$ may be used to determine whether released bacteria actually divide under environmental conditions. Lack of instability under these conditions would indicate no growth whereas loss of an unstable marker would indicate that cell division had occurred following release [37]. The reproducibility exhibited by the $x y l E$ system has indicated that differences observed in lake water microcosms were a result of environmental factors, such as changes in seasonal water quality, and not as the result of host or plasmid stability [22, 37-39]. The $x y I E$ marker system functions in Gram positive bacteria and has been incorporated into Streptomyces plasmids to track streptomycetes in soil [40]. The thermoregulated $x y l E$ expression cassettes utilising lambda promoters, $p_{\mathrm{R}}$ and $p_{\mathrm{L}}$ described above for Pseudomonas spp. [38] were incorporated into Streptomyces plasmids plJ680, plJ486 [34] and plJ673, all of which are derivatives of plJ101 [14]. Of the cointegrates formed between these plasmids and a series of broad host range Gram negative plasmids containing $x y / E, p_{R}, p_{\mathrm{L}}$ and $\mathrm{cl}_{857}, \mathrm{pNW} 4\left(p_{\mathrm{L}}, x y / E\right)$ utilising plJ486 and pLV1010, and pNW5 $\left(p_{R}, x y / E, c_{857}\right)$ utilising plJ486 and pLV1012 proved most stable, as judged over two rounds of sporulation on laboratory medium in Streptomyces lividans. Furthermore, both survived 
in non-sterile soil microcosms for more than 80 days in spores of $S$. lividans. The plasmids were stably maintained, but strains harbouring these plasmids exhibited a reduced degree of sporulation compared with those carrying the parental plasmid. This may reflect the extra metabolic load contributed by $x y l E$. The lambda promoters, $p_{\mathrm{R}}$ and $p_{\mathrm{L}}$ function in streptomycetes and there is a marked increase in C230 activity in $\mathrm{Cl}_{857}$-regulated constructs upon induction at $37^{\circ} \mathrm{C}$. However, thermoregulation is less efficient and induced C230 activity lower in Streptomyces than in Pseudomonas spp. and other Gram negative bacteria. Stabilities of the regulated and unregulated constructs appear to be similar in S. lividans hosts.

As in Gram negative bacteria, Streptomyces xylE plasmids can be detected by a number of methods, including phenotypic identification and DNA hybridisation. $X Y I E{ }^{+}$streptomycetes can be detected as yellow colonies against a background of typical soil microorganisms, following culture on solid medium at $28^{\circ} \mathrm{C}$ and then at $37^{\circ} \mathrm{C}$ to induce $x y I E$ expression. Furthermore, marked $S$. lividans strains can be detected at less than $10 \mathrm{cfu}^{-1}$ dry weight soil as mycelium and $103 \mathrm{cfu} \mathrm{g}^{-1}$ dry weight soil as spores by hybridization with either the whole $x y I E$ gene or a 20-mer $x y I E$-specific oligonucleotide probe using PCR-amplified DNA from soil [40]. The lower sensitivity of detection for spores may be due to the relative difficulties in disruption and extraction of DNA of suitable quality for PCR. Additionally there may be an increased plasmid copy number in growing mycelium than in spores [7].

Fusions with $x y l E$ are not confined to $\lambda$ promoters. Examples include fusion with lac promoters encoding $\beta$-galactosidase activity [10, 11, 33], $\operatorname{dag} A$ and topA promoters [9] and fliC [41], all resulting in successful expression of $x y l E$ as a single or fused protein. The host range has also been extended with expression in Pseudomonas aeruginosa [41], Pseudomonas fluorescens [32], Mycobacterium species [8], Rhizobium species [17, 28, 36], Aeromonas salmonicida [21], Salmonella typhimurium [30], Xenorhabdus nematophilus and Photorhabdus luminescens [20] and methylotrophs such as $M$. extorquens [18]. The versatility of delivery on IncO and IncP vectors is a key factor in the usefulness of $x y I E[18,32]$ as is its use as a plasmid or chromosomal marker [1, 37]. This is also shown by Turnbull and coworkers who used $x y I E$ both as a mutagenic insert (creating non-motile variants) 
and as a marker for survival [32]. Marx and Lidstrom [18] developed the reporter system in order to develop more efficient vectors for the expression of foreign genes in methylotrophs. Similarly, GonzalezCaron and coworkers [9] showed that levels of both $x y I E$ mRNA and C230 activities were increased if $x y / T$ was present upstream in the same fusion. However, Hasset and coworkers [11], showed that activity could be compromised by oxidative stress, particularly when catalase-deficient strains were used.

This review has shown the use of $x y I E$-based markers systems in a range of bacteria under a variety of promoters. It should be concluded that once introduced into a host, marker survival can be successfully monitored in temperate fresh water [16, 37, 39], tropical fresh water [2], leaf litter [3, 4], invertebrates [4], soil [3, 4, 40], rhizosphere [15, $32]$, phyloplane [6] and within model systems [19, 21, 22].

\section{Acknowledgements}

The authors wish to thank NERC and DEFRA (formerly Department of the Environment) for funding this work.

\section{References}

1. Abebe, H. M., R. J. Seidler, S. E. Lindow, K. A. Short, E. Clark, R. J. King (1997) Relative expression and stability of a chromosomally integrated and plasmid-borne marker gene fusion in environmentally competent bacteria. Curr Microbiol 34:71-78.

2. Alvarez, A. J., G. M. Yumet, C. L. Santiago, T. C. Hazen, R. Chaudhry, G. A. Toranzos (1996) In situ survival of genetically engineered microorganisms in a tropical aquatic environment. Environ Toxicol Water Qual 11:21-25.

3. Byzov, B. A., H. Claus, E. B. Tretyakova, N. F. Ryabchenko, I. N. Mozgovaya, D. G. Zvyagintsev, Z. Filip (1999) Plasmid transfer between introduced and indigenous bacteria in leaf litter, soil and vermicompost as affected by soil invertebrates. Biol Fertil Soils 28:169-176.

4. Byzov, B. A., H. Claus, E. B. Tretyakova, D. G. Zvyagintsev, Z. Filip (1996) Effects of soil invertebrates on the survival of some genetically engineered bacteria in leaf litter and soil. Biol and Fertil Soils 23:221-228.

5. Chatfield, L. K., P. A. Williams (1986) Naturally-occurring TOL plasmids in Pseudomonas strains carry either 2 homologous or 2 nonhomologous catechol 2,3-oxygenase genes. J Bacteriol 168:878-885.

6. Cirvilleri, G., G. Caldarera (1998) Use of lux-marker genes to monitor survival of antagonistic Pseudomonas fluorescens on the phylloplane. Zeitschrift Fur Pflanzenkrankheiten Und Pflanzenschutz-Journal of Plant Diseases and Protection 105:441-451.

7. Cresswell, N., V. A. Saunders, E. M. H. Wellington (1991) Detection and Quantification of Streptomyces violaceolatus Plasmid DNA in Soil. Lett Appl Microbiol 13: 193-197. 
8. Dastur, A., U. Varshney (2001) Promoter analysis in mycobacteria using $x y l E$ reporter assays and its implication in high throughput screening. Tuberculosis 81:267-269.

9. Gonzalez-Ceron, G., P. Licona, L. Servin-Gonzalez (2001) Modified $x y l E$ and $x y l T$ reporter genes for use in Streptomyces: analysis of the effect of xylT. FEMS Microbiol Lett 196:229-234.

10. Han, H. Y., C. K. Kim, Y. K. Park, J. O. Ka, B. J. Lee, K. H. Min (1996) Construction of genetically engineered microorganisms for overexpression of $x y l E$ gene encoding catechol 2,3dioxygenase and the functional stability of the recombinant plasmid pSW3a containing $x y l E$ in aquatic environment. J Microbiol 34:341-348.

11. Hassett, D. J., U. A. Ochsner, S. L. Groce, K. Parvatiyar, J. F. Ma, J. D. Lipscomb (2000) Hydrogen peroxide sensitivity of catechol-2,3-dioxygenase: a cautionary note on use of $x y l E$ reporter fusions under aerobic conditions. Appl Environ Microbiol 66:4119-4123.

12. Keil, H., S. Keil, R. W. Pickup, P. A. Williams (1985) Evolutionary conservation of genes coding for meta pathway enzymes within TOL plasmids pWW0 and pWW53. J Bacteriol 164:887895.

13. Khan, A. A., R. A. Jones, C. E. Cerniglia (1998) Rapid method for the detection of genetically engineered microorganisms by polymerase chain reaction from soil and sediments. J Indust Microbiol Biotechnol 20:90-94.

14. Kieser, T., D. A. Hopwood, H. M. Wright, C. J. Thompson (1982) Pij101, a Multi-Copy Broad Host-Range Streptomyces Plasmid-Functional-Analysis and Development of DNA Cloning Vectors. Mol Gen Gen 185:223-238.

15. Kluepfel, D. A. (1993) The Behavior and Tracking of Bacteria in the Rhizosphere. Ann Rev Phytopathol 31:441-472.

16. Leff, L. G., J. V. McArthur, L. J. Shimkets (1998) Persistence and dissemination of introduced bacteria in freshwater microcosms. Microb Ecol 36:202-211.

17. Lindstrom, K., M. M. Jussila, H. Hintsa, A. Kaksonen, L. Mokelke, K. Makelainen, J. Pitkajarvi, L. Suominen (2003) Potential of the Galega Rhizobium galegae system for bioremediation of oil-contaminated soil. Food Technol Biotechnol 41:11-16.

18. Marx, C. J., M. E. Lidstrom (2001) Development of improved versatile broad-host-range vectors for use in methylotrophs and other Gram-negative bacteria. Microbiology-Sgm 147: 2065-2075.

19. Mater, D. D. G., J. E. N. Saucedo, N. Truffaut, J. N. Barbotin, D. Thomas (1999) Conjugative plasmid transfer between Pseudomonas strains within alginate bead microcosms: Effect of the internal gel structure. Biotech Bioeng 65:34-43.

20. Morgan, J. A. W., V. Kuntzelmann, S. Tavernor, M. A. Ousley, C. Winstanley (1997) Survival of Xenorhabdus nematophilus and Photorhabdus luminescens in water and soil. J Appl Microbiol 83:665-670.

21. Morgan, J. A. W., G. Rhodes, R. W. Pickup (1993) Survival of nonculturable Aeromonas salmonicida in lake water. Appl Environ Microbiol 59:874-880.

22. Morgan, J. A. W., G. Rhodes, R. W. Pickup, C. Winstanley, J. R. Saunders (1992) The effect of microcosm design on the survival of recombinant Pseudomonas putida in lake water. Microbial Releases 1:155-159.

23. Morgan, J. A. W., C. Winstanley, R. W. Pickup, J. G. Jones, J. R. Saunders (1989) Direct Phenotypic and Genotypic Detection of a Recombinant Pseudomonad Population Released into Lake Water. Appl Environ Microbiol 55:2537-2544.

24. Nakai, C., H. Kagamiyama, M. Nozaki, T. Nakazawa, S. Inouye, Y. Ebina, A. Nakazawa (1983) Complete nucleotide sequence of the metapyrocatechase gene on the TOL plasmid of Pseudomonas putida Mt-2. J Biol Chem 258:2923-2928.

25. Pickup, R. W., J. A. W. Morgan, C. Winstanley, J. R. Saunders (1991) Implications for the Release of Genetically Engineered Organisms. J Appl Bacteriol 70:S19-S30.

26. Remaut, E., H. Tsao, W. Fiers (1983) Improved Plasmid Vectors with a Thermoinducible Expression and Temperature-Regulated Runaway Replication. Gene 22:103-113.

27. Sala-Trepat, J. M., W. C. Evan (1971) The meta cleavage of catechol by Azotobacter species: 4-oxalocrotonate pathway. Europ J Biochem 20. 
28. Sessitsch, A., G. Hardarson, W. M. de Vos, K. J. Wilson (1998) Use of marker genes in competition studies of Rhizobium. Plant Soil 204:35-45.

29. Shepherd, J. M., P. L. Yu (1998) Molecular markers in environmental biotechnology. Australasian Biotechnology 8:43-46.

30. Taylor-Robinson, J. D., M. Child, R. Pickup, P. Strike, C. Edwards (2003) Cell-cell interactions influence resistance and survival of Salmonella serotype typhimurium to environmental stress. J Appl Microbiol 94:95-102.

31. Tsushima, S., A. Hasebe, Y. Komoto, J. P. Carter, K. Miyashita, K. Yokoyama, R. W. Pickup (1995) Detection of genetically-engineered microorganisms in paddy soil using a simple and rapid nested polymerase chain reaction method. Soil Biol Biochem 27:219-227.

32. Turnbull, G. A., J. A. W. Morgan, J. M. Whipps, J. R. Saunders (2001) The role of bacterial motility in the survival and spread of Pseudomonas fluorescens in soil and in the attachment and colonisation of wheat roots. FEMS Microbiol Ecol 36:21-31.

33. Ueda, H., A. Kitayama, E. Suzuki, T. Nagamune (1998) Construction of catechol 2, 3dioxygenase-protein $\mathrm{G}$ chimeric proteins and its application to immunoassay. Kagaku Kogaku Ronbunshu 24:169-173.

34. Ward, J. M., G. R. Janssen, T. Kieser, M. J. Bibb, M. J. Buttner (1986) Construction and Characterization of a Series of Multi-Copy Promoter-Probe Plasmid Vectors for Streptomyces Using the Aminoglycoside Phosphotransferase Gene from Tn5 as Indicator. Mol Gen Gen 203:468-478.

35. Williams, P. A., K. Murray (1974) Metabolism of benzoate and methylbenzoates by Pseudonomas putida (arvilla) mt-2. J Bacteriol 120.

36. Wilson, K. (1995) Molecular Techniques for the Study of Rhizobial Ecology in the Field. Soil Biol Biochem 27:501-514.

37. Winstanley, C., J. P. Carter, M. Seasman, J. A. W. Morgan, R. W. Pickup, J. R. Saunders (1993) A comparison of the survival of stable and unstable chromosomally-located $x y l E$ marker cassettes as an indicator of cell division within populations of Pseudomonas putida released into lake water. Micro Releases 2:97-107.

38. Winstanley, C., J. A. W. Morgan, R. W. Pickup, J. G. Jones, J. R. Saunders (1989) Differential regulation of Lambda- $p_{\mathrm{L}}$ and Lambda- $p_{\mathrm{r}}$ promoters by a ${ }_{\mathrm{C}} \mathrm{I}$ repressor in a broad-host-range thermoregulated plasmid marker system. Appl Environ Microb 55:771-777.

39. Winstanley, C., J. A. W. Morgan, R. W. Pickup, J. R. Saunders (1991) Use of a XylE marker gene to monitor survival of recombinant Pseudomonas putida populations in lake water by culture on nonselective media. Appl Environ Microbiol 57:1905-1913.

40. Wipat, A., E. M. H. Wellington, V. A. Saunders (1991) Streptomyces marker plasmids for monitoring survival and spread of streptomycetes in soil. Appl Environ Microbiol 57:3322-3330.

41. Wyckoff, T. J. O., B. Thomas, D. J. Hassett, D. J. Wozniak (2002) Static growth of mucoid Pseudomonas aeruginosa selects for non- mucoid variants that have acquired flagellum-dependent motility. Microbiol-SGM 148:3423-3430. 


\title{
GUS as a marker to track microbes
}

\author{
KATE J. WILSON \\ Center for the Application of Molecular Biology to International Agriculture (CAMBIA) GPO \\ Box 3200, Canberra ACT 2601, Australia (Present address: Australian Institute of Marine \\ Science, PMB 3, Townsville QLD 4810, Australia)
}

\section{Introduction}

The gusA gene encodes the enzyme B-glucuronidase (GUS). It is widely used as a reporter gene in plant molecular biology because there is no background activity in plants, and because the enzyme is easy to assay in a variety of both histochemical and quantitative assays. Over the past few years it has also become adopted as a marker gene for microbial ecology, particularly for studying the ecology of bacteria that interact with plants.

The enzyme is a hydrolase, which cleaves substrates in which an aglycone group is conjugated in a hemiacetal linkage to D-glucuronic acid. The spectrum of such substrates which can be cleaved is very broad, and gives rise to the variety of assays that are available for GUS. Thus there is a range of quantitative, histochemical and selective compounds available for GUS assays (Table 1). This variety of substrates can be used creatively in different experimental situations.

The gene, gusA, comes from the bacterium Escherichia coli [17]. There are other bacteria present in soil which exhibit GUS activity-about the same proportion which exhibit LAC (B-galactosidase) activity-and GUS activity is found in a number of intestinal bacteria [45]. However, GUS has not been detected in any bacteria under study for reasons of agronomic importance, such as Rhizobium, Bradyrhizobium, Pseudomonas, Agrobacterium or Streptomyces species. The absence of GUS activity in these bacteria, coupled with the absence of activity in plants with which they might associate, makes a very powerful reporter gene for studying plant-microbe interactions.

The substrates, which are most applicable to microbial ecology studies are the histochemical substrates as they enable spatial localization of the marked microbes. The first such substrate to be widely used was 5-bromo-4-chloro-3-indolyl-B-Dglucuronic acid (X-gluc, or, more correctly, X-glcA), which, on cleavage by GUS and subsequent dimerization of the cleavage product, gives rise to an indigo precipitate. Thus, GUS-marked bacteria can be detected as blue colonies on plates, or concentrations of bacteria in association with plants are visible as blue areas on the root surface or inside root tissue. For example, an assay for rhizobial nodule 
Table 1. Histochemical GUS substrates

\begin{tabular}{|c|c|c|c|}
\hline Common name & Chemical Name & Colour of Product & Company \\
\hline X-gluc, $\mathrm{X}$-glcA & 5-bromo-4-chloro-3-indolyl- $\beta$-D glucuronide & Blue & $\begin{array}{l}\text { Biosynth AG, } \\
\text { Research } \\
\text { Organics Inc. }\end{array}$ \\
\hline Magenta-glcA & 5-bromo-6-chloro-3-indolyl-B-D-glucuronide & Magenta & Biosynth AG \\
\hline Salmon-glcA* & 6-chloro-3-indolyl-B-D-glucuronide & Salmon pink (Red) & Biosynth AG \\
\hline Indoxyl-glcA & Indoxyl- $\beta$-D-glucuronide & Indigo blue & Biosynth AG \\
\hline Red-Gluc* & 6-chloro-3-indolyl- $\beta$-D-glucuronide & Red (Salmon pink) & $\begin{array}{l}\text { Research } \\
\text { Organics Inc. }\end{array}$ \\
\hline
\end{tabular}

*These two substrates are the same chemical, but synthesized by different manufacturers

occupancy becomes simply a matter of immersing a root system in buffer containing a GUS substrate-generally X-glcA-and observing which nodules become blue (or whatever colour the cleavage product of the substrate used is).

GUS activity also appears to be absent from all fungi examined so far, and GUS has therefore been used as a transformation tool and gene expression marker in: Aspergillus nidulans, A. niger and Cladosporium fulvum [28]; Aspergillus oryzae [34]; Phytophthora infestans, P. megasperma f. sp. glycinea and Achlya ambisexualis [18]; Fusarium oxysporum [7]; Cochliobolus heterotrophus [20] and Rhizopus niveus [35]. Almost all of these fungi are plant pathogens, and the expression of GUS can therefore also be used as a tool to study the ecology of plant infection by these economically important fungi. This has been demonstrated in studies of root colonization by Fusarium oxysporum [1, 7, 21] and Fusarium graminearum [24] and by using GUS activity as a bioassay for the degree of infection of the pathogen, Cladosporium fulvum, on tomato plants [13, 22]. Although this chapter will concentrate on bacterial ecology studied using GUS, many of the techniques would be equally applicable to fungal ecology, and potential gene constructs for this purpose may be found in the literature.

We developed a series of transposons containing gusA expressed under a variety of promoters specifically for use in microbial ecology studies [48] and these will be the focus of this chapter. However, the reader should be aware that further gusA-containing vectors have since been developed for use in microbial ecology. These include both plasmid and transposon-based vectors, and features include alternative antibiotic resistance markers or dual labeling with $g u s A$ and $g f p[11,25$, $26,43,49]$. A number of considerations must be taken into account when selecting an appropriate vector including: transposon or plasmid-based (transposons are more stable but may cause insertional mutagenesis); antibiotic resistance selection; nature of promoter required to drive gusA expression.

The transposons that we developed are based on the mini-transposon system developed by de Lorenzo et al. [10] and Herrero et al. [14]. These are constructed so that the tnpA gene encoding the transposase does not lie within the $19 \mathrm{bp}$ inverted repeats which delimit the transposon (see Figure 3 in [48]). The gene of interestin this case gusA-is inserted between the transposon ends. Hence, following 
transposition, they form stable insertions in the genome of the recipient bacteria. This series of GUS transposons is derived from mini-Tn5 Sm/Sp, and thus they encode streptomycin/spectinomycin resistance in addition to GUS. They are summarized in Table 2 together with their precursor plasmids. GUS transposons encoding phosphinotricin (pUT/Ptt), mercury (pUT/Hg), arsenite (pUT/Ars), tetracycline (mini-Tn5 Tc), chloramphenicol (mini-Tn5 Cm), or kanamycin (mini-Tn5 $\mathrm{Km}$ ) resistance could be readily constructed by inserting the NotI fragments from the precursor plasmids into the NotI sites of the various mini-transposons indicated above in parentheses and described in de Lorenzo et al. [10] and Herrero et al. [14].

These GUS transposons have been constructed with a variety of purposes (see Table 2). One of the key uses of GUS in microbial ecology at present is as a marker for rhizobial competition in nodule occupancy studies. Previously it was only possible to assay 20-30 nodules per replication (out of a possible total of thousands of nodules on all the plants growing within a single field plot) for determination of percentage occupancy of nodules by an inoculated strain of Rhizobium or Bradyrhizobium, because methods for strain identification required laborious analysis of individual nodules (e.g. antibiotic resistance typing or immunological methods such as ELISA). The GUS assay changes this, and makes it possible to determine nodule occupancy for all of the nodules on a single root. For example, we were able to assay occupancy of every nodule on the roots of 100 Phaseolus vulgaris plants, each with approximately 200 nodules per root, by incubating the roots overnight in 2 litres of buffer containing X-GlcA. The cost of the assay is also reasonable, despite the high cost of the substrate X-GlcA. In this example, US $\$ 80$ worth of substrate was sufficient to provide nodule occupancy data on approximately 20,000 nodules [46].

Examples of the use of GUS to study rhizobial competition include: several studies on competition for nodule occupancy on Phaseolus vulgaris [32, 33, 46]; studies of the role of rhibotoxine in competition by Bradyrhizobium elkanii [50]; a study of colonization of clover by Rhizobium together with Pseudomonas [19]; demonstration of the competitive ability of potential inoculant strains of Bradyrhizobium japonicus in South African soils containing endogenous B. japonicus [2]. GUS is also widely used to study plant colonization by associative or endophytic bacteria $[5,12,15,25,31,36,38,39]$.

An important question when using any transgenic approach for microbial ecology is the impact of the introduced gene on the ecology of the host. We have shown that the presence of the GUS transposons does not by itself perturb the ecological behaviour of Rhizobium strains into which it is introduced [29]. However, it must be recognized that insertion of the GUS transposons into the recipient genome constitutes transposon mutagenesis, and typically $20 \%$ or more of marked isolates may be affected in competitive abilities. Therefore independent GUS-marked isolates must undergo preliminary screening to identify those in which there have been no apparent effects on their ecological behaviour. The same holds true for any other invasive technique for studying microbial ecology including the use of other marker genes or the use of spontaneous antibiotic resistant mutants. 


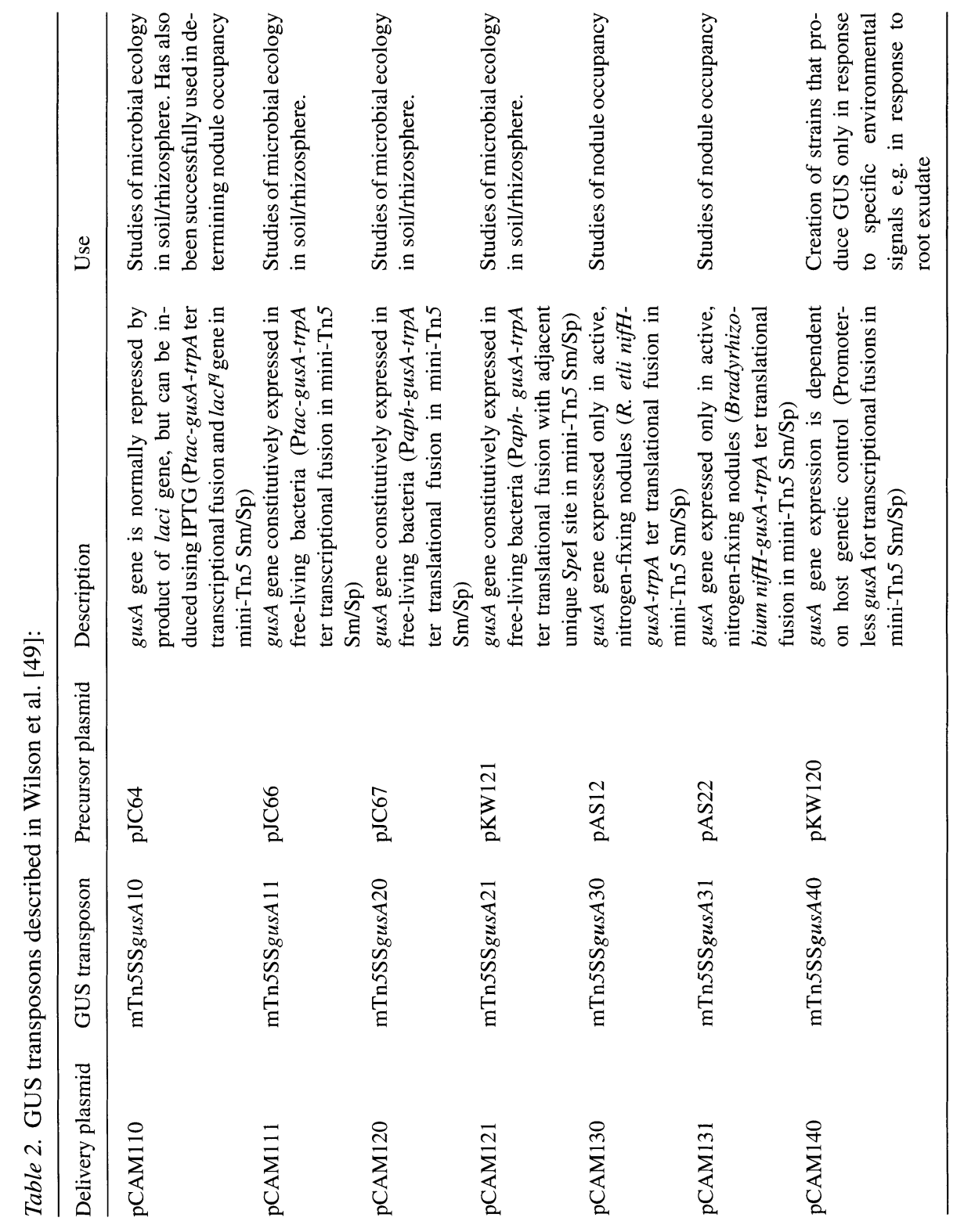


In fact, this mutagenic property of transposons has been used to advantage by some groups. For example Vinuesa et al. [42] used mTn5SSgusA30 to study lipopolysaccharide synthesis in Rhizobium etli. The same group also studied the basis of acid tolerance in $R$. tropici [41]. Ullrich et al. used mTn5SSgusA40 to screen for temperature-responsive genetic loci in Psuedomonas syringeae pathovar glycinea [37].

Finally, as introduced marker genes by definition create genetically altered organisms, it is important to consider possible transfer of the genes and any conceivable risk that such marked strains could present if released into the environment. In this context it is important to note that field release of any strains that contain introduced marker genes may be subject to regulation by national bodies concerned with overseeing the safe use of genetically engineered organisms. However, as there are already a number of precedents for the release of genetically engineered microbes into the environment, including microbes marked with GUS [27], this is unlikely to prove a major obstacle.

\section{Experimental approach}

To use GUS as a marker gene, a number of steps must be carried out:

1. Selection of the appropriate construct

2. Introduction of the GUS transposon into the strain of choice

3. Quantitative determination of GUS activity (optional)

4. Assessment of a sample of marked derivatives to ensure no major ecological changes

5. Use of GUS-marked strains in ecological experiments.

\section{Procedures}

\section{Selection of the appropriate construct}

A number of different GUS transposons are available for use in different experimental contexts. These are discussed in general terms in Wilson [44] and are described in detail in Wilson et al. [48]. They are summarized in Table 2. Briefly, transposons are available which allow expression of GUS to be:

- constitutive

- regulated by the experimenter

- induced in microaerobic/symbiotic conditions in the case of rhizobia

- dependent on adjacent genomic host promoters 
The choice of transposon will depend on the experimental purpose. Thus, someone studying rhizosphere colonization may wish to have strong, constitutive expression, whereas someone studying changes in soil populations may wish to be able to regulate GUS expression by inclusion of a specific inducer (IPTG in the case of mTn5SSgusA10) in the media in plating experiments. For studying rhizobial competition, the transposons which specifically induce gusA in symbiotic conditions are recommended because they allow detection of strong GUS activity even in fully mature nodules [48]. Alternatively, the researcher may wish to have gus $A$ under control of an endogenous, host promoter, in which case a promoter-probe transposon may be used e.g. mTn5SSgusA40.

In addition, a number of other constructs are available from other laboratories [11, 25, 26, 43, 49]. They will not be discussed further here, but the general protocols described in this chapter are likely to be applicable for work with other gusA-containing constructs for use in microbial ecology.

\section{Introduction of the GUS-transposon into the strain of choice}

The transposons carrying the gusA marker gene are maintained on a plasmid in an E. coli host strain, and are transferred to the recipient from the donor $E$. coli by bacterial conjugation (mating). The process of bacterial conjugation is very simple: all that is required is to mix the donor and recipient strains in non-selective conditions overnight, and then to plate the mating mixture on plates that will select for recipient strains that have received the GUS marker i.e. plates that inhibit growth of the $E$. coli donor strain and also inhibit growth of colonies of the recipient strain that have not received the transposon marker.

\section{2a. Devising a selection for the recipient strain}

First it is necessary to identify conditions in which the recipient strain can grow but the donor E. coli strain cannot. There are two possibilities. Frequently it is possible to use minimal medium lacking certain essential nutrients required for growth of the donor E. coli strain. For instance, E. coli strain S17-1 [30] and its derivative S17-1 $\lambda$ pir are auxotrophic for proline and can therefore be counterselected using 
minimal medium that lacks this amino acid. Alternatively, many bacterial strains exhibit endogenous antibiotic resistances not shared by the donor E. coli strain. Such endogenous resistances can therefore be used to select against growth of the E. coli donor. However, it is strongly recommended not to actually select for such resistances as induction of spontaneous antibiotic resistance can have major impacts on the physiology and ecology of a bacterial strain (e.g. [23]).

Secondly, it is also necessary to ensure that the recipient is sensitive to the antibiotic being used to select for the transposon. The transposons commonly used carry either the aph gene encoding resistance to the aminoglycosides kanamycin and neomycin, or the $\operatorname{aad} A$ gene encoding resistance to streptomycin and spectinomycin. Although both streptomycin and spectinomycin can be inactivated by the same enzyme, the two antibiotics actually target different components of the ribosome. Streptomycin affects the S12 protein of the 30 S ribosomal subunit whereas spectinomycin acts on the S5 protein of the same subunit [4]. Thus, a strain with endogenous or acquired resistance to streptomycin will frequently still be sensitive to spectinomycin.

\section{Steps in the procedure}

1. Pour separate batches of Brown and Dilworth minimal plates with different carbon sources (e.g. glucose, glycerol, mannose) to check which one gives optimal growth of the recipient strain. Streak the recipient strain and the donor strain on these plates and place plates at the normal temperature for growth of each strain. Select the media which gives the best growth of the recipient, provided that there is no growth of the donor strain. Alternatively, use the standard rich media for the recipient strain in combination with various antibiotics to test for endogenous resistance to antibiotics which are not being used to select for the transposon. Again ensure that the donor strain is sensitive to these antibiotics.

2. Pour plates containing the antibiotic to be used to select the presence of the transposon: typical concentrations would be: spectinomycin $50 \mu \mathrm{g} \mathrm{ml}^{-1}$; streptomycin $250 \mu \mathrm{g} \mathrm{ml}^{-1}$; kanamycin $100 \mu \mathrm{g}$ $\mathrm{ml}^{-1}$; neomycin $50 \mu \mathrm{g} \mathrm{ml}^{-1}$. As above, streak the recipient strain and incubate in the conditions normally used for the growth of the recipient strain. For the procedure to work, the recipient strain 
must be sensitive to an antibiotic for which the transposon encodes resistance. It is worth testing different antibiotics e.g. kanamycin and neomycin, or streptomycin and spectinomycin, as some strains show greater sensitivity to one than to the other. If strong growth of the recipient strain is observed, repeat the procedure using higher levels of the antibiotic(s) e.g. make kanamycin plates with 150, 200 and $250 \mu \mathrm{g} \mathrm{ml}^{-1}$, until the level of antibiotic at which the recipient strain does not grow is identified.

\section{Notes}

1) There may be micro-colonies of the donor strain on the selective media. This is acceptable provided that growth ceases at this stage whereas large colonies of the recipient strain are obtained.

2) The plates used in this case should either be rich media, or the minimal media which best supports growth of the recipient strain.

\section{2b. Carrying out the bacterial mating}

1. In advance pour two kinds of agar plates: non-selective plates which will allow growth of both donor and recipient, e.g. yeastmannitol plates (three per mating) and selective plates (six per mating).

2. Inoculate the recipient strain into $5 \mathrm{ml}$ broth culture. The evening before this culture will be densely-grown (e.g. after 3-4 days in the case of Bradyrhizobium strains) inoculate a $5 \mathrm{ml}$ culture of the donor E. coli strain in LB broth plus the appropriate antibiotic to select for presence of the plasmid containing the transposon.

3. The next day spin down both densely-grown cultures in sterile tubes-a $1.5 \mathrm{ml}$ Eppendorf tube is usually adequate. Resuspend each culture in $1 \mathrm{ml}$ non-selective broth (the broth used for growth of the recipient strain) and re-centrifuge.

4. Resuspend the E. coli culture in $1 \mathrm{ml}$ non-selective broth and the recipient strain culture in $0.25 \mathrm{ml}$. Put $100 \mu \mathrm{l}$ of each culture on a separate non-selective plate and spread this drop on the plate (see 6). Be sure to let the remainder of the drop dry before inverting the plates and putting them in the incubator. These two plates are controls.

5. Spot $100 \mu \mathrm{l}$ of the recipient strain and $100 \mu \mathrm{l}$ of the E. coli donor strain onto the same non-selective plate. Using a sterilized glass 
spreader, mix the two drops thoroughly and then spread all over the surface of the plate. Let the plate dry and then invert and put in the incubator at a temperature appropriate for the recipient strain overnight. This is the mating plate.

6. The next day, take the two control plates. Some growth should have occurred on both of them. Pick up cells from a densely grown region and streak each for single colonies on a selective plate.

7. Take the mating plate. This should now be covered by a dense bacterial lawn. Pipette $2 \mathrm{ml}$ sterile saline solution onto the surface and spread this around using a sterile glass spreader to resuspend the mating mixture. Using a fresh pipette transfer this suspension to a sterile Eppendorf tube. Make two serial tenfold dilutions in saline i.e. $10 x$ and $100 x$ dilutions of the original suspension.

8. Plate $100 \mu \mathrm{l}$ of each of the dilutions on a selective plate. Make sure the plates have completely dried after spreading and then invert and place in an incubator at a temperature permissive for growth of the recipient strain. Place the controls that were streaked on selective plates in the same incubator.

9. Check the selective plates regularly for growth of single colonies. If the mating is successful, one of the dilution plates will show growth of 20-50 well-dispersed single colonies and there will be no growth of single colonies on the control plates.

10. Restreak four or more independent colonies on selective plates that also contain $X$-glcA at $50 \mu \mathrm{g} \mathrm{ml}^{-1}$ to purify single colonies and check qualitatively for GUS activity.

Notes

1) Selective plates will either be minimal media plates with the addition of the antibiotic being used to select the transposon e.g. spectinomycin $50 \mu \mathrm{g} \mathrm{ml}^{-1}$, or plates with both this antibiotic and a second one to counterselect the donor strain. It is possible to include the GUS substrate X-glcA in the selective plates. However, it is not necessary, and as the substrate is relatively expensive, it is recommended against including it in plates until there are colonies to be screened for GUS activity.

2) Ampicillin at $50 \mu \mathrm{g} \mathrm{ml}^{-1}$ can be used for E. coli carrying all the transposons described in Table 2 as this is the antibiotic resistance marker on the carrier plasmid.

3 ) This washes the cells and removes any remaining trace of antibiotic from the $E$. coli culture.

6) It is important to streak for single colonies, as it is sometimes possible for growth of a dense inoculum to occur by cross-feeding in circumstances where single colonies would not survive. 
7) It is usually only possible to take up 1-1.5 $\mathrm{ml}$ of suspension as some of the water gets absorbed into the agar.

8) It is a good idea to do duplicates of each to avoid potential loss of the best mating plate to contamination. The mating suspension can be stored in the refrigerator or even frozen in $20 \%$ glycerol and stored at $-70^{\circ} \mathrm{C}$ for later reuse. If it is necessary to know the efficiency of GUS marking, i.e. the number of isolates that become marked out of the total number of recipient bacteria, plate dilutions of the mating mixture on plates that select for the recipient whether marked or not e.g. appropriate minimal media without any antibiotics. As the number of recipients will be large, $100 \mu$ of $10^{4}, 10^{5}$ and $10^{6}$ dilutions should be used. For convenience and to save media, the Miles and Misra drop count method can be used [6].

9) Frequently good colonies form on top of a light lawn of bacterial growth. This is a successful mating and the transconjugant colonies can be further purified by restreaking. Typical frequencies are of the order of 1 transconjugant in $10^{5}$ recipient colonies for Rhizobium species. However, for some other species, e.g. Azospirillum, transfer frequencies can be as much as two orders of magnitude lower, and therefore more of the mating mixture may have to be spread on selective plates to isolate only a few colonies.

10) The colonies do not always turn very blue, as $X$-glcA is a very hydrophilic substrate and does not easily pass across cell membranes.

\section{Solutions}

- Brown and Dilworth minimal media [3], per litre:

$-0.7 \mathrm{~g} \mathrm{KNO}_{3}$

$-0.25 \mathrm{~g} \mathrm{MgSO}_{4}: 7 \mathrm{H}_{2} \mathrm{O}$

$-0.02 \mathrm{~g} \mathrm{CaCl}_{2}$

$-0.2 \mathrm{~g} \mathrm{NaCl}$

$-0.36 \mathrm{~g} \mathrm{KH}_{2} \mathrm{PO}_{4}$

$-1.4 \mathrm{~g} \mathrm{~K}_{2} \mathrm{HPO}_{4}$

$-6.6 \mathrm{mg} \mathrm{FeCl} 3$

$-0.15 \mathrm{mg}$ EDTA

$-1 \mathrm{ml}$ of a filter-sterilized solution of thiamine $\mathrm{HCl}\left(1 \mathrm{mg} \mathrm{ml}^{-1}\right)$, biotin $\left(1 \mu \mathrm{g} \mathrm{ml}^{-1}\right)$ and Ca pantothenate $\left(2 \mathrm{mg} \mathrm{ml}^{-1}\right)$

- a suitable carbon source e.g. glucose or glycerol $0.2 \% \mathrm{w} / \mathrm{v}$

- (It does not appear to be necessary to include the micronutrients recommended in the original Brown and Dilworth [3] recipe).

- Add $15 \mathrm{~g}$ agar per plate for solid media

- Rich media plates: Use yeast-mannitol plates or other appropriate plates which support growth of both host and donor strain. Yeast mannitol [40] is per litre:

$-0.5 \mathrm{~g} \mathrm{~K}_{2} \mathrm{HPO}_{4}$ 
$-0.2 \mathrm{~g} \mathrm{MgSO}_{4}: 7 \mathrm{H}_{2} \mathrm{O}$

$-0.1 \mathrm{~g} \mathrm{NaCl}$

$-10 \mathrm{~g}$ Mannitol

$-0.5 \mathrm{~g}$ Yeast extract

- Add $15 \mathrm{~g}$ agar per plate for solid media

- Saline solution $(0.85 \% \mathrm{w} / \mathrm{v} \mathrm{NaCl})$ :

$-850 \mathrm{mg} \mathrm{NaCl}$ in $100 \mathrm{ml}$ water

\section{Quantitative determination of GUS activity (optional)}

Quantitative assays can be carried out to ensure that there is an easily detectable level of GUS enzyme activity in the marked recipient prior to using them further in ecological experiments. However it is not essential to carry out this assay as sufficient evidence of GUS activity should be provided by the appearance of blue colonies following the mating. If the transposons carrying the nifH-gusA fusions are used, free-living expression of GUS will be very low. Quantitative GUS assays can also be applied to nodules [47], or to measure relative gene expression [38].

\section{3a. Quantitative GUS Assays}

\section{Steps in the procedure}

1. Grow $5 \mathrm{ml}$ liquid cultures of GUS-marked strains in rich medium.

2. Spin down $1 \mathrm{ml}$ cells in an Eppendorf tube and resuspend in $1 \mathrm{ml}$ $50 \mathrm{mM}$ sodium phosphate pH 7.0, $1 \mathrm{mM}$ EDTA. Remove $500 \mu \mathrm{l}$ of cells to a fresh tube for the protein assay. Keep on ice temporarily.

3. Permeabilize remaining $500 \mu \mathrm{l}$ cells by vortexing with 1 drop $0.1 \%$ SDS and 2 drops chloroform for 10 seconds.

4. Prepare a 96-well microtitre plate as follows: in column 1 place $100 \mu$ permeabilised cells; in column $2,3,4,5,6$ place $140 \mu \mathrm{l}$ of pNPG GUS assay buffer

5. Start the reaction by transferring $10 \mu \mathrm{l}$ of the permeabilized cells (column 1) to the pNPG assay buffer (columns 2-6) as rapidly as possible. Mix briefly using pipette tips.

6. Incubate microtitre dish at $37^{\circ} \mathrm{C}$, monitoring colour change closely. Stop reactions in successive columns at successive time points by adding $50 \mu \mathrm{l} 0.4 \mathrm{M} \mathrm{Na}_{2} \mathrm{CO}_{3}$ (column 2 for the first time point, column 3 for the second etc.). 
7. Use pNP from Sigma to calibrate an ELISA machine. Make a range of concentrations from $5 \mu \mathrm{M}$ to $200 \mu \mathrm{M}$ in the same buffer as the experimental samples as indicated below and add to the plate.

8. Measure $\mathrm{OD}_{405}$ of standards and samples on an ELISA reader.

\section{Notes}

1) It is not necessary to use the antibiotic

4) Use of an eight channel multi-pipette greatly facilitates this assay

6) Choose the time points to give a good spread of colour for each extract. The time points do not have to be regular, but remember to note each one! Having five time points allows good rate determination for all samples even when some have very fast reaction rates and others are slow. Take care at all times not to spill any of the reaction as it is critical that the final volume in each well be known in order to be able to calculate the rate of GUS activity. For this reason the microtitre plate lid should also be kept on throughout the reaction to minimize loss of solution through evaporation.

7) $\mathrm{OD}_{405}$ shows a linear relation with $\mathrm{pNP}$ up to a concentration of about $200 \mu \mathrm{M}$. The reading has to be calculated empirically when using a microtitre reader, rather than using the molar extinction coefficient for pNP, as the path length is not known.

\section{Solutions}

- $100 \mathrm{mM}$ sodium phosphate $4 \mathrm{pH} 7.0$ (per $100 \mathrm{ml}$ )

- Mix $30.5 \mathrm{ml} 0.2 \mathrm{M} \mathrm{Na}_{2} \mathrm{HPO}_{4}$ with $19.5 \mathrm{ml} 0.2 \mathrm{M} \mathrm{NaH}_{2} \mathrm{PO}_{4}$ and add $50 \mathrm{ml}$ water

- $50 \mathrm{mM}$ sodium phosphate $1 \mathrm{mM}$ EDTA (per $100 \mathrm{ml}$ )

- $50 \mathrm{ml} 100 \mathrm{mM}$ sodium phosphate $\mathrm{pH} 7.0$

- $200 \mu \mathrm{l} 0.5 \mathrm{M}$ EDTA

- add $50 \mathrm{ml}$ water

- $0.1 \% w / v S D S$

- chloroform

- 100 mM para nitrophenyl B-D-glucuronide (pNPG) (stock solution) - Dissolve $31.5 \mathrm{mg}$ pNPG in $1 \mathrm{ml}$ of water. Keep stock frozen at $-20^{\circ} \mathrm{C}$.

- pNPG GUS assay buffer (10 ml)

- $10 \mathrm{ml} 50 \mathrm{mM}$ sodium phosphate, $1 \mathrm{mM}$ EDTA

- $100 \mu \mathrm{l} 100 \mathrm{mM}$ pNPG

- $27 \mu \mathrm{l}$ B-mercaptoethanol or $100 \mu \mathrm{l} 1 \mathrm{M}$ dithiothreitol

- $0.4 \mathrm{M} \mathrm{Na}_{2} \mathrm{CO}_{3}$

- Dissolve $4.24 \mathrm{~g}$ in $100 \mathrm{ml}$ water 
- Para-nitrophenol (pNP) standards:

- Prepare a $10 \mathrm{mM}$ stock by dissolving $14 \mathrm{mg}$ p-nitrophenol (spectrophotometric grade) in $10 \mathrm{ml} 0.4 \mathrm{M} \mathrm{NaCO}_{3}$

- Then prepare the following standards:

\begin{tabular}{crll}
\hline & \multicolumn{3}{c}{ Components to mix } \\
\cline { 2 - 4 } Concentration of pNP & pNP solution & $0.4 \mathrm{M} \mathrm{NaCO}_{3}$ & $\begin{array}{l}\text { pNPG GUS } \\
\text { assay buffer }\end{array}$ \\
\hline & & & \\
$1 \mathrm{mM}$ & $100 \mu \mathrm{l} 10 \mathrm{mM}$ & $150 \mu \mathrm{l}$ & $750 \mu \mathrm{l}$ \\
$500 \mu \mathrm{M}$ & $50 \mu \mathrm{l} 10 \mathrm{mM}$ & $200 \mu \mathrm{l}$ & $750 \mu \mathrm{l}$ \\
$100 \mu \mathrm{M}$ & $100 \mu \mathrm{l} 1 \mathrm{mM}$ & $225 \mu \mathrm{l}$ & $675 \mu \mathrm{l}$ \\
$75 \mu \mathrm{M}$ & $75 \mu \mathrm{l} 1 \mathrm{mM}$ & $230 \mu \mathrm{l}$ & $695 \mu \mathrm{l}$ \\
$50 \mu \mathrm{M}$ & $50 \mu \mathrm{l} 1 \mathrm{mM}$ & $240 \mu \mathrm{l}$ & $710 \mu \mathrm{l}$ \\
$25 \mu \mathrm{M}$ & $25 \mu \mathrm{l} 1 \mathrm{mM}$ & $245 \mu \mathrm{l}$ & $730 \mu \mathrm{l}$ \\
$10 \mu \mathrm{M}$ & $10 \mu \mathrm{l} 1 \mathrm{mM}$ & $250 \mu \mathrm{l}$ & $740 \mu \mathrm{l}$ \\
$5 \mu \mathrm{M}$ & $5 \mu \mathrm{l} 1 \mathrm{mM}$ & $250 \mu \mathrm{l}$ & $745 \mu \mathrm{l}$ \\
\hline
\end{tabular}

These all maintain the same ratio of assay buffer to $\mathrm{NaCO}_{3}$ as in the experimental treatments.

\section{3b. Protein assays}

Protein assays can conveniently be carried out in a microtitre format using the BIO-RAD Protein assay kit, which is based on the Bradford dye-binding procedure (BIO-RAD catalogue number 500-0002)

\section{Steps in the procedure}

1. Prepare $1 \mathrm{ml}$ of protein standards at the following concentrations: $20,15,10,5,1 \mu \mathrm{g} \mathrm{ml}^{-1}$.

2. Heat the samples that were kept aside for protein assays to $95{ }^{\circ} \mathrm{C}$ for 2 minutes.

3. Dilute protein extracts $1: 10$ in Eppendorf tubes in $50 \mathrm{mM}$ sodium phosphate, 1 mM EDTA.

4. Mix $160 \mu \mathrm{l}$ protein extract or standard and $40 \mu \mathrm{l}$ of BIO-RAD reagent in the wells of a microtitre. plate. Let stand 5-60 minutes at room temperature. Measure $\mathrm{OD}_{595}$ in an ELISA reader. 
5. Calculate protein concentration from standard curve after subtracting value for reagent blank ( $\left.0 \mu \mathrm{g} \mathrm{ml}^{-1} \mathrm{BSA}\right)$.

\section{Notes}

2) This extracts the proteins. Boiling has no effect on measurement of total protein concentration, at least for a BSA standard.

5) A standard curve should be generated for each set of assays, as the exact colour development can vary with factors such as the age of the reagent and the length of time of the incubation. Different proteins give rise to slightly different standard curves, and so the same protein e.g. BSA, should be used as the standard for all assays. Standard protein solutions can be kept frozen at $-20^{\circ} \mathrm{C}$

\section{Solutions}

- Protein stock solution $\left(20 \mu \mathrm{g} \mathrm{m}^{-1}\right)$

- Dissolve $20 \mathrm{mg}$ known protein e.g. BSA in $1 \mathrm{ml}$ water, and dilute $1,000 x$

- Protein standards

\begin{tabular}{ccc}
\hline Concentration & $\begin{array}{c}\text { Amount of } \\
20 \mu \mathrm{gl}^{-1} \text { stock }(\mu \mathrm{l})\end{array}$ & $\begin{array}{l}\text { Amount of } \\
\text { phosphate buffer }(\mu \mathrm{l})\end{array}$ \\
\hline $20 \mu \mathrm{g} \mathrm{ml}^{-1}$ & 1,000 & - \\
$15 \mu \mathrm{g} \mathrm{ml}^{-1}$ & 750 & 250 \\
$10 \mu \mathrm{g} \mathrm{ml}^{-1}$ & 500 & 500 \\
$5 \mu \mathrm{g} \mathrm{ml}^{-1}$ & 250 & 750 \\
$1 \mu \mathrm{g} \mathrm{ml}^{-1}$ & 50 & 950 \\
$0 \mu \mathrm{g} \mathrm{ml}^{-1}$ & - & 1,000 \\
\hline
\end{tabular}

3c. Calculation of quantitative GUS activity

Steps in the procedure

1. For each sample plot a graph of $\mathrm{OD}_{405}$ (Y-axis) versus time in minutes (X-axis). Calculate the slope, $\mathrm{S}$, of the graph in $\mathrm{OD}_{405}$ units per minute.

2. Plot a standard curve of pNP concentration $(x)$ against $\mathrm{OD}_{405}(y)$. The slope of this curve $(C)$ is the increase in $O D_{405}$ value per $1 \mu \mathrm{M}$ increase in pNP in the $200 \mu \mathrm{l}$ of solution in the microtitre well. This volume of a $1 \mu \mathrm{M}$ solution would contain $0.2 \mathrm{nmols}$ of $\mathrm{pNP}$, and these values are used to convert $\mathrm{OD}_{405}$ to nmols $\mathrm{pNP}$ 
e.g. for a given slope, $S$, rate of production of pNP $(P$, in nmols per minute) becomes:

$$
P=\frac{S \times 0.2}{C} \text { nmols per minute }
$$

3. Finally this value has to be normalized to protein concentration. The protein concentration of each sample is calculated by first subtracting the value for the reagent blank, and then using the slope of the standard curve to calculate protein concentrations in $\mu \mathrm{g} \mathrm{ml}^{-1}$

e.g. if the slope of the standard curve $\left(\mathrm{OD}_{595}\right.$ on $\mathrm{y}$-axis, protein concentration on $x$-axis) is 0.5 , the reagent blank is 0.05 , and sample 1 has a reading of 0.25 , the protein concentration is:

$$
\frac{0.25-0.05 \mu \mathrm{g} \mathrm{ml}^{-1}}{0.5}
$$

Remember that if the sample was diluted for the protein measurement, this dilution factor has to be taken into account e.g. in the protocol given above, the value would have to be multiplied by 10 to account for the 10 -fold dilution used for the samples.

4. Rate of reaction, $R$, is then:

$\mathrm{R}$ (nmols pNP $\min ^{-1} \mu \mathrm{g}$ protein $\left.{ }^{-1}\right)=$

$\mathrm{P}$

$\overline{V(m l)} \times$ protein concentration $\left(\mu \mathrm{g} \mathrm{ml}^{-1}\right)$

where $\mathrm{V}=$ volume of material assayed for GUS activity in $\mathrm{ml} \mathrm{e.g.} \mathrm{in}$ the protocol given above, $10 \mu \mathrm{l}$ of permeabilised cells were taken for the GUS assay, and thus the volume was $0.01 \mathrm{ml}$.

\section{Notes}

1) It is important that the relationship between $O D_{405}$ and time is linear. This can be checked by looking at the correlation coefficient using standard spreadsheet packages. If it is not linear, take the slope of that part of the curve which does show a linear relationship e.g. a sample with high activity may only show a linear relationship over the first three time points.

4) Alternatively the rate of reaction can be normalized to the number of viable cells, if these are assessed at the point of assay using the Miles and Misra drop count [6].

\section{Assessment of marked derivatives to ensure no major ecological changes}

The GUS gene is introduced into the recipient's genome on a transposon, and therefore it is necessary to check whether there are any 
readily detectable changes in phenotype due to the site of transposon insertion, before proceeding further. The researcher must decide what is the most important phenotype, and devise experiments to test for changes. The following types of experiments are examples of possible ways of screening for ecological changes:

1. Comparison of growth rates of wild-type and marked strains. This can simply be a measurement of the rate of change of $\mathrm{OD}_{600}$ over time when each is inoculated into liquid culture. However, we have found that this is not necessarily a reliable indicator of changes in competitive behaviour of Rhizobium strains [29].

2. Competitive growth of a mixed culture of wild-type and marked strain to determine whether the wild-type outcompetes the marked strain.

3. For rhizobia, co-inoculation of a marked and unmarked strain in equal ratio onto host legume plants grown in an aseptic system such as a growth pouch or agar tube to determine whether the marked strain forms about $50 \%$ of the nodules. This has been found to be a reasonable indicator for unaltered competitive success [29, 32], although see [47] for further discussion of this assay.

4. If antisera are available, carry out a small scale test to see if colonization / nodule occupancy or other ecological parameters are the same when measured for the parental strain using antisera (e.g. through immunofluorescence) and for the marked strain using GUS and antisera.

\section{Use of GUS-marked strains in ecological experiments}

The key to using GUS in ecological experiments is to fine-tune the assay conditions so that the marked bacteria can be readily detected and so that there is no background staining activity whatsoever. Background activity can be a problem, because of the existence of soil bacteria that exhibit B-glucuronidase activity, but is readily avoided as long as the proper controls are carried out. Three types of ecological experiments will be described:

- monitoring free-living populations of bacteria in soil

- monitoring colonization of plants by bacteria

- determination of percentage nodule occupancy 
Experiments in which GUS was used to monitor changes in the population of a Pseudomonas strain are described in Wilson et al. [47]. These experiments are carried out using plating assays and most probable number (MPN) counts to determine the number of marked bacteria per gram of soil. The sensitively is therefore approximately the same as for any plating assay, that is approximately 100 colony forming units per gram of soil.

\section{Steps in the procedure}

1. Identify plating media which specifically selects the marked strain. Plates could be made selective based on the antibiotic resistance encoded on the transposon, or using nutritional media which are selective for the species being studied.

2. Inoculate soil or other environmental sample with the marked strain according to usual procedures, and incubate for the required time. Also keep an uninoculated sample as a control for background activity.

3. To isolate marked bacteria back from soil, it is necessary to make soil suspensions as follows: weigh $10 \mathrm{~g}$ of soil into a $500 \mathrm{ml}$ flask. Add $10 \mathrm{~g}$ of sterilized gravel. Add $90 \mathrm{ml}$ sterile $0.1 \%(\mathrm{w} / \mathrm{v}) \mathrm{NaPPi}$ (sodium pyrophosphate) solution. Shake at room temperature at 200 r.p.m. for 10 minutes. Do the same with the uninoculated control.

4. For each sample, make a series of four further 10 -fold dilutions in $0.1 \% \mathrm{NaPPi}$ down to a final dilution of $10^{-5}$. Do the dilutions in Eppendorf tubes by transferring $100 \mu \mathrm{l}$ to $900 \mu \mathrm{l} 0.1 \% \mathrm{NaPPi}$ in a fresh Eppendorf tube. Vortex well, and use a fresh pipette tip for subsequent dilutions.

5. Plate $100 \mu \mathrm{l}$ aliquots of each of five dilutions on selective media containing X-glcA $\left(50 \mu \mathrm{g} \mathrm{ml}^{-1}\right)$. For accurate MPN counts, there should be at least three replications per dilution. Incubate the plates in normal conditions and use the number of blue colonies formed to calculate the population of the GUS-marked strain in the soil. If any blue colonies are observed on the plates from the uninoculated control soil, these numbers should be subtracted from the final count. 
Notes

1a) Unlike with assays which rely entirely on nutritional selections or antibiotic resistance, it is not necessary to identify media on which no bacteria other than the strain under study will grow; it is only necessary to identify media on which no other GUS ${ }^{+}$bacteria will grow. For example, in Wilson et al. [47], selective plates used to detect a GUS ${ }^{+}$kanamycin resistant Pseudomonas were Kings B Medium plus kanamycin $\left(100 \mu \mathrm{g} \mathrm{ml}^{-1}\right)$ and $\mathrm{X}-\mathrm{GlcA}\left(50 \mu \mathrm{g} \mathrm{ml}^{-1}\right)$. Although native soil bacteria which were kanamycin-resistant did grow on this media, none of them expressed GUS activity, and hence the marked strain under study could be identified unambiguously. (In the experiments described in that paper, an earlier GUS transposon which encodes kanamycin resistance was used, and hence kanamycin was added to the selective medium. With the current series of transposons it would be necessary to use spectinomycin.)

1b) Because there is no uptake system for the substrate X-GlcA, the blue colour can take a long time to develop as it relies either on very slow uptake of the substrate, or on death of sufficient cells which release their B-glucuronidase into the medium. It is not unusual for transposon-marked colonies to not develop blue colour for twothree days after becoming visible on the plates. IPTG must be included at $1 \mathrm{mM}$ to induce gus $A$ expression if $\mathrm{mTn} 5 \mathrm{SS}$ gusA10 is used.

4) Remember that the initial isolation step involved a 10-fold dilution.

5) This range of dilutions should be adequate to count a population that may lie anywhere between $10^{2}$ and $10^{7}$ c.f.u. per gram of soil.

\section{Solutions}

- $0.1 \%(w / v) ~ N a P P i$

- Dissolve $1 \mathrm{~g} \mathrm{NaPPi}$ in 1 litre of water

- $50 \mathrm{mgml}^{-1} X$-GlcA stock

- dissolve $50 \mathrm{mg} \mathrm{X-glcA}$ in DMSO or DMF (if using a plastic container ensure that it is resistant to these chemicals)

\section{5b. Monitoring colonization of plants by bacteria}

GUS has successfully been used to monitor colonization of plant roots by Azospirillum [5, 38], Azoarcus [15] and Rhizobium [9]. In most cases colonization was assayed using a concentration of X-glcA of $500 \mu \mathrm{g}$ $\mathrm{ml}^{-1}$ in an appropriate buffer, and was visualized as patches of intense blue staining on the root surface. Additionally, it was possible to visualize infection threads and incipient nodules in the case of Rhizobium [9].

We have found that this concentration of X-glcA is necessary to detect colonization of roots, despite being substantially higher than that required for determination of nodule occupancy. At concentrations of 
100 or $250 \mu \mathrm{g} \mathrm{ml}^{-1} \mathrm{X}$-glcA it was not possible to detect colonization of rice roots by an Azospirillum strain marked with mTn5SSgusA20; however, when $500 \mu \mathrm{g} \mathrm{ml}^{-1} \mathrm{X}$-glcA was used, colonization of the region immediately behind the root tips was clearly revealed by discrete regions of blue staining (C.B. Nirmala, SPIC Science Foundation, Madras and KJW, unpublished observations). Using a concentration of $800 \mu \mathrm{g} \mathrm{ml}^{-1} \mathrm{X}-\mathrm{glcA}$, it is even possible to see individual blue azospirilla on the root surface (S. Katupitiya, University of Sydney, personal communication).

It is also possible to include potassium ferricyanide and potassium ferrocyanide in the staining buffer. This enhances the rate of oxidative dimerizaton of the initial colourless GUS cleavage product from $X-G I c A$ to form the blue precipitate (see [44]) and hence increases the accuracy of spatial localization by preventing diffusion of the colourless cleavage product away from the site of GUS activity [8, 16]. However, inclusion of these compounds also reduces the total amount of blue product produced $[8,48]$.

\section{Steps in the procedure}

1. Harvest control (uninoculated) and inoculated roots and rinse several times in dilute buffer $-50 \mathrm{mM}$ sodium phosphatepH 7.0 or saline are both perfectly adequate. This removes any adhering sand, soil or other growth medium.

2. Place roots in X-glcA staining buffer containing $500 \mu \mathrm{g} \mathrm{ml}^{-1} \mathrm{X}$-glcA and incubate at $37^{\circ} \mathrm{C}$ for 2-24 hours.

3. When good staining is observed, rinse roots in fresh buffer without X-glcA.

4. When blue colour development is complete, clear the roots by immersing them in $2.5 \%$ sodium hypochlorite (commercial bleach is usually $5 \%$ hypochlorite) for approximately 30 minutes to clear the tissue.

Notes

2) It is worth experimenting with inclusion of potassium ferricyanide and potassium ferrocyanide at concentrations from 1-5 mM in the staining buffer to enhance the accuracy of spatial localization. However, recall that inclusion of these compounds also reduces the total amount of blue product produced.

3) We have found that endogenous GUS activity in root-associated bacteria may be induced when a concentration of $500 \mu \mathrm{g} / \mathrm{ml} \mathrm{X-glcA}$ is used, leading to blue staining 
on the uninoculated control plants, particularly around the cut surface of the root. If this occurs, repeat the experiment, this time incorporating $100 \mu \mathrm{g} / \mathrm{ml}$ chloramphenicol in the buffer. This acts as an inhibitor of de novo protein synthesis, and prevents expression of any endogenous GUS activity (see [46] and [49] for further discussion). Alternatively, $0.02 \%$ sodium azide may be included for this purpose. However, caution must be exercised as sodium azide is extremely toxic.

4) This bleaches the brown-coloured phenolics present in the root and makes comparison of stained and unstained nodules far easier.

\section{Solutions}

- X-GlcA staining buffer for colonization studies (per litre)

$-500 \mathrm{ml} 100 \mathrm{mM}$ sodium phosphate $\mathrm{pH} 7.0$

$-2 \mathrm{ml} 0.5 \mathrm{M}$ EDTA

$-10 \mathrm{ml} 10 \% \mathrm{w} / \mathrm{v}$ sarkosyl

$-10 \mathrm{ml} 10 \% \mathrm{w} / \mathrm{v}$ triton $\mathrm{X}-100$

$-500 \mathrm{mg} \mathrm{X-glcA}$

- \% hypochlorite

- Dilute commercial bleach 1:1 with water

\section{5c. Determination of percentage nodule occupancy}

A key use of GUS in microbial ecology experiments is to determine the percentage of nodules occupied by a marked inoculum strain. As this assay should be high throughput and low cost, staining conditions are somewhat different to those routinely used in plant molecular biology or in the colonization studies discussed in section $5 b$ above (see [48]). In particular, far lower concentrations of X-glcA are used, and potassium ferricyanide and potassium ferrocyanide are omitted from the buffer. Additionally, long incubation times may be used-with inclusion of appropriate negative controls-as GUS activity continues in nodules for periods up to one week after harvest. A key factor in rapid development of the blue colour is adequate aeration of the buffer, and a simple aquarium pump is recommended for this purpose [46].

\section{Steps in the procedure}

1. Set up an experiment with different inoculation treatments, including one treatment inoculated only with the unmarked parental strain, and one inoculated only with the marked derivative, to act as negative and positive controls for staining respectively. 
2. Grow plants to the age at which you want to determine nodule occupancy

3. Harvest plants. Rinse several times to remove adhering grown material. Immerse nodules in X-glcA staining buffer. The roots can be densely packed, but it is essential to ensure adequate aeration of the buffer e.g. by use of an aquarium aerator. If roots from more than one treatment are placed in the same container, labels can be attached directly to the roots e.g. using masking tape.

4. Incubate for one to five days until full colour is observed in all the nodules on the positive control (single strain inoculum of the GUS-marked strain). The temperature of incubation can be anything from $20-37^{\circ} \mathrm{C}$

5. Count the number of blue, partially-blue and white nodules and calculate percentage nodule occupancy.

\section{Notes}

2) We have had no trouble detecting GUS activity in pigeonpea nodules harvested up to 70 days after planting using mTn5SSgusA31 (gusA driven by a symbiotic nifH promoter). However, the time period over which GUS activity can be measured for a particular combination of host plant/strain/growing conditions may need to be determined empirically.

3a) It is possible to use vacuum infiltration to enhance access of the substrate to the nodule interior.

3) We recommend against inclusion of potassium ferricyanide or potassium ferrocyanide in the staining buffer for nodules as these compounds actually reduce overall accumulation of product $[8,48]$. The spatial localization obtained without these compounds is more than adequate for nodule occupancy studies.

4a) We have found that colour development continues over this period, and this enables lower concentrations of substrate to be used (typically $50-100 \mu \mathrm{g} \mathrm{ml}^{-1}$, substantially lower than that used in the colonization studies or for histochemistry in plant molecular biology), so saving on the cost of the assay. We generally incubate the roots at $37^{\circ}$ for one to two days, and then leave them at room temperature until satisfactory colour development is observed. Colour development continues because the GUS enzyme is very stable and its activity can continue for at least one week. However, with additional aeration, colour development should be sufficient after overnight incubation. It is recommended to include $0.02 \%(\mathrm{w} / \mathrm{v})$ sodium azide in the buffer as this will inhibit growth of microorganisms which cause the roots to rot and to smell unpleasant. This also eliminates any background GUS activity due to endogenous GUS $^{+}$microbes. However, caution must be exercised as sodium azide is extremely toxic.

4b) If blue staining occurs on the uninoculated control plants, particularly around the cut surface of the root, this may be due to induction of endogenous GUS activity 
in plant-associated bacteria. In this case include $100 \mu \mathrm{g} \mathrm{ml}^{-1}$ chloramphenicol or $0.02 \%$ sodium azide in the buffer (see section $5 b$ Note 3 and Note $4 a$, above). However, we do not usually observe this happening at the concentrations of $X$ glcA used (no greater than $100 \mu \mathrm{g} \mathrm{ml}^{-1}$ ) for determining nodule occupancy.

5) Partially-stained nodules are almost certainly due to dual occupancy by the marked and unmarked strain, rather than to failure of staining [29]. Thus this method makes identification of mixed occupancy nodules straightforward.

\section{Solutions}

- X-glcA staining buffer for nodule occupancy (per litre)

$-500 \mathrm{ml} 100 \mathrm{mM}$ sodium phosphate $\mathrm{pH} 7.0$

$-2 \mathrm{ml} 0.5 \mathrm{M}$ EDTA

$-10 \mathrm{ml} 10 \%$ sarkosyl

$-10 \mathrm{ml} \mathrm{10 \%} \mathrm{triton} \mathrm{X-100}$

- 50-100 mg X-glcA

$-10 \mathrm{ml} 2 \%(\mathrm{w} / \mathrm{v})$ sodium azide (optional)

\section{References}

1. Bao JR, Lazarovits G (2001) Differential colonization of tomato roots by nonpathogenic and pathogenic Fusarium oxysporum strains may influence Fusarium wilt control. Phytopathology 91: 449-456.

2. Bloem JF, Law IJ (2001) Determination of competitive abilities of Bradyrhizobium japonicum strains in soils from soybean production regions in South Africa. Biol Fertil Soils 33: 181-189.

3. Brown CM, Dilworth MJ (1975) Ammonia assimilation by Rhizobium cultures and bacteroids. J Gen Micro 122: 61-67.

4. Bryan LE (1982) Bacterial resistance and susceptibility to chemotherapeutic agents. Cambridge University Press, Cambridge.

5. Christiansen-Weniger C, Vanderleyden J (1993) Ammonium-excreting Azospirillum sp. become intracellularly established in maize (Zea mays) para-nodules. Biol Fertil Soils 17: 1-8.

6. Collins CH, Lyne PM (1970) Microbiological Methods. Butterworths, London.

7. Couteaudier Y, Daboussi M-J, Eparvier A, Langin T, Orcival J (1993) The GUS gene fusion system (Escherichia coli ß-D-glucuronidase gene), a useful tool in studies of root colonization by Fusarium oxysporum. Appl Environ Microbiol 59: 1767-1773.

8. de Block M, Debrouwer D (1992) In-situ enzyme histochemistry on plastic-embedded plant material. The development of an artefact-free B-glucuronidase assay. Plant J 2: 261-266.

9. de Boer MH, Djordjevic MA (1995) The inhibition of infection thread development in the cultivarspecific interaction of Rhizobium and subterranean clover is not caused by a hypersensitive response. Protoplasma 185: 58-71.

10. de Lorenzo V, Herrero M, Jakubzik U, Timmis KT (1990) Mini-Tn5 transposon derivatives for insertion mutagenesis, promoter probing, and chromosomal insertion of cloned DNA in gramnegative Eubacteria. J Bacteriol 172: 6568-6572.

11. Dombrecht B, Vanderleyden J, Michiels J (2001) Stable RK2-derived cloning vectors for the analysis of gene expression and gene function in gram-negative bacteria. Mol Plant-Microbe Interact 14: 426-430.

12. Gyaneshwar P, James EK, Mathan N, Reddy PM, Reinhold-Hurek B, Ladha JK (2001) Endophytic colonization of rice by a diazotrophic strain of Serratia marcescens. J Bacteriol 183: 2634-2645. 
13. Hammond-Kosack KE, Jones DA, Jones JDG (1994) Identification of two genes required in tomato for full Cf9-dependent resistance to Cladosporium fulvum. Plant Cell 6: 361-374.

14. Herrero M, de Lorenzo V, Timmis KT (1990) Transposon vectors containing non-antibiotic resistance selection markers for cloning and stable chromosome insertion of foreign genes in gram-negative bacteria. J Bacteriol 172: 6557-6567.

15. Hurek T, Reinhold-Hurek B, van Montagu M, Kellenberger E (1994) Root colonization and systemic spreading of Azoarcus sp. strain BH72 in grasses. J Bacteriol 176: 1913-1923.

16. Jefferson RA (1985) Assaying chimeric genes in plants, The GUS gene fusion system. Plant Mol Biol Rep 5: 387-405.

17. Jefferson RA, Carlson RW, Hirsch D (1986) B-glucuronidase from E. coli as a gene-fusion marker. Proc Natl Acad Sci USA 83: 8447-8451.

18. Judelson HS, Tyler BM, Michelmore RW (1992) Regulatory sequences for expressing genes in oomycete fungi. Mol Gen Genet 234: 138-146.

19. Marek-Kozaczuk M, Kopciska J, otocka B, Golinowski W, Skorupska A (2000) Infection of clover by plant growth promoting Pseudomonas fluorescens strain 267 and Rhizobium leguminosarum bv. trifolii studied by mTn5-gusA. Antonie Van Leeuwenhoek 78: 1-11.

20. Monke E, Schafer W (1993) Transient and stable gene expression in the fungal maize pathogen Cochliobolus heterostrophus after transformation with the ß-glucuronidase (GUS) gene. Mol Gen Genet 241: 73-80.

21. Olivain C, Alabouvette C (1997) Colonization of tomato root by a non-pathogenic strain of Fusarium oxysporum. New Phytol 137: 481-494.

22. Oliver RP, Farman ML, Jones JDG, Hammond-Kosack KE (1993) Use of fungal transformants expressing $\beta$-glucuronidase activity to detect infection and measure hyphal biomass in infected plant tissues. Mol Plant-Microbe Interact 6: 521-525.

23. Pankhurst CE (1977) Symbiotic effectiveness of antibiotic-resistant mutants of fast and slowgrowing strains of Rhizobium nodulating Lotus species. Can J Microbiol 23: 1026-1033.

24. Pritsch C, Vance CP, Bushnell WR, Somers DA, Hohn TM, Muehlbauer GJ (2001) Systemic expression of defense response genes in wheat spikes as a response to Fusarium graminearum infection. Physiol Mol Plant Pathol 58: 1-12.

25. Ramos HJO, Roncato-Maccari LDB, Souza EM, Soares-Ramos JRL, Hungria M, Pedrosa FO (2002) Monitoring Azospirillum-wheat interactions using the $g f p$ and $g u s A$ genes constitutively expressed from a new broad-host range vector. J Biotechnol 97: 243-252.

26. Reeve WG, Tiwari RP, Worsley PS, Dilworth MJ, Glenn AR, Howieson JG (1999) Constructs for insertional mutagenesis, transcriptional signal localization and gene regulation studies in root nodule and other bacteria. Microbiology 145: 1307-1316.

27. Resca R, Basaglia M, Poggiolini S, Vian P, Bardin S, Walsh UF, Enriquez Barreiros CM, O'Gara F, Nuti MP, Casella S, Peruch U (2001) An integrated approach for the evaluation of biological control of the complex Polymyxa betae/Beet Necrotic Yellow Vein Virus, by means of seed inoculants. Plant Soil 232: 215-226.

28. Roberts IN, Oliver RP, Punt PJ, van den Hondel CA (1989) Expression of the Escherichia coli B-glucuronidase gene in industrial and phytopathogenic filamentous fungi. Curr Genet 15: 177180 .

29. Sessitsch A, Jjemba PK, Hardarson G, Akkermans ADL, Wilson KJ (1997) Measurement of the competitiveness index of Rhizobium tropici strain CIAT899 derivatives marked with the gusA gene. Soil Biol Biochem 29: 1099-1110.

30. Simon R, Priefer U, Pühler A (1983) A broad host-range mobilization system for in vivo genetic engineering, transposon mutagenesis in gram-negative bacteria. Bio/Technology 1: 784791.

31. Stoltzfus JR, So R, Malarvithi PP, Ladha JK, De Bruijn FJ (1997) Isolation of endophytic bacteria from rice and assessment of their potential for supplying rice with biologically fixed nitrogen. Plant Soil 194: 25-36.

32. Streit WR, Botero L, Werner D, Beck D (1995) Competition for nodule occupancy on Phaseolus vulgaris by Rhizobium etli and Rhizobium tropici can be efficiently monitored in an ultisol during 
the early stages of growth using a constitutive GUS gene fusion. Soil Biol Biochem 27: 10751082.

33. Streit WR, Kosch K, Werner D (1992) Nodulation competitiveness of Rhizobium leguminosarum bv. phaseoli and Rhizobium tropici measured by glucuronidase (GUS) gene fusions. Biol Fertil Soils 14: 140-144.

34. Tada S, Gomi K, Kitamoto K, Takahashi K, Tamura G, Hara S (1991) Construction of a fusion gene comprising the Taka-amylase A promoter and the Escherichia coli ß-glucuronidase gene and analysis of its expression in Aspergillus oryzae. Mol Gen Genet 229: 301-306.

35. Takaya N, Yanai K, Horiuchi H, Ohta A, Takagi M (1994) Cloning and characterization of two 3-phosphoglycerate kinase genes of Rhizopus niveus and heterologous gene expression using their promoters. Curr Genet 25: 524-530.

36. Tchebotar VK, Kang UG, Asis CJ, Akao S (1998) The use of GUS-reporter gene to study the effect of Azospirillum-Rhizobium coinoculation on nodulation of white clover. Biol Fertil Soils 27: 349-352.

37. Ullrich MS, Schergaut M, Boch J, Ullrich B (2000) Temperature-responsive genetic loci in the plant pathogen Pseudomonas syringae pv. glycinea. Microbiology 146: 2457-2468.

38. Vande Broek A, Michiels J, van Gool A, Vanderleyden J (1993) Spatial-temporal colonization patterns of Azospirillum brasilense on the wheat root surface and expression of the bacterial nifH gene during association. Mol Plant-Microbe Interact 6: 592-600.

39. Verma SC, Ladha JK, Tripathi AK (2001) Evaluation of plant growth promoting and colonization ability of endophytic diazotrophs from deep water rice. J Biotechnol 91: 127-141.

40. Vincent JM (1970) A Manual For The Practical Study Of The Root-Nodule Bacteria. Blackwell Scientific Publications, Oxford.

41. Vinuesa P, Neumann-Silkow F, Pacios-Bras C, Spaink HP, Martinez-Romero E, Werner D (2003) Genetic analysis of a pH-regulated operon from Rhizobium tropici CIAT899 involved in acid tolerance and nodulation competitiveness. Mol Plant-Microbe Interact 16: 159-168.

42. Vinuesa P, Reuhs BL, Breton C, Werner D (1999) Identification of a plasmid-borne locus in Rhizobium etli KIM5s involved in lipopolysaccharide O-chain biosynthesis and nodulation of Phaseolus vulgaris. J Bacteriol 181: 5606-5614.

43. Wielbo J, Skorupska A (2001) Construction of improved vectors and cassettes containing gusA and antibiotic resistance genes for studies of transcriptional activity and bacterial localization. J Microbiol Meth 45: 197-205.

44. Wilson KJ (1995) Molecular techniques for the study of rhizobial ecology in the field. Soil Biol Biochem 26: 501-514.

45. Wilson KJ, Hughes SG, Jefferson RA (1992) The Escherichia coli gus operon, induction and expression of the gus operon in E. coli and the occurrence and use of GUS in other bacteria. In: Gallagher S (ed) GUS Protocols, Using the GUS Gene as a Reporter of Gene Expression, pp 7-23. Academic Press, New York.

46. Wilson KJ, Parra A, Botero L (1999) Application of the GUS marker gene technique to highthroughput screening of rhizobial competition. Can J Microbiol 45: 678-685.

47. Wilson KJ, Sessitsch A, Akkermans ADL (1994) Molecular markers as tools to study the ecology of microorganisms. In: Ritz K, Dighton J, Giller KE (eds) Beyond the Biomass: Compositional and Functional Analysis of Soil Microbial Communities, pp 149-156. John Wiley, Chichester.

48. Wilson KJ, Sessitsch A, Corbo JC, Giller KE, Akkermans ADL, Jefferson RA (1995) Beta -glucuronidase (GUS) transposons for ecological and genetic studies of rhizobia and other gramnegative bacteria. Microbiology, 141: 1691-1705.

49. Xi C, Lambrecht M, Vanderleyden J, Michiels J (1999) Bi-functional gfp and gusA-containing mini-Tn5 transposon derivatives for combined gene expression and bacterial localization studies. J Microbiol Meth 35: 85-92.

50. Yuhashi K, Ichikawa N, Ezura H, Akao S, Minakawa Y, Nukui N, Yasuta T, Minamisawa K (2000) Rhizobitoxine production by Bradyrhizobium elkanii enhances nodulation and competitiveness on Macroptilium atropurpureum. Appl Environ Microbiol 66: 2658-2663. 


\title{
The $c e l B$ marker gene
}

\author{
ANGELA SESSITSCH ${ }^{1}$, KATE J. WILSON ${ }^{2}$, ANTOON D. L. \\ AKKERMANS $^{3}$ and WILLEM M. DE VOS ${ }^{3}$ \\ ${ }^{1}$ ARC Seibersdorf research GmbH, Div. of Environmental and Life Sciences, A-2444 \\ Seibersdorf, Austria ${ }^{2}$ Australian Institute of Marine Science, Tropical Aquaculture,PMB 3, \\ Townsville MC QLD4810, Australia ${ }^{3}$ Wageningen University, Laboratory of Microbiology, \\ Hesselink van Suchtelenweg 4, 6703 CT Wageningen, The Netherlands
}

\section{Introduction}

The $E$. coli lac Z gene, encoding $\beta$-galactosidase, has been used as a marker gene in many ecological studies but has only been demonstrated to be suitable when used with $\mathrm{Lac}^{-}$bacteria [4-6]. However, many microbes show high levels of endogenous B-galactosidase and the background enzyme activity in plants restricts the use of this marker gene in studying plant-microbe interactions.

The $c e l B$ marker gene system is based on a thermostable $B$-galactosidase activity that allows detection of a marked strain after heat-inactivation of the endogenous enzyme. The $c e l B$ gene was isolated from the hyperthermophylic archaeon Pyrococcus furiosus, an organism that has an optimum growth temperature above $85^{\circ} \mathrm{C}$ [15]. The enzyme encoded by this gene is a B-glucosidase that also shows a high $\beta$-galactosidase activity. It is one of the most thermostable enzymes identified up to now, with a half-life of 85 hours at $100{ }^{\circ} \mathrm{C}$ [8].

The enzyme $B$-galactosidase cleaves B-galactopyranosides, and several histochemical and chromogenic substrates are available to detect enzyme activity. A widely used histochemical compound allowing the detection of spatial localization of a marked microbe is 5-bromo-4-chloro-3-indolyl-ß-D-galactopyranoside (Xgal) that forms an indigo precipitate due to B-galactosidase activity. celB-marked bacteria can be visualized for example as blue spots or blue areas on roots or within root nodules after heat-denaturation of endogenous enzymes. The $c e l B$ marker gene has been used to determine rhizobial nodule occupancy by incubating the roots in a phosphate buffer at $70^{\circ} \mathrm{C}$ followed by incubation in the same buffer amended with $\mathrm{X}$-gal at $37^{\circ} \mathrm{C}$. Enzyme activity has been quantified by using o-nitrophenyl-B-Dgalactopyranoside (oNPG) and by measuring spectrophotometrically the amount of p-nitrophenol (pNP) produced [11].

The $c e l B$ gene constructs for marking gram-negative bacteria are essentially the same as the gusA marker gene constructs that have been described extensively in a previous chapter of this manual [see also 16]. The constructs developed are 
maintained on transposons and can thereby be easily and stably inserted in the genome of the strain to be marked. Different transposons containing the $c e l B$ gene are available using different promoters corresponding to the GUS constructs as they were initially designed to be used in combination. They are based on the minitransposon mini- $\mathrm{Tn} 5 \mathrm{Sm} / \mathrm{Sp}$ developed previously $[2,7]$. The $\mathrm{celB}$ gene has been inserted in these mini-transposons using different expression systems. The minitransposon is maintained on a "suicide" plasmid with a narrow replication range and that therefore can replicate in a particular E. coli strain but not in Rhizobium (or other gram-negative bacteria). The delivery plasmid carrying the marker can be transferred from $E$. coli to the recipient strain by bacterial conjugation. In the new host it cannot be maintained, but the mini-transposon can be transferred by transposition to a random location in the genome of the host. For most ecological experiments it is advantageous to insert foreign genes into the chromosome, where they are stably maintained and not overexpressed as a result of a high plasmid copy number.

Initially, the $c e l B$ marker gene system has been developed to be used in combination with the gusA marker in order to detect more than two rhizobial strains on or in plant tissue. The similar staining procedures using different histochemical reagents for $g u s A$ and $c e l B$ marked cells giving rise to different colours allow their simultaneous localization for example on roots by using a combined $\mathrm{gus} A / \mathrm{celB}$ assay that will be presented in this chapter. However, as the histochemical substrates used for glycosides are substantially cheaper than the corresponding glucuronide substrates, the $c e l B$ marker will find additional applications.

The fact that the marker gene inserts randomly into the recipient's genome and that it therefore can have a negative impact on ecological properties of the host has to be considered carefully. We have shown that the insertion of GUS transposons per se does not alter the ecological behaviour of the host but in some transconjugants the marker might insert into essential genes [12]. As described in a previous chapter on the gusA marker gene, preliminary screening of the marked transconjugants is recommended in order to ensure that there have been no major changes in the property to be studied due to the transposon mutagenesis.

The resulting marked strains have to be considered as genetically modified microorganisms and their release is subject to the applicable biosafety regulations.

\section{Procedures}

\section{Experimental approach}

Several procedures are required in order to use the reporter gene in ecological studies. The first step is, depending on the application of the marked strain, to select the appropiate expression system. After 
Table 1. Mini-transposons containing the $c e l B$ marker gene

\begin{tabular}{|c|c|c|c|c|c|}
\hline $\begin{array}{l}\text { Name of } c e l B \\
\text { minitransposon }\end{array}$ & $\begin{array}{l}\text { Marker } \\
\text { gene ca }\end{array}$ & ette & & $\begin{array}{l}\text { Promoter } \\
\text { type }\end{array}$ & Description \\
\hline \multirow{3}{*}{ mTn5SScelB11 } & Ptac & celB & ter & & \\
\hline & & & & constitutive & $\begin{array}{l}\text { celB gene is constitutively ex- } \\
\text { pressed in free-living bacteria and } \\
\text { can be used in soil and rhizosphere } \\
\text { studies }\end{array}$ \\
\hline & Ptac & celB & ter $\operatorname{lacl}^{q}$ & & \\
\hline mTn5SScelB 10 & & & 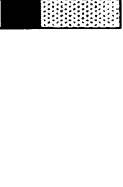 & repressible & $\begin{array}{l}\text { celB gene is repressed by the } l a c I^{q} \\
\text { gene product, but can be induced } \\
\text { by IPTG; can be used in soil and } \\
\text { rhizosphere studies and it has been } \\
\text { used to study nodule occupancy }\end{array}$ \\
\hline mTn5SScelB31 & PnifH & celB & & symbiotic & $\begin{array}{l}\text { celB is only expressed in active, } \\
\text { nitrogen fixing nodules and can be } \\
\text { used to study nodule occupancy }\end{array}$ \\
\hline
\end{tabular}

introducing the $c e l B$ marker gene into the strain of choice, different transconjugants should be tested for any impact on important ecological characteristics due to the insertion of the foreign gene. A quantification of the activity of thermostable B-galactosidase is optional. After these procedures, the selected marked transconjugant is ready to be used in an ecological experiment.

\section{Selection of the marker gene construct}

Different celB constructs, shown in Table 1, have been developed in accordance with the GUS transposons described in a previous chapter. The choice of the most appropiate one will depend on the experiment to be carried out. The promoters used induce expression of the marker gene to be either constitutive, regulated or induced under microaerophilic conditions. In mTn5SScelB 10, the tac promoter has been used to regulate expression of the structural gene in combination with the $\mathrm{lacl}^{q}$ repressor gene. As long as the $\mathrm{lacl}^{a}$ product blocks expression, production of the thermostable $B$-galactosidase remains at a low level. However, addition of the inducer IPTG (isopropyl-BD-thiogalactoside) alleviates this repression and results in high level production of the heat-stable enzyme. Using this construct possible 
effects on the ecological fitness (such as lower growth rate or decreased competitive ability) should be reduced as the marker gene is not induced until the moment of assay. mTn5SScelB 10 has been used to detect Rhizobium both in the free-living state and to study nodule occupancy $[11,12]$. In mTn5SScelB11 the marker gene is constitutively expressed and this expression system is suitable to study rhizosphere colonization. Constitutive expression is not optimal for detection of Rhizobium cells in nodules due to a decline in gene expression in older nodules as it has been shown for a gus $A$ gene construct containing the aph promoter [14]. Furthermore, it was demonstrated that constitutive expression using the aph or the tac promoter resulted in insufficient staining of nodules that was independent of the substrate concentration [10]. mTn5SScelB31 carries the nifH promoter of a Bradyrhizobium strain. The nifH gene codes for the Fe-component of the enzyme nitrogenase and gene expression occurs only in symbiotic or microaerophilic conditions. The symbiotic gene fusion is recommended for the study of nodule occupancy, particularly in longer-term experiments.

Marking a gram-negative strain with celB

The marking procedures for mini-Tn 5 transposons containing a spectinomycin/streptomycin resistance gene for selection have been extensively explained in a previous chapter of this manual and therefore will not be presented here in detail. The marking system was designed to be used with gram-negative bacteria and the B-galactosidase expressed by celB can be detected also in $\mathrm{Lac}^{+}$strains due to the heat stability of the new enzyme. The plasmid carrying the celB minitransposon is transferred from the $E$. coli host strain to the recipient strain by bacterial conjugation (mating). This is done by simply mixing donor and recipient strain on non-selective plates that allow equal and good growth of both strains. After overnight incubation, the mating suspension is grown on plates that are selective for those cells containing the minitransposon. The selection is done by using a modified Brown \& Dilworth minimal medium that prohibits growth of the $E$. coli donor strain and which is supplemented with spectinomycin in order to prevent the growth of the unmarked recipient strain. Neither the donor strain nor the recipient strain should be able to grow on these plates. 
The next step is to streak some of the transconjugants again on selective plates. For strains that produce exopolysaccharides, as some strains of Rhizobium do, it is recommended to wash the transconjugants in $0.1 \%$ Tween, $10 \mathrm{mM} \mathrm{MgSO}_{4}$ and to grow them again on selective plates. This washing step prevents enclosure of cells of the E. coli donor strain in the bacterial gum.

All procedures needed for marking a gram-negative bacterial strain with celB are exactly the same as for introducing the GUS-transposon and are described in a previous chapter. The procedure for checking qualitatively for CelB activity is outlined here.

Testing the transconjugants for CelB activity

\section{Approach 1}

1. Transfer part of the transconjugant colony onto a piece of nylon membrane commonly used for hybridizations by using a sterile toothpick.

2. Wet the membrane carefully by layering some distilled water on the top.

3. Incubate the membrane for 30 minutes at $70^{\circ} \mathrm{C}$.

4. Soak the membrane briefly in $50 \mathrm{mM}$ sodium phosphate buffer (pH 7.0) containing $1 \mathrm{mM}$ EDTA and $400 \mu \mathrm{g} / \mathrm{ml} \mathrm{X-gal.}$

5. Incubate for $2-3$ hours at $37{ }^{\circ} \mathrm{C}$. Transconjugants expressing the celB gene will turn blue.

\section{Approach 2}

1. Resuspend part of the transconjugant colony in $50 \mu \mathrm{l} 50 \mathrm{mM}$ sodium phosphate buffer ( $\mathrm{pH} 7.0)$ amended with 1 mM EDTA.

2. Incubate for 30 minutes at $70{ }^{\circ} \mathrm{C}$.

3. Add $1 \mu \mathrm{l} 0.1 \%$ SDS and $0.1 \%$ chloroform and vortex for 10 seconds.

4. Add $450 \mu$ l oNPG enzyme buffer and mix well.

5. Incubate at $37{ }^{\circ} \mathrm{C}$. Transconjugants expressing the celB gene will turn yellow after about 1 hour incubation.

\section{Approach 3}

1. Resuspend part of the transconjugant colony in $50 \mu \mathrm{l} 50 \mathrm{mM}$ sodium phosphate buffer ( $\mathrm{pH} 7.0$ ) amended with 1 mM EDTA. 
2. Incubate for 30 minutes at $70{ }^{\circ} \mathrm{C}$.

3. Add $1 \mu \mathrm{l} 0.1 \%$ SDS and $0.1 \%$ chloroform and vortex for 10 seconds.

4. Add $450 \mu \mathrm{l} \mathrm{X}$-gal enzyme buffer and mix well.

5. Incubate at $37^{\circ} \mathrm{C}$. Transconjugants expressing the celB gene will turn blue after about 2 hours incubation.

\section{Solutions}

- $50 \mathrm{mM}$ sodium phosphate buffer $(\mathrm{pH} 7.0)$

$28.9 \mathrm{ml} 1 \mathrm{M} \mathrm{Na}_{2} \mathrm{HPO}_{4}$

$21.2 \mathrm{ml} 1 \mathrm{M} \mathrm{NaH}_{2} \mathrm{PO}_{4}$

Dilute the combined solution to $1000 \mathrm{ml}$ with distilled $\mathrm{H}_{2} \mathrm{O}$.

- $50 \mathrm{mM}$ sodium phosphate buffer (pH 7.0), 1 mM EDTA

- $0.1 \%$ SDS

- chloroform

- oNPG enzyme buffer $50 \mathrm{mM} \mathrm{NaPO}_{4} \mathrm{pH} 7.0$ 1 mM EDTA

$10 \mathrm{mM}$ B-mercaptoethanol

$1.1 \mathrm{mM}$ o-nitrophenyl-B-D-galactopyranoside (oNPG)

- X-gal enzyme buffer

$50 \mathrm{mM}$ sodium phosphate buffer $(\mathrm{pH} 7.0)$

1 mM EDTA

$10 \mathrm{mM}$ B-mercaptoethanol

$2 \mathrm{~g} / \mathrm{ml}$ 5-bromo-4-chloro-3-indolyl-B-D-galactopyranoside (X-gal)

Quantitative determination of thermostable B-galactosidase activity

The enzyme activities in different transconjugants can be compared before using them in ecological experiments. However, in general it is sufficient to check for CelB activity qualitatively. When using cells carrying the mTn5SScelB10 transposon, IPTG has to be added to the growth medium in order to achieve maximal gene expression. Free-living cells carrying $\mathrm{mTn} 5 \mathrm{SS}$ celB31 will show very low CelB activity as gene expression is driven by a nifH promoter and is therefore only switched on in symbiotic or other microaerophilic conditions. 
Determination of thermostable B-galactosidase activity in liquid culture

Steps in the procedure

1. Grow the marked strain in $5 \mathrm{ml}$ rich medium (containing $2 \mathrm{mM}$ IPTG if $\mathrm{mTn} 5 \mathrm{SS}$ celB10 is used).

2. Centrifuge $1.5 \mathrm{ml}$ culture and resuspend the pellet in $1 \mathrm{ml} 50 \mathrm{mM}$ sodium phosphate buffer ( $\mathrm{pH} 7.0$ ) amended with 1 mM EDTA.

3. Take an aliquot for a viable cell count, e.g. by using the Miles \& Misra drop count method [1] and keep the sample on ice.

4. Incubate the cells for 30 minutes at $70^{\circ} \mathrm{C}$.

5. Permeabilize by vortexing with $20 \mu \mathrm{l}$ chloroform and $10 \mu \mathrm{l} 0.1 \%$ SDS for 10 seconds.

6. Prepare 4 tubes containing $450 \mu$ oNPG enzyme buffer and add $50 \mu \mathrm{l}$ of the permeabilized cell suspension to each tube. Prepare one control tube with $450 \mu \mathrm{l}$ oNPG enzyme buffer and $50 \mu \mathrm{l}$ medium. The latter tube will serve as a blank for measuring the absorbance.

7. Incubate the reactions at $37{ }^{\circ} \mathrm{C}$ and stop them at different time points (one tube for each time point) by adding $400 \mu \mathrm{l} 0.4 \mathrm{M} \mathrm{Na}_{2} \mathrm{CO}_{3}$ and note the time points.

8. Measure the absorbances at $420 \mathrm{~nm}$ in a spectrophotometer using $1 \mathrm{~cm}$ cuvettes. Add to the control tube $400 \mu \mathrm{I} \mathrm{Na}_{2} \mathrm{CO}_{3}$ and use it as blank.

\section{Solutions}

- $50 \mathrm{mM}$ sodium phosphate buffer ( $\mathrm{pH}$ 7.0) (see above), 1 mM EDTA

- $0.1 \%$ SDS

- chloroform

- oNPG enzyme assay buffer (see above)

$-0.4 \mathrm{M} \mathrm{Na}_{2} \mathrm{CO}_{3}$

Determination of thermostable B-galactosidase activity in nodules

1. Weigh a single nodule

2. Crush the nodule in $1 \mathrm{ml} 50 \mathrm{mM}$ sodium phosphate buffer $(\mathrm{pH} 7.0)$, 1 mM EDTA.

3. Incubate the nodule suspension at $70^{\circ} \mathrm{C}$ for 30 minutes.

4. Carry out steps 5-8 as described above. 


\section{Calculation of CelB activity}

1. Prepare a graph of $O D_{420}$ (Y-axis) versus time in minutes (X-axis) for each sample - this should give a straight line - and calculate the slope, $\mathrm{S}$, of the graph in $\mathrm{OD}_{420}$ units per minute.

The molar extinction coefficient of ONP at $420 \mathrm{~nm}$ is 5000 , therefore $0.9 \mathrm{ml}$ solution containing $1 \mathrm{nmol} O N P$ has an $\mathrm{OD}_{420}$ of 0.0056 . Calculate the nmol ONP produced per minute

e.g. for a given slope, $S$, the amount of nmol ONP produced $(P)$ becomes: $P$ (nmols ONP per minute) $=S / 0.0056$

2. The production rate has to be normalised to the cell number. e.g. for the calculation of production rate, $P$, and the number of cells in $50 \mu$ suspension used for the assay, $C$, the CelB activity becomes: CelB activity (nmols ONP produced per minute per cell) $=\mathrm{P} / \mathrm{C}$

Assessment of impact on the phenotype of the strain due to the presence of the marker gene

This point has been addressed in a previous chapter of this manual. The same procedures of screening for ecological changes can be utilized for celB-marked bacterial strains. In the case of Rhizobium, important criteria are the growth rate, nodulation, nitrogen fixation, competitive ability and survival in soil, but it depends on the experiment what phenotype is the most important to test for changes. Competitive ability of rhizobaial strains is an important and frequently tested parameter and alterations can be assessed by co-inoculation of the marked and unmarked strain in equal numbers onto the host plant. The marked strain can be considered as equal competitive if it forms about $50 \%$ of the nodules [12].

Use of celB-marked strains in ecological experiments

The following procedures that are essential for ecological experiments utilizing $c e / B$-marked strains will be presented:

- simultaneous detection of celB-marked and gusA-marked strains on plates

- studying root colonization by celB-marked strains

- detection of celB-marked rhizobia (bradyrhizobia) in nodules

- simultaneous detection of celB-marked and gusA-marked rhizobia (bradyrhizobia) in nodules 
Simultaneous detection of celB-and gusA-marked strains on plates

The celB marking system can, in combination with the GUS marking system, be used to monitor free-living populations of bacteria in soil. Experimental procedures for detecting population changes of a gusAmarked strain introduced into soil by plating assays and most probable number (MPN) counts are described in a previous chapter. Here, a complementary protocol for detecting differently marked strains on plates is given. Simultaneous detection is based on the use of different chromogenic substrates. The gusA-marked strain can be detected by using the substrate Magenta-glcA giving rise to a red colour due to GUS activity. Then, after heat-inactivation of endogenous Bgalactosidase activity, the celB-marked strain develops a blue colour when X-gal is used as substrate.

1. Plate the bacteria isolated from soil on appropiate plates (see chapter $x$ of this manual) and grow them until the formation of well grown colonies. If gusA-marked strains have to be detected, the plates should contain $400 \mu \mathrm{g} / \mathrm{ml}$ 5-bromo-4-chloro-3-indolyl-B-Dglucuronic acid (Magenta-glcA). When using strains marked with either mTn5SSgusA10 or mTn5SScelB10, $1 \mathrm{mM}$ IPTG has to be used to induce gene expression.

2. Lift the colonies carefully on a nylon membrane commonly used for colony hybridization [9] and place it in an empty Petri dish with the colony side up. Carefully wet the membrane by adding some sterile distilled water. gusA-marked colonies will turn red (magenta) on plates containing Magenta-glcA. When lifting the colonies on the membrane, the red color is also transferred to the membrane.

3. Incubate 30 minutes at $70^{\circ} \mathrm{C}$.

4. Soak the membrane briefly in $50 \mathrm{mM}$ sodium phosphate buffer (pH 7.0), 1 mM EDTA amended with $400 \mu \mathrm{g} / \mathrm{ml} \mathrm{X-gal.}$

5. Incubate for several hours or overnight at $37^{\circ} \mathrm{C}$. Colonies containing the $c e l B$ gene will turn blue.

\section{Solution}

- $50 \mathrm{mM}$ sodium phosphate buffer (see above), pH 7.0, $1 \mathrm{mM}$ EDTA, $400 \mu \mathrm{g} / \mathrm{ml} \mathrm{X-gal}$ 
The celB gene can be used to monitor the colonization of roots by a marked bacterial strain and marker gene activity can be visualized as discrete regions of blue staining. Colonization is detected by an initial heat treatment in order to eliminate endogenous B-galactosidase activity followed by staining the roots in an appropiate buffer containing $\mathrm{X}$-gal. The minitransposon $\mathrm{mTn} 5 \mathrm{SS}$ celB11 is recommended for such studies. As described for the GUS-staining in a previous chapter, it is possible to include potassium ferricyanide and potassium ferrocyanide in the staining buffer in order to enhance the accuracy of spatial localization. The use of these compounds prevents the diffusion of the initial colourless product from X-gal away from the site of marker gene activity (see chapter $x$ of this manual).

1. Harvest uninoculated and inoculated roots and rinse several times in dilute buffer such as $50 \mathrm{mM}$ sodium phosphate buffer, $\mathrm{pH} 7.0$ or saline.

2. Put roots in $50 \mathrm{mM}$ sodium phosphate buffer ( $\mathrm{pH} 7.0), 1 \mathrm{mM}$ EDTA and incubate them at $70^{\circ} \mathrm{C}$ for 1 hour.

3. Cool down to room temperature, then add $400 \mu \mathrm{g} / \mathrm{ml} \mathrm{X-gal.}$

4. Incubate at $37^{\circ} \mathrm{C}$ for several hours.

5. Clear the roots by immersing them in $2.5 \%$ sodium hypochlorite for 5-10 minutes. Sodium hypochlorite clears the brown pigmentation of roots and therefore makes the detection of the marked strain easier.

\section{Solutions}

- $50 \mathrm{mM}$ sodium phosphate buffer, $\mathrm{pH} 7.0$ (see above)

- $50 \mathrm{mM}$ sodium phosphate buffer, pH 7.0, 1 mM EDTA

- $50 \mathrm{mg} / \mathrm{ml} \mathrm{X-gal} \mathrm{(stock} \mathrm{solution)}$

- $2.5 \%$ hypochlorite

Detection of celB-marked rhizobia (bradyrhizobia) in nodules

Both, the gus $A$ and the celB marker gene, are suitable tools to study nodule occupancy. However, the histochemical substrate for the detection of a celB-marked strain, X-gal, is far cheaper than the corresponding substrate for GUS. 
1. Harvest inoculated and uninoculated plants at the time nodule occupancy is to be assessed. Wash them with distilled water until adhering soil or sand is removed.

2. Put the roots in staining buffer.

3. Incubate at $70^{\circ} \mathrm{C}$ for 1 hour.

4. Cool down to room temperature, then add $200 \mu \mathrm{g} / \mathrm{ml} \mathrm{X-gal.}$

5. Apply vacuum for $10-15$ minutes. to facilitate penetration of the substrate into the nodule.

6. Incubate overnight at $37{ }^{\circ} \mathrm{C}$. When nodules are densely packed in the staining buffer, aeration is recommended, e.g. by using a shaking incubator, by not covering the staining vessels or by the use of an aquarium aerator.

7. Count the number of white, blue and partially blue nodules to determine the percentage nodule occupancy. Clearing of the roots with $2.5 \%$ sodium hypochlorite as described above is optional. Partially stained nodules may be occupied by the marked and by the unmarked strain simultaneously.

\section{Solutions}

- Staining buffer (per litre)

$50 \mathrm{ml} 1 \mathrm{M}$ sodium phosphate buffer, $\mathrm{pH} 7.0$ (see above)

$2 \mathrm{ml} 0.5 \mathrm{M}$ EDTA

$5 \mathrm{ml} 10 \%$ SDS

$10 \mathrm{ml} 10 \%$ sarkosyl

$10 \mathrm{ml} 10 \%$ triton X-100

- $50 \mathrm{mg} / \mathrm{ml} \mathrm{X-gal} \mathrm{(stock} \mathrm{solution)}$

Simultaneous detection of celB-marked and GUS-marked rhizobia (bradyrhizobia) in nodules

Many studies on rhizobial ecology require simultaneous detection of several strains in symbiosis with plants. The combined gusA/celB assay employs different histochemical substrates and allows easy detection of two or more strains on plant. Magenta-glcA is used to detect the gus $A$ marked strain giving rise to a magenta colour, while the celB marked strain can be visualized, after a heat-treatment, by the blue colour that is developed after incubation in the presence of $X$ gal (Fig. 1). Additionally, differently marked strains could be detected within the same nodule [11]. 


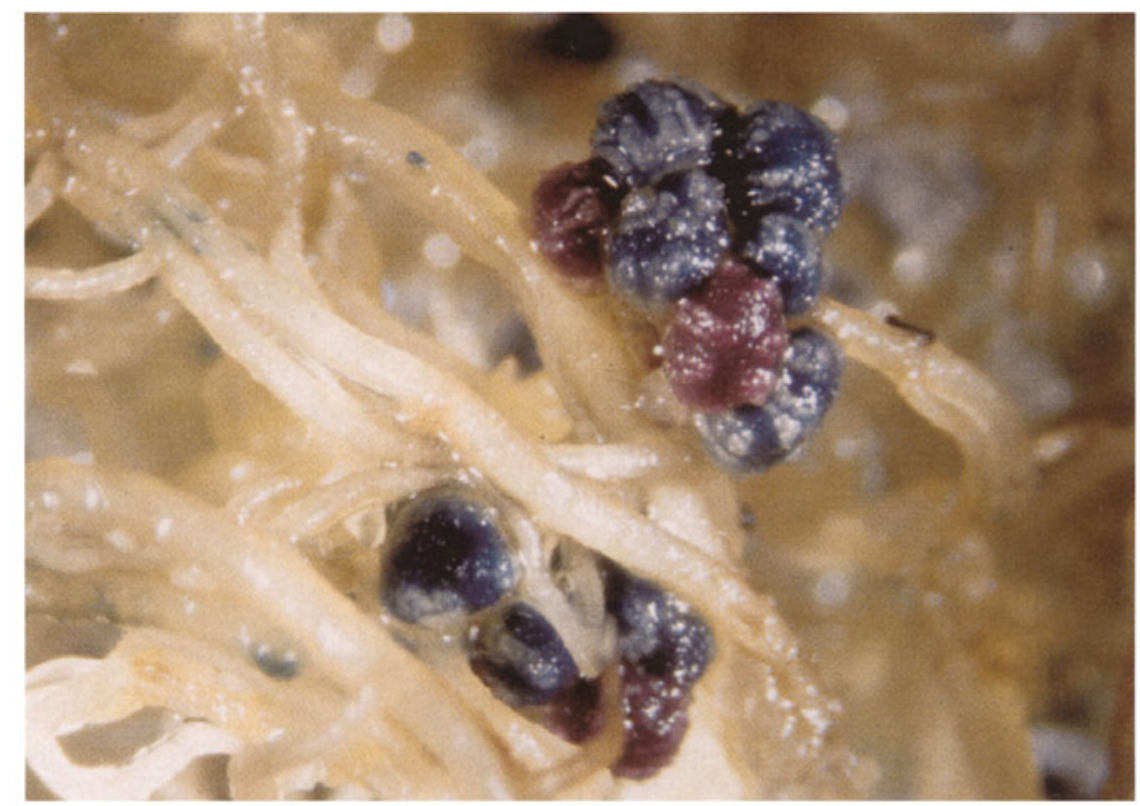

Figure 1. Common bean root nodules occupied by either CIAT899::gusA10 (red) or CIAT899::celB10 (blue) [from 11].

1. Harvest the inoculated and uninoculated plants at the time nodule occupancy has to be assessed. Wash the roots in distilled water until the adhering soil or sand is removed.

2. Put the roots in Magenta-glcA staining buffer.

3. Apply vacuum for $10-15$ minutes.

4. Incubate the roots at $37^{\circ} \mathrm{C}$ overnight.

5. Incubate at $70^{\circ} \mathrm{C}$ for 1 hour.

6. Cool down until room temperature and add $200 \mu \mathrm{g} / \mathrm{ml} \mathrm{X-gal.}$

7. Apply vacuum for $10-15$ minutes.

8. Incubate at $37^{\circ} \mathrm{C}$ overnight.

9. Count the white, red (due to GUS-activity), blue (due to celBactivity) and partially stained nodules.

\section{Solutions}

- Magenta-glcA staining buffer (per litre)

$50 \mathrm{ml} 1 \mathrm{M}$ sodium phosphate buffer, $\mathrm{pH} 7.0$

$2 \mathrm{ml} 0.5 \mathrm{M}$ EDTA

$10 \mathrm{ml} 10 \%$ sarkosyl 
$10 \mathrm{ml} 10 \%$ triton X-100

$5 \mathrm{ml} 10 \%$ SDS

$200 \mathrm{mg}$ Magenta-glcA

- $50 \mathrm{mg} / \mathrm{ml} \mathrm{X-gal} \mathrm{(stock} \mathrm{solution)}$

\section{Application of the method}

Initially, the celB marker gene has been developed as a complementary tool to the gus $A$ marker gene in order to facilitate the identification of rhizobial strains. Both marker systems have been applied in rhizobial competition studies, where several inoculant strains are applied simultaneously in order to determine their competitive ability for nodulation [3, 11, 13]. Sessitsch et al. [11] described the characterization of $c e / B$ marked rhizobia and their simultaneous detection with gusA marked strains. $R$. tropici strain ClAT899, nodulating common bean (Phaseolus vulgaris), has been marked with mTn5SScelB10 and $\mathrm{mTn} 5 \mathrm{SS}$ celB31 and four individual celB transconjugants from each mating were further characterized. Transfer frequencies on the order of one per $10^{7}$ recipients were obtained. First the activity of the thermostable B-galactosidase in liquid culture was determined. Transconjugants harbouring the celB10 construct showed comparable activities in liquid culture when cells were grown in the presence of IPTG (Table 2). CIAT899::celB31 showed no enzyme activity in liquid culture (Table 2), as gene expression is inhibited under areobic conditions. Transconjugants were then used to inoculate Phaseolus vulgaris $\mathrm{L}$. cv. Riz30 plants and proved to have a nodulation efficiency similar to that of the unmarked strain. Enzyme activities in nodules are shown in Table 2. Depending on the transconjugant inoculated significantly different B-galactosidase activities in nodules were found.

For simultanous detection of gus $A$ and celB marked strains, bean plants were inoculated with a combination of CIAT899, CIAT899:: gusA10 and CIAT899::celB 10 or a combination of CIAT899, CIAT899::celB31 and CIAT899::gusA30. Staining with Magenta-glcA and $X$-gal as described above resulted in clearly distinguishable red and blue nodules formed by the marked strains. The parental strain CIAT899 remained unstained indicating that the heat treatment was sufficient to destroy endogenous enzyme activity. Dual-strain occupancy could be easily detected. 
Table 2. B-galactosidase activities in derivatives of $R$. tropici strain CIAT899 containing the minitransposon mTn5SScelB10 or mTn5SScelB31 [from 11]

\begin{tabular}{|c|c|c|c|}
\hline Strain & $\begin{array}{l}\text { Enzyme activity } \\
\text { in liquid culture } \\
\text { with IPTG induction } \\
\left(\text { nmol oNP } \text { min }^{-1}\right. \\
\left.10^{7} \text { cells }^{-1}\right)\end{array}$ & $\begin{array}{l}\text { Enzyme activity } \\
\text { in liquid culture } \\
\text { without IPTG induction } \\
\left(\text { nmol oNP } \text { min }^{-1}\right. \\
10^{7} \text { cells }^{-1} \text { ) }\end{array}$ & $\begin{array}{l}\text { Enzyme activity } \\
\text { in nodules } \\
\text { (nmol oNP } \\
\text { nodule } \mathrm{mg}^{-1} \text { ) }\end{array}$ \\
\hline CIAT899 & n.a. & $<0.01$ & $<0.01$ \\
\hline CIAT899::celB10 A & $6.80^{\mathrm{a}}$ & $0.50^{\mathrm{a}}$ & $0.14^{\mathrm{d}}$ \\
\hline CIAT899::celB10 B & $6.55^{\mathrm{a}}$ & $0.53^{\mathrm{a}}$ & $0.14^{\mathrm{d}}$ \\
\hline CIAT899::celB10 C & $7.47^{\mathrm{a}}$ & $0.68^{\mathrm{a}}$ & $0.20^{\mathrm{bc}}$ \\
\hline CIAT899::celB10 D & $7.76^{\mathrm{a}}$ & $0.63^{\mathrm{a}}$ & $0.20^{\mathrm{bc}}$ \\
\hline CIAT899::celB31 A & n.a. & $<0.01$ & $0.22^{\mathrm{b}}$ \\
\hline CIAT899::celB31 B & n.a. & $<0.01$ & $1.22^{\mathrm{a}}$ \\
\hline CIAT899::celB31 C & n.a. & $<0.01$ & $0.15^{\mathrm{cd}}$ \\
\hline CIAT899::celB31 D & n.a. & $<0.01$ & $0.23^{\mathrm{b}}$ \\
\hline
\end{tabular}

Enzyme activities in liquid culture are the mean of three replicates, while the enzyme activities in nodules are the mean of six replicates. Means within each column which are not significantly different from each other at $\mathrm{P}=0.05$ share the same letters as superscripts. Samples that have not been assayed are indicated with n.a.

The great advantage of this technique is that different strains can be simultaneously and rapidly detected on plant. The methodology is highly useful to study multistrain rhizobial inocula in competition with indigenous populations of rhizobia. However, as the use of marker genes is a unique and simple tool to monitor the fate of microorganisms, the celB marker gene will find also other applications in studies on microbial ecology.

\section{References}

1. Collins CH, Lyne PM (1985) Microbiological Methods, 5th edn., Butterworths, London.

2. de Lorenzo V, Herrero M, Jakubzik U, Timmis KT (1990) Mini-Tn5 transposon derivatives for insertion mutagenesis, promoter probing, and chromosomal insertion of cloned DNA in gramnegative Eubacteria. J Bacteriol 172:6568-6572.

3. de Oliveira WS, Meinhardt LW, Sessitsch A, Tsai SM (1998) Analysis of Phaseolus-Rhizobium interactions in a subsistence farming. Plant and Soil 204:107-115.

4. Drahos DJ, Hemming BC, McPherson S (1986) Tracking recombinant organisms in the environment: B-galactosidase as a selectable, non-antibiotic marker for fluorescent pseudomonads. Bio/Technology 4:439-443.

5. Hartel PG, Fuhrmann JJ, Johnson Jr. WF, Lawrence EG, Lopez CS, Mullen MD, Skipper HD, Staley TE, Wolf DC, Wollum II AG, Zuberer DA (1994) Survival of a lacZY-containing Pseudomonas putida strain under stressful abiotic soil conditions. Soil Sci Soc Am J 58:770776.

6. Hattemer-Frey HA, Brandt EJ, Travis CC (1990) Small-scale field test of the genetically engineered lacZY marker. Reg Toxicol Pharmacol 11:253-261. 
7. Herrero M, de Lorenzo V, Timmis KT (1990) Transposon vectors containing non-antibiotic resistance selection markers for cloning and stable chromosome insertion of foreign genes in gram-negative bacteria. J Bacteriol 172:6557-6567.

8. Kengen SWM, Luesink EJ, Stams AJM, Zehnder AJB (1993) Purification and characterization of an extremely stable B-glucosidase from the hyperthermophilic archaeon Pyrococcus furiosus. Eur J Biochem 213:305-312.

9. Sambrook J, Fritsch EF, and Maniatis T (1989) Molecular cloning: a laboratory manual, 2nd ed. Cold Spring Harbor Laboratory, Cold Spring Harbor, N.Y.

10. Sessitsch, A. (1994) Studies on rhizobial ecology using marker genes. In Proceedings of the International FAO/IAEA Symposium on Nuclear Techniques in Soil/Plant Studies on Sustainable Agriculture and Environmental Preservation, 17-21 Oct. 1994, Vienna. pp.251-261.

11. Sessitsch A, Wilson KJ, Akkermans ADL, de Vos WM (1996) Simultaneous detection of different Rhizobium strains marked with either the Escherichia coli gusA or the Pyrococcus furiosus celB gene. Appl Environ Microbiol 62:4191-4194.

12. Sessitsch A, Jjemba PK, Hardarson G, Akkermans ADL, Wilson KJ (1997) Measurement of the competitiveness index of Rhizobium tropici strain CIAT899 derivatives marked with the gusA gene. Soil Biol Biochem 29:1099-1110.

13. Sessitsch A, Hardarson G, de Vos WM, Wilson KJ (1998) Use of marker genes in competition studies of Rhizobium. Plant and Soil 204:35-45.

14. Streit W, Botero L, Werner D, Beck D (1995) Competition for nodule occupancy on Phaseolus vulgaris $\mathrm{L}$. by $R$. etli and $R$. tropici can be efficiently monitored in an ultisol during the early stages of growth using a constitutive GUS gene fusion. Soil Biol Biochem 27:1075-1081.

15. Voorhorst WGB, Eggen RIL, Luesink EJ, de Vos WM (1995) Characterization of the celB gene coding for B-glucosidase from the hyperthermophylic archaeon Pyrococcus furiosus and its expression and site-directed mutation in Escherichia coli. J Bacteriol 177:7105-7111.

16. Wilson KJ, Sessitsch A, Corbo JC, Giller KE, Akkermans ADL, Jefferson RA (1995) Bglucuronidase (GUS) transposons for ecological studies of rhizobia and other Gram-negative bacteria. Microbiol 141:1691-1705. 


\title{
Visualisation of microbes and their interactions in the rhizosphere using auto fluorescent proteins as markers
}

\author{
GUIDO V. BLOEMBERG ${ }^{1 *}$, ANASTASIA LAGOPODI ${ }^{2}$, FRANS \\ J. DE BRUIJN ${ }^{3}$ and JANET K. JANSSON ${ }^{4}$ \\ ${ }^{1}$ Institute of Biology Leiden, Leiden University, Wassenaarseweg 64, 2333AL Leiden, The \\ Netherlands. ${ }^{2}$ Aristotelian University of Thessaloniki, Faculty of agriculture, Plant Pathology \\ Laboratory, P. O. box 269, 54006 Thessaloniki, Greece ${ }^{3}$ Laboratoire de Biologie Moléculaire \\ des Relations Plantes-Micro-Organisms, INRA-CNRS, Chemin de Borde-Rouge Auzeville-B.P. \\ 27-31326 Castanet-Tolosan, Cedex, France. ${ }^{4}$ Department of Biochemistry, Arrhenius \\ Laboratories, Stockholm University, S-10691 Stockholm, Sweden. ${ }^{*}$ Corresponding author: Dr. \\ Guido V. Bloemberg Institute of Biology Leiden (IBL) Leiden University Wassenaarseweg 64 \\ 2333AL Leiden The Netherlands E-mail: bloemberg@ rulbim.leidenuniv.nl Tel: \\ (+)-31-71-5275056 Fax: (+)-31-71-5275088
}

\section{Introduction}

Microscopy studies to visualize microorganisms at the single cell level are required to fully understand their functioning in their (natural) environment, such as the rhizosphere and soil. Studies of bacteria in natural environments show that they live in complex communities, predominantly in biofilms, where they interact with other species. Visualisation methods of individual cells have been stimulated by the recent developments in using auto fluorescent proteins (AFP's) as markers to monitor their presence and as reporters to study gene expression. Green Fluorescent Protein, isolated from the jellyfish Aequorea victoria, has been the most revolutionary reporter in biology since its application as a marker was published by Chalfie et al. [7]. In contrast to the use of fluorescent stains, fluorescent antibodies or fluorescent probes targeted to $16 \mathrm{~S}$ ribosomal RNA genes, the use of autofluorescent proteins as markers does not require any preparation steps, such as fixing with formaldehyde or ethanol, which might result in death and/or a change of the original in situ situation. The major advantages of GFP as a reporter are its (i) stability (due to its barrel protein structure), (ii) species independent application (pro- and eukaryotes), (iii) non-invasive analysis without the need for exogenous substrates, cofactors or energy and (iv) possibility of in vivo monitoring while preserving the integrity of the organism. Colour variants of the GFP, e.g. EGFP, ECFP and EYFP, with shifted excitation and emission maxima and an increased brightness and stability have been developed and used for dual colour imaging [12, 20, 32, 36] (Tab. 1). The DsRed (RFP) protein [21] (Tab.1) isolated 
Table 1. Excitation and emission maxima of autofluorescent proteins.

\begin{tabular}{lcc}
\hline Autofluorescent protein & Excitation max. (nm) & Emission max. (nm) \\
\hline GFP (wt) & 395 & 509 \\
P11 & 471 & 509 \\
EGFP & 488 & 507 \\
SGFP & 490 & 509 \\
ECFP & 433 & 475 \\
EYFP & 513 & 527 \\
DsRed & 558 & 583 \\
\hline
\end{tabular}

from Discosoma has broadened the range of auto-fluorescent proteins creating the opportunity for triple colour imaging. The $r f p$ sequence shows only weak homology to $g f p$ and therefore can be cloned together with $g f p$ (or $g f p$ variants) in one plasmid without the danger of recombination. Slow protein maturation (up to 48 hours) and tetramerization of DsRed [2] can form a problem in its application. Very recently, a DsRed derivative has been reported with an enhanced maturation and brightness which will facilitate the application of DsRed [28].

Transposon-based delivery systems have been constructed for integration of $g f p$ into bacterial chromosomes [3, 31, 34]. A promotorless $g f p$ reporter system was constructed for generation of transcriptional fusions in bacteria [3]. Alternatively, for stable chromosomal tagging of bacteria with constitutively expressed $g f p$, a broad-host range $g f p$-tagging system was developed $[3,31]$, based on a mini-Tn5 delivery system [16]. In order to achieve $g f p$ gene expression in different bacteria, the $p s b A$ promoter, known to be expressed at a high level in a wide variety of bacterial species [38], was cloned in front of the $g f p$ coding sequences and the resulting cassette was inserted in a mini-Tn5 delivery vector [3, 31]. The $g f p$ cassette in the mini-Tn5 consists of the following elements: the psbA promoter, T7 gene 10 RBS and P11 gene (A red shifted $g f p$ derivative with an excitation wavelength of $471 \mathrm{~nm}$; Heim et al., 1994) [31] (Fig. 1). This cassette (and variants thereof) has been used to stably integrate and express the $g f p$ marker gene into different gram-negative [3, 30, 31] and gram-positive bacteria [34]. The introduction of the marker gene cassette by electroporation [13], or conjugal transfer, has proven to be a useful technique for the $g f p$-tagging of a number of bacterial strains.

As an alternative for transposon mutagenesis we have constructed a set of four rhizosphere stable plasmids to express the egfp, ecfp, eyfp and $r f p$ genes under control of the lac promoter, which resulted in plasmids pMP2444, pMP4516, pMP4518 and pMP4661, respectively [29]. Since pBBR1-based plasmids appeared not to be stable in Pseudomonas during subsequent sub-culturing in medium without antibiotic pressure, they were fused to the rhizosphere-stable cloning vector pME6010, which is based on the pVS1 replicon [15]. This resulted in plasmids pMP4655, pMP4641, pMP4658 and pMP4662, respectively [5]. Due to 

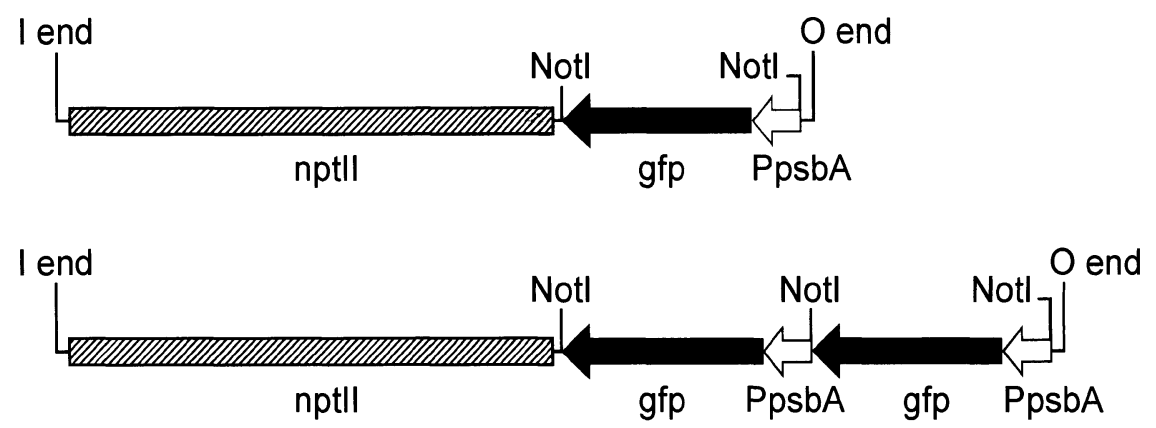

$1000 \mathrm{bp}$

Figure 1. Tn5 borne gfp cassettes for chromosomal integration; The upper panel shows the structure of the $g f p$ containing Tn5 derivative carried by pUTGFP [31] and the lower panel the Tn5 borne $g f p$ fragment of pUTGFP2 [33].

the pVS1 replicon the constructed plasmids are presumably stable in many other Gram negative bacteria [15] and highly suitable to visualize bacteria in environments where no antibiotic pressure can be applied.

Fungi form an important part of the microbial life in soil and the rhizosphere. Plant diseases caused by fungi result in major crop losses. Tagging of fungi with autofluorescent proteins in order to visualize them at the cellular level and thereby getting a better understanding of their ecological role is an important goal. Genetic introduction of afp's into fungi is usually based on the chromosomal integration of a plasmid harbouring the afp under control of a selected promoter [9]. We have made use of the pGDP promoter [37] which results in constitutive expression and is applicable in a wide range of fungi. In order to express $g f p$ in $F$. oxysporum f. sp. radicis-lycopersici, the $s g f p$ gene [8] was cloned between the A. nidulans gpdA (glyceraldehyde-3-phosphate dehydrogenase) promoter [24] and the $\operatorname{trp} C$ terminator [22] sequences to give pGPDGFP [18]. pAN7-1 [23] carrying the Escherichia coli hygromycin-B (Hm-B) resistance gene $h p h$, cloned also between the Pgpd promoter and $\operatorname{tr} \mathrm{C}$ terminator, together with pGPDGFP were used in a co-transformation of $F$. oxysporum $\mathrm{f}$. sp. radicis-lycopersici. pAN7-1 allows selection of transformants on media containing this antibiotic hygromycin-B. Both plasmids were also successful for tagging Aspergillus with gfp (Ram, personal communication).

The afp-tagged microorganims can be visualized and tracked by a variety of methods developed for the detection of fluorescent cells, such as epifluorescence microscopy, confocal laser microscopy, flow cytometry and fluorescence photospectrometry. Progress has been made during the past year in using confocal laser scanning microscopy (CLSM) in combination with various fluorescent markers to visualize and monitor bacterial populations in the rhizosphere. Visualization of GFP-labelled organisms with CLSM is an effective, fast and non-invasive tool that allows the spatio-temporal analysis of interactions while preserving the 
integrity of the organisms under study. Useful information on autofluorescent proteins can be found on the website: http://www.bdbiosciences.com/clontech/gfp/ index.shtml.

Auto fluorescent proteins have shown to be very suitable markers for studying bacterial and fungal behaviour at the single cell level in the rhizosphere, such as Pseudomonas root colonization (Fig. 2) [4, 5, 30, 31, 35]. The use of multiple autofluorescent proteins (ECFP, EGFP and DsRed) was used to show the dynamics of three microbial populations simultaneously [5]. A combination of GFP and DsRed made it also possible to show that infection threads of S. meliloti can contain mixed population of cells, which sometimes results in mixed populations in root nodules, providing the possibility to study competition events among rhizobial strains [14]. Tagging of the phytopathogenic Fusarium oxysporum f.sp. radicis lycopersici with GFP made it possible to analyse the infection process of tomato in detail using confocal laser scanning microcopy (Fig. 3; [18]. Recently, simultaneous imaging of the GFP labelled Fusarium strain and DsRed labelled biocontrol Pseudomonas spp. resulted in the visualization of interactions between at the cellular level such as the colonization of hyphae by Pseudomonas spp. in the rhizosphere (Fig. 4) [6].

Combinations of different reporter genes have shown to be powerful tools in studying biofilm formation and gene expression in the rhizosphere. Using a dual marker system $g f p$ and $l u x A B$ genes the metabolic activity of $P$. fluorescens SBW25 was analyzed on all parts of wheat $[34,35]$. Since the luciferase reaction requires energy the output of light decreases during starvation this was used as a marker for metabolic activity (e.g. cellular energy status), whereas the $g f p$ (which does not require energy) was used to localize and quantify the bacterial cells. The construction of instable variants of the Green Fluorescent Protein [1] facilitates the analysis of transient gene expression in the rhizosphere. Spatio-temporal analysis of gene expression in the rhizosphere will be possible by visualizing bacterial cells which harbour an unstable $g f p$ variant under control of the promoter to be analysed and the constitutive expression of $r f p$.

In this chapter procedures are provided for tagging of bacteria and fungi with auto fluorescent proteins and methods to analyze the expression of $a f p$. We focus on soil- and rhizosphere organism.

\section{Procedures}

\section{Tagging of bacteria with autofluorescent proteins.}

Bacteria can be marked with reporter genes by using a transposon resulting in a single copy of the marker gene integrated into the chromosome or by the introduction of a plasmid resulting in multiple copies 

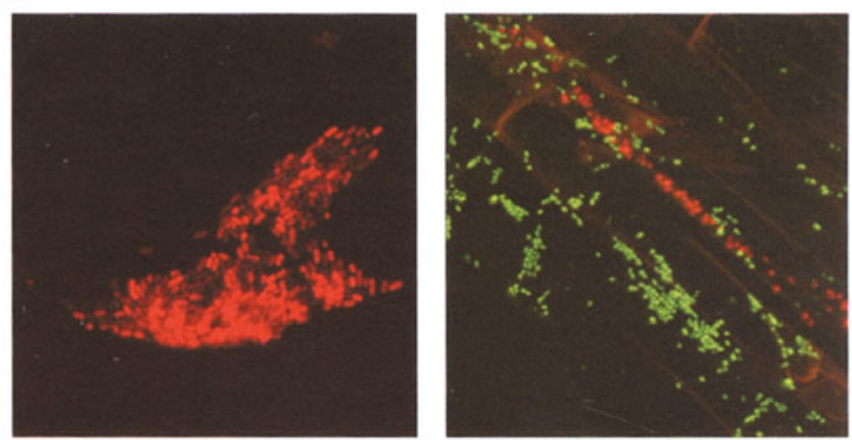

Figure 2. Confocal laser scanning microscopy analysis (inverted Leica-DMIRBE ) of tomato root colonization by two Pseudomonas putida strains differentially marked with auto fluorescent proteins. Rhizosphere isolates $P$. putida PCL1444 and PCL1445 were marked with plasmids harbouring egfp and $r f p$, respectively. Two day old germinated tomato seedlings were inoculated with a 1:1 mixture of PCL1444 and PCL1445 and grown in a gnotobiotic sand system. Seven days after inoculation the roots were taken out of the sand and examined for the presence of both strains using Confocal laser scanning microcopy. Panel A shows a microcolony solely consisting of PCL1445 on the root surface. Panel B shows the simultaneous imaging of PCL1444 and PCL1445 microcolonies in the rhizosphere (Images were provided by E. Lagendijk)

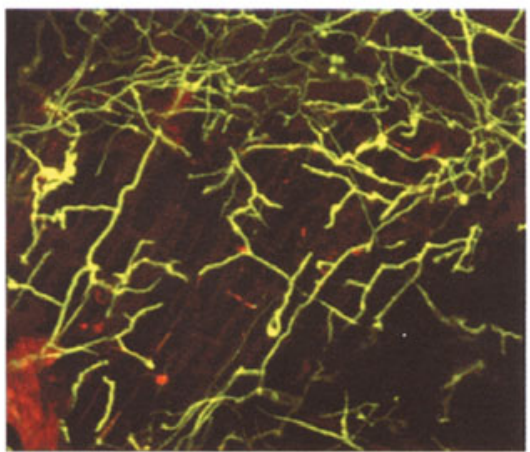

Figure 3. Colonization of the tomato rhizosphere by the pythopathogenic fungus Fusarium oxysporum f.sp. radicis lycopersici tagged with SGFP as analyzed using Confocal laser scanning microcopy (MRC 1024 SE BIORAD confocal system). Hyphae form a branched network on the root surface. Cells walls are visualized this image by red autofluorescence.

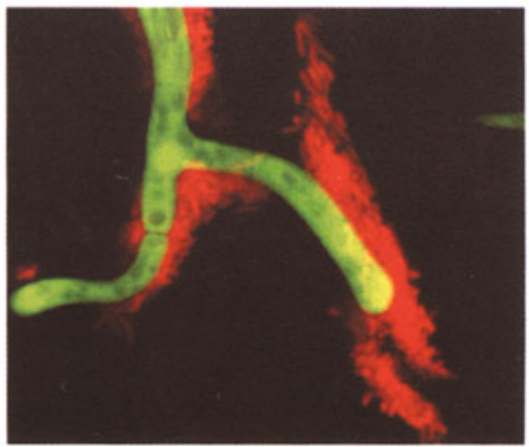

Figure 4. Confocal laser scanning microcopy (inverted Leica-DMIRBE) analysis of interactions in the tomato rhizosphere between the phytopathogenic fungus Fusarium oxysporum f.sp. radicis lycopersici tagged with SGFP and $P$. fluorescens WCS365 tagged with DsRed. Dark areas in the fungal hyphae represent vacuoles. 
of the marker gene. Alternatively a marker gene could be introduced by homologous recombination targeted at a specific site of the chromosome, which does not influence the functioning of the bacterium. However, the latter strategy requires knowledge of such chromosomal sites for each bacterial strain to be used.

Using a transposon has the advantage of stable integration into the chromosome and a limited production of the marker protein due to the single copy. The latter is of relevance since overexpression of $g f p$ can result in growth inhibition of for example E.coli. Before using the labeled transposant it should be tested for defects due to the chromosomal integration or preferentially the location of insertion into the chromosome should be determined. We recommend the Tn5-based mini-transposon system, because of the low probability of continued mobilization of inserted fragments using this transposon.

The use of a plasmid circumvents the chromosomal location problem. Since in general antibiotics cannot be applied in ecological studies, plasmids which require the presence of an antibiotic for maintenance are not useful. Recently low copy number plasmids which are stably maintained in Gram negative bacteria were developed [15] and have been shown to be useful for tagging and visualization of Pseudomonas [5], Rhizobium [29], Agrobacterium (Hooykaas personal communication) and Azospirillum (VanderLeijden, personal communication) in the rhizosphere. A set of plasmids was constructed containing auto fluorescent proteins genes, e.g. ecfp, egfp, eyfp and $r f p$, under control of the lac-promoter which results in a low constitutive expression [5].

Introduction of plasmids into bacteria can be established by 1) Transformation of competent bacteria, 2) Conjugal transfer and 3) Electroporation. Methods for making cells competent have been developed for only a small number of bacterial strains. Natural competence for DNA uptake under laboratory conditions has been shown for a very limited number of strains (for example Bacillus strains) and is also depend upon the growth medium and growth conditions. In contrast conjugation transfer and electroporation can be applied more generally and are most frequently used for the introduction of plasmids. Below, the methodologies for conjugative transfer and electroporation are described. 
Conjugative plasmid transfer to Pseudomonas soil/rhizosphere isolates.

\section{Materials}

- sterile PBS-buffer (Phosphate Buffered Saline)

- LB-medium [25]

- King's B medium [17]

- King's B-agar plates containing the antibiotics naladixine $(40 \mu \mathrm{g} / \mathrm{ml})$ and kanamycine $(50 \mu \mathrm{g} / \mathrm{ml}$ ) or tetracycline $(8 \mu \mathrm{g} / \mathrm{ml}$ ) (or another antibiotic depending upon the plasmid of transposon to be used)

- E. coli S17-1 [26] donor strain (containing the transposon plasmid)

- Pseudomonas acceptor strain

\section{Protocol}

\section{Day 1}

1. Inoculation of cultures :

- E. coli S17-1 harboring a plasmid in LB-medium supplemented with kanamycine $(50 \mu \mathrm{g} / \mathrm{ml})$ or tetracycline $(8 \mu \mathrm{g} / \mathrm{ml})$ at $37^{\circ} \mathrm{C}$

- Pseudomonas strain in KB-medium at $28^{\circ} \mathrm{C}$

\section{Day2}

2. Dilute the overnight culture $1 / 20$ in $5 \mathrm{ml}$ fresh medium

3. Grow the cultures to $\mathrm{OD}_{620}=0.4$ (log phase cells)

4. Add $750 \mu \mathrm{l}$ Pseudomonas to $750 \mu \mathrm{l}$ E. coli in a sterile eppendorf tube (As controls: separately $750 \mu$ l Pseudomonas and $750 \mu \mathrm{l}$ E. coli)

5. Centrifuge for 2 minutes. at $13,000 \mathrm{rpm}$. Remove the supernatant and resuspend the pellet in $50 \mu \mathrm{l}$ of fresh LB medium (without antibiotics)

6. Pipet the $50 \mu \mathrm{l}$ as a single droplet on a KB agar plate (without antibiotics)

7. Incubate for $3-4$ hours or overnight at $28{ }^{\circ} \mathrm{C}$ for conjugation and chromosomal integration to occur

8. Scrape the cells of the plate and resuspend in $1 \mathrm{ml}$ sterile PBSbuffer (use vortex for resuspending)

9. Plate 10,50 and $100 \mu \mathrm{l}$ of the suspension on KB selection plates (containing appropriate antibiotics) and the control plates 
10. Incubate (if necessary $2 \times$ ) $\mathrm{O} / \mathrm{N}$ at $28^{\circ} \mathrm{C}$ for the appearance of transposants/transformants as single colonies

11. Streak single colonies on a fresh agar plate containing antibiotics, incubate $\mathrm{O} / \mathrm{N}$ at $28{ }^{\circ} \mathrm{C}$

\section{Notes}

1. Step 1. S17-1 contains the ability to transfer the plasmid which it contains. Alternatively E.colistrain pRK 2013 can be used as helper strain for an E.colistrain containing a plasmid to be transferred.

2. Step3. Cells to a maximum of $\mathrm{OD}_{620}=0.7$ can be used.

3. Step 4. An incubation of the Pseudomonas cells at $42^{\circ} \mathrm{C}$ can stimulate the acceptance of the foreign DNA.

4. Step 4. In case of using pRK2013 [11], a mixture of $500 \mu$ l of each strain, e.g. pRK2013, E.coli plasmid donor strain and the Pseudomonas strain should be made.

Plasmid transfer by electroporation.

\section{Materials}

- sterile demineralised water

- electropration apparatus (for example BioRad)

- SOC-medium

- For 1 litre SOC: $\quad-10 \mathrm{~g}$ Bacto trypton

$-5 \mathrm{~g}$ Bacto yeast

$-5 \mathrm{~g} \mathrm{NaCl}$

$-2,5 \mathrm{mM} \mathrm{KCl}$

$-10 \mathrm{mM} \mathrm{MgSO}_{4}$

$-10 \mathrm{mM} \mathrm{MgCl}_{2}$

$-200 \mathrm{mM}$ glucose

- Adjust the $\mathrm{pH}$ using $\mathrm{NaOH}$ to 7.0

- Sterilise during 40 minutes. at $110{ }^{\circ} \mathrm{C}$

- selection agar-plates

- sterile $10 \%$ glycerol

\section{Protocol}

1. Inoculate KB medium with the Pseudomonas strain to be transformed and grow the culture $\mathrm{O} / \mathrm{N}$ at $28^{\circ} \mathrm{C}$.

2. Harvest the cells by centrifugation during 10 minutes at $5,000 \mathrm{rpm}$.

3. Wash the pellet 5 times with sterile ice-cold demi-water. Use equal volumes of water per wash step in order to remove capsular 
polysaccharides and salts. Handle the cells gently in order to keep them in tact.

4. Resuspend the pellet for the last washing step in $10 \%$ sterile glycerol.

5. Resuspend the pellet in $1 / 100$ start culture volume (approximately $10^{9}-10^{10}$ cells $/ \mathrm{ml}$ ) of $10 \%$ sterile glycerol.

6. For storage at $-80{ }^{\circ} \mathrm{C}$, divide the cell suspension in aliquots of $40 \mu \mathrm{l} / \mathrm{eppendorf}$ tube and freeze the cells in liquid nitrogen.

7. Use for electroporation approximately $1 \mu \mathrm{g}$ plasmid DNA in a volume $<10 \mu$ l dissolved in demi-water.

8. Thaw $40 \mu$ l of frozen cell suspension on ice.

9. Add the plasmid DNA to the cells, mix gently and transfer the mixture to the sterile cuvette previously chilled on ice and incubate for 5 minutes on ice.

10. Adjust the settings of the electroporation-apparatus (for example Gene Pulser + Pulse Controller, BioRad) for optimal conditions for Pseudomonas: 25 microF, $200 \mathrm{Ohm}$ and 12,5 KV/cm (=2,5 kV/2 $\mathrm{mm}$ ) check the maximum capacity of the cuvette to be used.

11. Add immediately after the electrical pulse $1 \mathrm{ml} \mathrm{SOC}$-medium and incubate for 2 hours at $28^{\circ} \mathrm{C}$.

12. Plate $100 \mu \mathrm{l}$ cell suspension on a KB-agar plate containing the selective antibiotic(s).

13. Concentrate the rest of the cell suspension by centrifugation ( 5 minutes 5,000 rpm) and resuspend in $100 \mu \mathrm{l} \mathrm{SOC}$ medium. Plate the suspension on a KB-agar plate containing the selective antibiotic(s).

14. Incubate (if necessary $2 x$ ) $\mathrm{O} / \mathrm{N}$ at $28^{\circ} \mathrm{C}$ for the appearance of transposants/transformants as single colonies.

15. Streak single colonies on a fresh agar plate containing antibiotics, incubate $\mathrm{O} / \mathrm{N}$ at $28{ }^{\circ} \mathrm{C}$ and screen the plates for colonies which have received the plasmid.

Notes

1. Step 1. Optimal growth conditions should be determined for every bacterial strain to be used. In this protocol we give the optimal conditions for Pseudomonas strains.

2. Step 1. Alternatively small amounts of cells can be used for electroporation using the following mini protocol. Pellet in total $3 \mathrm{ml}$ of an exponential growing bacterial cell culture $\left(\mathrm{OD}_{620}=0.7\right)$ in an eppendorf tube. Wash the pellet three times with 1.5 $\mathrm{ml}$ ice-cold sterile demi water. Centrifuge at maximum speed during one minute to pellet the cells. Carefully remove as much as possible supernatant. After the 
last washing step resuspend the cells in $40 \mu \mathrm{l}$ of ice-cold demiwater and use this suspension direct for transformation as from step 7 in the above protocol.

3. Step 7. It is important to dissolve DNA in water instead of buffers containing salts in order to reduce the risk of electrical charge.

4. Steps 8 and 13 . Plate $10^{4} \cdot 10^{5}, 10^{6}$ and $10^{7} \times$ dilutions on KB-agar plates without selective antibiotics to determine the number of surviving cells.

5. Step 10. Optimal settings for electroporation should be determined for each individual bacterial strain.

6. Step 10-11. Wear safety glasses during the use of the electroporation apparatus.

\section{Flow cytometric analysis of gfp-tagged bacterial populations}

Bacteria tagged with gfp can be directly injected into a flow cytometer without fixation or staining. By flow cytometry (FCM) thousands of cells can be analyzed in a few minutes. Since the flow cytometer detects fluorescence from single cells, the proportion of fluorescent cells in a population can be accurately determined. The number of cells can be quantified by FCM after the addition of an internal standard (fluorescent beads) to the sample, before injection into the flow cytometer. Pure cultures of $g f p$-tagged bacteria can be analyzed by flow cytometry to monitor the fluorescence intensity of single cells during growth and to enumerate the proportion of fluorescent cells in the total cell population. The latter can be used for analyzing gene expression and determining the number of bacterial cells that show gene expression. The following protocol can be used for the quantitation of $g f p$-tagged bacteria in an environmental sample. It is necessary to incorporate an internal standard of fluorescent beads for accurate quantitative measurements.

\section{Materials}

- $2.2 \mu \mathrm{m}$ diameter fluorescent polystyrene beads (for example, Catalog number G0220, Duke Scientific, Palo Alto, CA, USA).

\section{Protocol}

1. Prepare a suspension of $2.2 \mathrm{gm}$ diameter fluorescent polystyrene beads in $1.5 \times$ PBS to a specified concentration in the range 105106 beads $/ \mathrm{ml}$, as determined microscopically using a counting chamber.

2. Wash in $1.5 \times$ PBS and resuspend the gfp-tagged bacteria in the bead suspension. 
3. Dilute cells in the bead suspension so that approximately 1,000 events/sec are detected by the flow cytometer.

4. Place a band pass emission filter (centred at $505 \mathrm{~nm}$ ) in front of one of the fluorescence detectors of the flow cytometer.

5. Set the detector amplification to appropriate levels for the following: forward scatter (FS), side scatter (SS), and fluorescence.

6. Pass the sample through the flow cytometer, according to the instrument specifications. For example, introduction by needle suction or by positive pressure.

7. Collect data corresponding to 10,000 cells.

8. Analyze the data using the statistics software of the flow cytometer.

9. From the statistics values derive the respective number of bacteria and beads. The ratio of total bacteria to total beads, multiplied by the known concentration of beads, yields the concentration of fluorescent bacteria. For a more detailed description of flow cytometry as applied to microbiology, see the review by Davey and Kell [10].

Notes

1. Step 1: If a fluorescent standard is not necessary, non-fluorescent beads may be used instead.

2. Step 2: For natural samples, the bacteria first need to be extracted from particulate matter using a cell extraction technique.

3. Step 3: The number of events, or particles, counted per second is determined by the flux of sample introduction into the flow cytometer and the dilution of the sample.

4. Step 3: If many dilutions are necessary, the initial dilutions can be made in $1.5 \times$ PBS in order to conserve beads. Then, the final dilution should be made in the bead suspension, containing a known concentration of beads.

5. Step 5: As each cell or particle passes through the flow cytometer, it is monitored by forward scatter (FS), side scatter (SS) and fluorescence (FL) detectors. The FS detector detects each particle according to its size; its size and shape are simultaneously determined by the side scatter detector (SS), and its fluorescence intensity (FL) is determined by the fluorescence detector. The amplification settings have to be optimized for each sample type in order to keep the significant signals corresponding to bacteria and beads to scale and to keep the background noise below zero. The method for adjustment of amplification gains is usually found in the manual of the flow cytometer.

6. Step 8: CellQuestTM, Becton Dickinson software. The region of the plot corresponding to bacterial cells should be gated on the FS/SS plot and the percentage of fluorescence events can be determined using the statistics of the software.

7. Step 9: The flow cytometry data can be presented graphically in the following ways: dot plots, histograms, or three-dimensional histograms. The y (or $z$ for threedimensional plots) axis is usually the number of events whereas the $x$ (and $y$ for 
three-dimensional plots) axis corresponds to FS, SS or FL data, respectively. For pure cultures of $g f p$-tagged bacteria obtained using the delivery system described [31], the percentage of fluorescent cells is generally greater than $90-95 \%$.

III. Tagging of fungi with auto fluorescent proteins.

Fungi are abundantly present in soil and interact frequently with plants and microorganims present in the soil and the rhizosphere. The following protocol describes the tagging of Fusarium oxysporum with GFP. This method has been successful in tagging several pathogenic and beneficialFusarium strains.

\section{A. Preparation of Fusarium protoplasts}

\section{Materials:}

Attention: before preparing solutions, fill all the glassware to be used with water and autoclave to remove traces of soap from the glass. The latter can have a large negative influence on the success of the transformation!

- Potato Dextrose Broth (PDB) medium (Difco)

- Miracloth filter (sterile)

- Hemacytometer

- $\mathrm{MgSO}_{4}$ solution (500 ml)

- $1.2 \mathrm{M} \mathrm{MgSO}_{4} 7 \mathrm{H}_{2} \mathrm{O}$

- $50 \mathrm{mM}$ NaCitrate (pH 5.8)

Autoclave for 20 minutes at $120^{\circ} \mathrm{C}$

- Sorbitol solution (500 ml)

- $1 \mathrm{M}$ sorbitol

$-50 \mathrm{mM} \mathrm{CaCl} 2.2 \mathrm{H} 2 \mathrm{O}$

$-10 \mathrm{mM}$ Tris (pH 7.4)

Autoclave for 20 minutes at $120^{\circ} \mathrm{C}$

- Enzyme solution:

$-20 \mathrm{ml}$ 1.2 M MgSO4

- 0.2 g lysing enzyme (Sigma L-2265, Sigma Chemicals Co., St. Louis, MO, USA)

- 0.3 g Cellulase "Onozuka" R10 (Yakult Honsha Co. LTD, Tokyo, Japan; Brunswick Chemicals)

Filter sterilise the solution before use. 


\section{Protocol}

1. Spot inoculate a PDB agar plate with Fusarium mycelium in the centre and incubate for 5 days at $28^{\circ} \mathrm{C}$.

2. Inoculate $100 \mathrm{ml}$ PDB medium in a $300 \mathrm{ml}$ flask with a piece of mycelium cut from the PDB agar plate and incubate for 2-5 days at $28{ }^{\circ} \mathrm{C}$ shaking (160 rpm).

3. Filter the culture over two layers of miracloth.

4. Centrifuge the filtrate for 10 minutes at $5,000 \mathrm{rpm}$ and discant instantly after centrifugation the supernantant.

5. Wash the pellet $3 x$ with $100 \mathrm{ml}$ sterile water. Collect the pellet and remove (if present) the purple upper layer.

6. Resuspend the pellet in $5 \mathrm{ml}$ sterile demiwater. Use a small aliquot of this suspension to make a 10 -fold dilution and determine the spore (conidia) concentration using a hemacytometer.

7. Inoculate $40 \mathrm{ml}$ PDB medium with $5 \times 10^{8}$ conidia in a $100 \mathrm{ml}$ flask.

8. Grow for 18 hours at $25{ }^{\circ} \mathrm{C}$ at $300 \mathrm{rpm}$ (non-germinated spores must be $<5 \%$ ).

9. Centrifuge the Fusarium culture for 10 minutes $(2,000 \mathrm{rpm})$.

10. Prepare the enzyme solution (recipe see above). Dissolve the enzymes by vortexing. Centrifuge the enzyme solution for $10 \mathrm{~min}-$ utes at 2,000 rpm to remove undissolved particles.

11. In case of a visible pellet add $25 \mathrm{ml} \mathrm{MgSO}_{4}$ solution to the pellet, mix and filter the suspension over three layers of miracloth (before filtering pour $5 \mathrm{ml}$ of $\mathrm{MgSO}_{4}$ solution over the filter in order to prevent lysis due to water in the filter). In case a pellet is not visible filter directly.

12. Collect the mycelium from the filter and wash the mycelium $2 x$

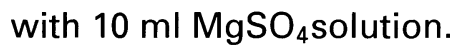

13. Gently transfer the mycelium from the filter to a Falcon tube using a cotton stick. Add the enzyme solution and incubate for 1-3 hours at $30{ }^{\circ} \mathrm{C}$ gently swirling at $65 \mathrm{rpm}$. Check after $1.5-2$ hours the amount of formed protoplasts. If no or little protoplast are present incubate for 24 hours.

14. Filter the protoplast suspension over 3 layers of miracloth. Collect filtrate containing the protoplasts and in a Falcon tube and store on ice. Wash the filter with $10 \mathrm{ml}$ ice-cold sorbitol solution to optimize the protoplast harvest. 
15. Add $20 \mathrm{ml}$ ice-cold sorbitol solution and pellet the protoplast by centrifugation for 15 minutes $(2,100 \mathrm{rpm})$ at $4{ }^{\circ} \mathrm{C}$.

16. Resuspend the protoplast in $0.6-1 \mathrm{ml}$ sorbitol solution. Determine the protoplast concentration using the hemacytometer.

\section{Notes}

1. Step 2: It has been observed that the final amount of spores produced in PDB can be dependent upon the batch of PDB and can differ for different Fusarium strains.

2. Step13-16: The osmotic balance of protoplasts in a suspension is usually maintained using sugars such as sucrose and sorbitol and salts such as magnesium chloride, potassium chloride, and ammonium sulphate.

B. Transformation of Fusarium protoplasts

\section{Materials}

- ATA (aurintricarbonacid ammoniumsalt) (L760128717, Merck KGaA, Darmstadt, Germany)

- PEG solution (100 ml)

- $50 \mathrm{mM} \mathrm{CaCl} 2.2 \mathrm{H} 2 \mathrm{O}$

- $10 \mathrm{mM}$ Tris (pH 7.4)

- 60 g PEG6000

Autoclave for 20 minutes at $120^{\circ} \mathrm{C}$

- $\mathrm{MgSO}_{4}$-PDB solution (500 ml)

$-0.5 \mathrm{M} \mathrm{MgSO}_{4} .7 \mathrm{H}_{2} \mathrm{O}$

$-10 \mathrm{mM}$ Tris (pH 7.4)

- $1.2 \mathrm{~g}$ PDB

Autoclave for 20 minutes at $120^{\circ} \mathrm{C}$

- Sucrose selection plates

- $0.8 \mathrm{M}$ sucrose

- $10 \mathrm{mM}$ Tris (pH 7.4)

- Difco agar (15 g / I)

Autoclave for 20 minutes at $120^{\circ} \mathrm{C}$

Add before pouring plates hygromycine $(100 \mu \mathrm{g} / \mathrm{ml})$

\section{Protocol}

1. Add $4 \mu \mathrm{l}$ ATA $(1 \mathrm{M})$ to $10-15 \mu \mathrm{l}$ DNA $(1 \mu \mathrm{gDNA} / \mu \mathrm{l})$ and place in a $10 \mathrm{ml}$ sterile tube and store on ice.

2. Add $200 \mu \mathrm{l}$ protoplast suspension and mix gently. 
3. Incubate on ice for 30 minutes. without motion.

4. Add drop wise $1 \mathrm{ml}$ of PEG solution and mix gently.

5. Incubate on ice for $\mathbf{3 0}$ minutes. without motion.

6. Add $\mathrm{MgSO}_{4}-\mathrm{PDB}$ solution $\left(4{ }^{\circ} \mathrm{C}\right)$ to a volume of $10 \mathrm{ml}$ and shake gently by inverting the tube.

7. Pellet the protoplast by centrifugation (at $4{ }^{\circ} \mathrm{C}$ ) during 10 minutes at $2500 \mathrm{rpm}(1121 \mathrm{~g})$.

8. Discant the supernatant immediately after centrifugation and gently resuspend the protoplasts in the remaining solution.

9. Incubate at room temperature during 30 minutes.

10. Gently plate protoplast suspension $(50-100 \mu \mathrm{l}$ per plate) on sucrose selection plates.

11. Incubate for $5-6$ days at $28{ }^{\circ} \mathrm{C}$ and examine transformants for the production of auto fluorescent proteins (for details see section $\mathrm{V}$ ).

12. Streak the brightest single auto fluorescent transformants on a fresh selection plate for usage and storage.

13. Analyze afp expression in the mycelium, micro- and macroconidia, and chlamydospores using epifluorescence microcopy or confocal laser scanning microcopy.

\section{Notes}

1. Step 1: As a control use demi-water.

2. Step 12: After selection the transformants should be streaked several times (approximately ten times) on fresh medium to check for the stability of the chromosomal integration of the plasmid and production of the auto fluorescent protein. Subsequently transformants should be checked for pathogenicity, which should be comparable to the wild-type.

\section{Detection of AFP-tagged microorganims by epifluorescence} microscopy

Expression of afp's can be easily visualized by epifluorescence microscopy. The production of autofluorescent proteins after plasmid transformation or transposition can easily be monitored on plate using an epifluorescence stereo microscope. For analysis of more complex samples such as soil or root samples the use of a normal epifluorescence microscope is advised. A major difficulty of analyzing bacteria in complex samples, such as in the presence of soil particles, is formed by autofluorescence of soil particles, such as sand partciles. The following protocol describes a method for direct visualization of 
gfp-tagged bacteria in a soil sample by epifluorescence microscopy. However, the protocol would need to be adapted to each different sample type under study.

1. Selection of autofluorescent microorganisms

\section{Material}

- Leica MZFLIII stereo microscope equipped with epifluorescence detection (Leica, Germany)

\section{Protocol}

1. For selection of fluorescent transformants (bacteria or fungi) or transposants (bacteria) agar plates with plated suspensions are incubated at the appropriate temperature until single colonies can be observed with the eye.

2. Place plates under a Leica MZFLIII epifluoresecnce stereo microscope.

3. Use the following filter sets tailored to the specific chromophore of each fluorescent protein:

a. ECFP $440 / 21 \mathrm{~nm}$ excitation, $480 / 36 \mathrm{~nm}$ emission

b. EGFP $480 / 40 \mathrm{~nm}$ excitation, $510 \mathrm{~nm}$ long pass emission

c. EYFP $500 / 10 \mathrm{~nm}$ excitation, $518 / 16 \mathrm{~nm}$ emission

d. DsRed $510 / 20 \mathrm{~nm}$ excitation with $560 / 40 \mathrm{~nm}$ emission

4. Colonies which show proper growth as compared with the wt and bright fluorescence are selected for further analysis.

Notes

1. Step 1: Instead of petri-dishes all kind of titre plates containing microorganisms grown on solid or in liquid medium can be used.

2. Step 1: Observation of fluorescent transformants could also be accomplished using a hand-held lamp emitting light containing the appropriate wavelength. For example selection of $g f p$ expressing transformants could be accomplished with a nearUV light lamp.

2. Detection of autofluorescent microorganims in a soil sample.

\section{Materials}

- PBS Buffer (see above)

- Mounting medium for epifluorescence microscopy (e.g. Vectashield $^{\circledR}$, Vector Laboratories Inc., Burlingame, CA, USA) 


\section{Protocol}

1. Resuspend a $1.0 \mathrm{~g}$ sample of soil containing afp-tagged bacteria in $5 \mathrm{ml}$ PBS buffer, in a $15 \mathrm{ml}$ plastic centrifuge tube, by vigorous shaking for 5 minutes.

2. Allow the larger soil particles to settle for 15 minutes, at room temperature.

3. Apply a drop of the upper level of the soil suspension to a microscope slide.

4. Air dry, 15 minutes at room temperature.

5. Fix the sample to the slide by 2-3 quick passes through a Bunsen burner flame, with cooling between each pass.

6. Apply a drop of mounting medium to the sample and add the cover slip.

7. Analyze the sample by epifluorescence microscopy using appropriate filter sets for the detection of green fluorescence. For example for GFP, a Chroma filter set number 41017 (Chroma Technology Corp., Brattleboro, Vermont, USA).

\section{Notes}

1. Step 3: This protocol is used for the visualization of afp-tagged cells in a soil sample. For exact quantitation of the number of cells/gram of soil sample it is necessary to serially dilute the soil sample and to filter specified amounts of different dilutions onto membrane filters [19]. The upper phase of the suspension is used in order to avoid large soil particles that would elevate the cover slip and thereby interfere with microscopic visualization of cells on the slide.

2. Step 5: Preparation of a fixed soil sample containing AFP-tagged bacteria for still visualization is especially useful for counting cells and image resolution by a CCD camera, when a more detailed image analysis is desired.

3. Step 7: The latter filter set, which is optimized for GFP, gives much better results than a FITC filter. The optimal filter sets for the detection of GFP fluorescence are determined by the sample type and the specific gfp mutant used for the construction of tagged strains. Different sample types (such as soil, or plant material) exhibit background fluorescence to different degrees and with varying wavelengths. A Long Pass filter is an option for natural samples where a greenish background fluorescence is masked by a reddish one. This permits better discrimination of GFP green fluorescence from the yellowish/brownish background fluorescence.

\section{Simple quantification of fluorescence by microorganims.}

afp expression will occur between different microorganism and depent on (i) the microbial species (despite the fat of an identical pro- 
moter used), (ii) the chromosomal integration site of the transposon of plasmid, and (iii) the promoter to be analyzed for expression. Fluorescence produced by a microbial culture can be followed and compared using a fluorescence spectrometer. Spectrometers that can handle titerplates have the advantage that a large number of samples can be handled, which for instance is of great advantage in screening for expression under different growth conditions and to select mutant strains on basis of higher or decreased fluorescence.

\section{Materials}

- Growth medium

- Titre plates

- Spectrometer

\section{Protocol}

1. Grow a culture in fresh medium to a selected $O D_{660 \mathrm{~nm}}$ using a LKB Biochrom Nova Spectrometer (Amersham Pharmacia Biotech; Roosendaal, The Netherlands).

2. Quantify the fluorescence of the diluted culture using a white flat bottom 96 well titer plate containing $200 \mu$ l culture aliquots.

3. Quantify the fluorescence using the following filters:

- ECFP excitation maximum at $430 \mathrm{~nm}( \pm 35 \mathrm{~nm})$ and emission maximum at $485 \mathrm{~nm}( \pm 20 \mathrm{~nm})$

- EGFP emission maximum at $485 \mathrm{~nm}( \pm 20 \mathrm{~nm})$ and emission maximum at $520 \mathrm{~nm}( \pm 10 \mathrm{~nm})$

- EYFP emission maximum at $510 \mathrm{~nm}( \pm 10 \mathrm{~nm})$ and emission maximum at $535 \mathrm{~nm}( \pm 25 \mathrm{~nm})$

Note

1. Step 2: Titerplates can be used containing different amounts of wells and colours.

VI. Detection of afp-tagged microorganism by confocal laser microscopy

Confocal laser scanning microscopy (CLSM) is a particularly useful non-invasive technique for the detection and localization of fluorescently-tagged microorganims in situ. The quality of images made by traditional fluorescence microscopy is often reduced by blur- 
ring due to the light emitted from regions above and below of the focal plane. The laser beam used in this technique results in the production of a sharp image of a single plane of the sample. Scanning in the Z-axis and subsequent stacking of the images results even in a three dimensional image of the specimen. CLSM has been used to visualize and study a number of biological processes at the single cell level, including the development and structure of biofilms, the colonization of plant roots, symbiotic interactions and the dynamics of multiple bacterial populations. Here, we describe a technique for the direct visualization of AFP-tagged bacteria and fungi on the surface of plant roots. The properties of the confocal laser scanning microscope will determine the way how samples are handled. An inverted microscope is very well suited to handle thicker samples, preventing squeezing and damaging of the sample between the glass slide and the coverslip. Below procedures are described for two microcopes, (i) an inverted Leica-DMIRBE and (ii) a Zeiss Axioplan coupled to an MRC 1024 SE BIORAD confocal system. The possibilities for simultaneous visualisation of two or three different auto fluorescent proteins are dependent upon the lasers present in the confocal laser scanning microscope. We describe the settings for simultaneous visualisation of CFP, EGFP (or EYFP) and DsRed.

\section{Materials}

- PBS buffer.

- Glass slides and coverslips

- Clear nail polish.

\section{Protocol}

1. Rinse gently roots with demi water to remove as much as possible soil and sand particles, which could interfere with the visualisation of the microorganims due to autofluorescence.

2. Section the roots (lengthwise or transverse depending on the length and thickness) with a razor blade (approximately $1 \mathrm{~cm} \mathrm{sec-}$ tions).

3. Place a root section on a glass slide and put a coverslip on top. In order to prevent drying, pipet PBS under the coverslip and seal the edges with clear nail polish. Alternatively a special glass slide with a central sunk area can be used. 


\section{In case of simultaneous imaging of up to three autofluorescent}

proteins: examine the samples with an inverted fluorescence microscope (Leica-DMIRBE) equipped with filter blocks with spectral properties matching those of CFP $(440 / 21 \mathrm{~nm}$ excitation, $480 / 36 \mathrm{~nm}$ emission, XF114 from Chroma, Brattleboro, VT) or EGFP and EYFP (470/20 nm excitation, $515 \mathrm{~nm}$ long pass emission, 13 from Leica) or DsRed (538/22 nm excitation, $590 \mathrm{~nm}$ emission long pass emission, N2.1 Leica), to which a Leica SP confocal scanhead is attached.

5. Acquire dual and triple color images by sequentially scanning with settings optimal for CFP (excitation with the $457 \mathrm{~nm}$ Argon laser line, emission detection between 470 and $490 \mathrm{~nm}$ ), followed by settings optimal for EGFP (excitation with the $488 \mathrm{~nm}$ Argon laser line, detection of emitted light between 500 and $520 \mathrm{~nm}$ ) or EYFP (excitation with the $488 \mathrm{~nm}$ Argon laser line, detection of emitted light between 530 and $550 \mathrm{~nm}$ ) and finally by settings optimal for DsRed (excitation with the $568 \mathrm{~nm}$ Krypton laser line, detection of emitted light between 580 and $620 \mathrm{~nm}$ ). Reflected light images for background purposes can be obtained by detection of light at the wavelength used for excitation. Examples are given in Fig. 1 and 2 .

6. In case of single GFP imaging: Examine the sample using a Zeiss Axioplan equipped with filter blocks with spectral properties matching those of GFP (450-490 nm excitation, 520 Long Pass emission) and the root's autofluorescence $(510-560 \mathrm{~nm}$ excitation, 590 Long Pass emission), coupled to an MRC 1024 SE BIORAD confocal system.

7. Acquir digital images by scanning with optimal settings for GFP: excitation with the 488 Argon/Krypton laser, detection of the emitted light at 522 DF32 (autofluorescence detection 585 Long Pass).

8. Merge the projections of the individual channels in Photoshop (Adobe, San Jose, CA) to facilitate visualization.

Notes

1. Step 1: A gnotobiotic sand growth system [27] has been successfully used to monitor mircoorganims in the rhizosphere and to study interactions between different populations or organism. The advantage for visualisation is that sand particles can be removed by gentle rinsing with water prior to microscopic analysis. 
2. Step 4-5: Cross talk between the channels in this set-up appears to be negligible in all cases.

3. Step 4,5 and 6: Auto fluorescence from the root cell walls can occur also depending on the plant, but are usually not disturbing the image. Rather they facilitate the precise localisation of the microorganims on the root surface.

4. Fluorescence can be reduced by photobleaching, especially after repeated in depth scanning at the same site on the root. Photobleaching can be reduced by reducing the power of the laser.

5. Step 8: The use of digital deconvolution software can improve the quality of the images substantially by removing the contribution due to out-of-focus light and thereby sharpening the image. This can be applied for normal fluorescence microscopy as well as for the correction of confocal laser scanning microscopy.

\section{Acknowledgements}

AL was financially supported by a Marie Curie Fellowship of the European Community program Training and Mobility of Researchers under the contract number ERBFMBICT982930. We want to thank E. Lagendijk for providing images and P. Hock for reconstituting Fig. 1.

\section{References}

1. Andersen JB, Sternberg C, Poulsen LK, Bjorn SP, Givskov M, Molin S (1999) New unstable variants of green fluorescent protein for studies of transient gene expression in bacteria. Appl Environ Microbiol 64: 2240-2246.

2. Baird GS, Zacharias DA, Tsien RY (2000) Biochemistry, mutagenesis, and oligomerization of DsRed, a red fluorescent protein from coral. Proc Natl Acad Sci USA 97: 11984-11989.

3. Burlage RS, Yang ZK, MehlhornT (1995) A transposon for green fluorescent protein transcriptional fusions: applications for bacterial experiments. Gene 173: 53-58.

4. Bloemberg GV, O'Toole G, Lugtenberg BJJ, Kolter R (1997). Green fluorescent protein as a marker for Pseudomonas spp. Appl Environ Microbiol 63: 4543-4551.

5. Bloemberg GV, Wijfjes AHM, Lamers GEM, Stuurman N, Lugtenberg BJJ (2000) Simultaneous imaging of Pseudomonas fluorescens WCS365 populations expressing three different autofluorescent proteins in the rhizosphere; new perspectives for studying microbial communities. Mol Plant Microbe Interact 13:1170-1176.

6. Bolwerk A, Lagopodi AL, Wijfjes AHM, Lamers GEM, Chin-A-Woeng TFC, Lugtenberg BJJ, Bloemberg GV(2003). Interactions in the tomato rhizosphere of two Pseudomonas biocontrol strains with the phytopathogenic fungus Fusarium oxysporum f. sp. radicis-lycopersici. Mol Plant-Microbe Interact 16: 983-993.

7. Chalfie M, Tu Y, Euskirchen G, Ward WW, Prasher DC (1994). Green fluorescent protein as a marker for gene expression. Science 263: 802-805.

8. Chiu WL, Niwa Y, Zeng W, Hirano T, Kobayashi H, Sheen J (1996). Engineered GFP as a vital reporter in plants. Curr Biol 6: 325-330.

9. Cormack B. (1998) Green fluorescent protein as a reporter of transcription and protein localization in fungi. Curr Opin Microbiol 1: 406-410.

10. Davey HM, Kell DB (1996) Flow cytometry and cell sorting of heterogeneous microbial populations: the importance of single-cell analyses. Microbiol Rev 60: 641-696. 
11. Ditta G, Stanfield S, Corbin D, Helinski DR (1980) Broad host range DNA cloning system for Gram-negative bacteria: construction of a gene bank of Rhizobium meliloti. Proc Natl Acad Sci USA 77: 7347-7351.

12. Ellenberg J, Lippincott SJ, Presley JF (1999). Dual-colour imaging with GFP variants. Trends Cell Biol 9: 52-56.

13. Fiedler S, Wirth E (1988) Transformation of bacteria with plasmid DNA by electroporation, Anal Bioch 170: 38-44.

14. Gage DJ (2002) Analysis of infection thread development using Gfp- and DsRed-expressing Sinorhizobium meliloti. J Bacteriol 184: 7042-7046.

15. Heeb S, Itoh Y, Nishijyo T, Schnider U, Keel C, Wade J, Walsh U, O'Gara F, Haas D (2000) Small, stable shuttle vectors based on the minimal pVS1 replicon for use in Gram-negative plantassociated bacteria. Mol Plant Microbe Interact 13: 232-237.

16. Herrero M, de Lorenzo V, Timmis KN (1990) Transposon vectors containing nonantibiotic resistance selection markers for cloning and stable chromosomal insertion of foreign genes in gram-negative bacteria. J Bacteriol 172: 6557-6567.

17. King EO, Ward MK, Raney DE (1954) J Lab Clin Med 44: 301-307.

18. Lagopodi AL, Ram AFJ, Lamers GEM, Punt PJ, van den Hondel CAMJJ, Lugtenberg BJJ, Bloemberg GV (2002). Confocal laser scanning mircoscopical analysis of tomato root colonization and infection by Fusarium oxysporum f.sp. radicis-lycopersici using the green fluorescent protein as a marker. Mol Plant Microb Interact 15: 172-179.

19. Lebaron P, Troussellier M, Got P (1994) Accuracy of epifluorescence microscopy counts for direct estimates of bacterial numbers. J Microbiol Meth 19: 89-94

20. Matus A (1999). GFP in motion CD-ROM - Introduction: GFP illuminates everything. Trends In Cell Biology 9:43.

21. Matz MMV, Fradkov AF, Labas YA, Savitsky AP, Zaraisky AG, Markelov ML, Lukyanov SA (1999). Fluorescent proteins from nonbioluminescent Anthozoa species. Nat Biotechnol 17: 969973.

22. Mullaney EJ, Hamer JE, Roberti KA, Yelton MM, Timberlake E (1985). Primary structure of the trpC gene from Aspergillus nidulans. Mol Gen Genet 199: 37-45.

23. Punt PJ, Oliver RP, Dingemanse MA, Powels PH, van den Hondel CAMJJ (1987) Transformation of Aspergillus based on the hygromycine-B marker from Escherichia coli. Gene 56: 117-124.

24. Punt PJ, Dingemanse MA, Jacobs-Meijsing B JM, Pouwels PH, van den Hondel CAMJJ (1988). Isolation and characterization of the glyceraldehyde-3-phosphate dehydrogenase gene of Aspergillus nidulans. Gene 69: 49-57.

25. Sambrook J, Fritsch EF, Maniatis T (1989) Molecular cloning: a laboratory manual. 2nd ed. New York: Cold Spring Harbor Lab.

26. Simon R, Priefer U, Pühler A (1983). A broad host range mobilization system for in vivo genetic engeneering: Transposon mutagenesis in gram-negative bacteria. Biotechnology 1: 784 791.

27. Simons M, van der Bij A.J, Brand I, de Weger LA, Wijffelman CA, Lugtenberg BJJ (1996). Gnotobiotic system for studying rhizosphere colonization by plant growth-promoting Pseudomonas bacteria. Mol Plant-Microbe Interact 9: 600-607.

28. Sörensen M, Lippuner C, Kaiser T, Misslitz A, Aebischer T, Bumann D (2003) Rapidly maturing red fluorescent protein variants with strongly enhanced brightness in bacteria. FEBS Lett 25:110114.

29. Stuurman N, Pacios Bras C, Schlaman CHRM, Wijfjes AHM, Bloemberg GV, Spaink HP (2000). The use of GFP color variants expressed on stable broad-host range vectors to visualize rhizobia interacting with plants. Mol Plant-Microbe Interact 13: 1063-1069.

30. Tombolini R, Jansson JK (1998) Monitoring of GFP-tagged bacterial cells. Methods Mol Biol 102: 285-298.

31. Tombolini R, Unge A, Davey ME, de Bruijn FJ, Jansson JK (1997) Flow cytometric and microscopic analysis of GFP-tagged Pseudomonas fluorescens bacteria. FEMS Microbiol Ecol, $22: 17-28$. 
32. Tsien RY (1998) The green fluorescent protein. Annu Rev Biochem 67: 509-544.

33. Unge A, Tombolini R, Moller A, Jansson JK (1997) Optimization of GFP as a marker for detection of bacteria in environmental samples. In: Hastings JW, Kricka LJ, Stanley PE (eds), 9th International Symposium on Bioluminescence and. Chemiluminescence: Proceedings volume: Bioluminescence and Chemiluminescence: Molecular Reporting With Photons.

34. Unge A, Tombolini R, Molbak L, Jansson JK. (1999) Simultaneous monitoring of cell number and metabolic activity of specific bacterial populations with a dual $g f p$-luxAB marker system. Appl Environ Microbiol 65: 813-821.

35. Unge A, Jansson JK. (2001) Monitoring population size, activity, and distribution of $g f p$-luxABtagged Pseudomonas fluorescens SBW25 during colonization of wheat. Microb Ecol 41: 290-300.

36. Yang TT, Sina P, Green G, Kitts PA, Chen YT, Lybarger L, Chervenak R, Patterson GH, Piston DW, Kain SR (1998) Improved fluorescence and dual color detection with enhanced blue and green variants of the green fluorescent protein. J Biol Chem 273: 8212-8216.

37. van den Hondel CAMJJ, Punt PJ, van Gorgom RFM (1991) Heterologus gene expression in filamentous fungi. Pages $398-428$ in: More gene manipulations in fungi. Academic Press, NY.

38. Wolk CP, Cai Y, Panoff J-M (1991) Use of a transposon with luciferase as a reporter to identify environmentally responsive genes in a cyanobacterium. Proc Natl Sci 88: 5355-5359. 


\title{
Identification of bacteria by their intrinsic sequences: Probe design and testing of their specificity
}

\author{
ÉVA TAS and KRISTINA LINDSTRÖM \\ Division of Microbiology, Department of Applied Chemistry and Microbiology, Viikki \\ Biocenter, University of Helsinki. P.O. Box 56, 00014 Helsinki, Finland
}

\section{Introduction}

Detection of specific nucleic acid sequences is today an indispensable approach for identification of microorganisms in environmental samples. Hybridization- or PCR-based detection systems involve recognition of a specific nucleic acid fragment or different electrophoretic patterns, also named fingerprints. A review about the early applications of nucleic acid hybridization in environmental studies was given by Sayler and Layton [12], and about the exploitation of PCR in environmental microbiology by Steffan and Atlas [14]. The modern fingerprinting methods are widely covered in this manual (see section 3 ). The initial steps necessary towards this recognition - probe design and testing the specificity and sensitivity of the probes - are the focus of this chapter.

\section{Approaches to probe design}

The target molecules for DNA hybridization or PCR are often ribosomal RNA or DNA. The design and usage of these probes are described in several chapters of this manual (sections 2 and 3). Specific genes other than ribosomal genes are also good targets. Toxin genes are often traced in clinical diagnostics or quality control of food (Chapter 2.12 [7]). Nodulation or nitrogen fixation genes are the natural choice for detection of rhizobia or other nitrogen-fixing organisms (Chapter $4.6[10,11])$. Microorganisms used for bioremediation can be tracked by their biodegradation genes [2]. DNA-based detection of introduced marker genes is an important tool, which supplements the direct assays for the new enzyme activity gained (see Chapter 6.2).

In addition to probes recognizing these well-characterized genes, probes of various specificities can be obtained without previous knowledge of sequences. A good experimental approach for getting probes is subtraction hybridization. This method selects DNA sequences that are present in one group of organisms but absent in another. Preparation of subtracter DNA from more than one organism 
allows generation of probes with desired species- or strain-specificity. For detailed principles and protocols on subtraction hybridization, see Chapter 6.7. The recently emerging macro- and microarray techniques would also provide convenient experimental setup to find unique sequences [13].

An alternative method is to screen random clones from a genomic library for sequences unique to a group of organisms. Although this approach is considered as too exhaustive, it can become straightforward when it is based on some preliminary genetic information. For this approach we show an example in this chapter.

\section{Experimental approach}

Although sequences of bacterial genes and complete genomes are increasingly available, the genome of an organism is not always described in great detail. Nevertheless, particular genomic regions can be assumed to contain unique sequences. An example is unique fragments of a rep-PCR pattern (Chapter 3.6) or any other genomic fingerprints. In addition, genes determining specific functions of a selected organism (e.g. virulence of a pathogen, host-specificity of symbiotic bacteria, etc.) are possibly mapped to a large genomic fragment but may not have been sequenced. In each case, these genomic fragments and possibly their shorter sub-fragments can be cloned and the clones analysed for their specificity.

Once a suitable DNA fragment has been isolated and its specificity for a selected taxon has been shown in dot blot hybridization, it is useful to sequence it. Based on the sequence, specific PCR primers are designed, potentially at the ends of the fragment. PCR amplification of the fragment should be optimized and the specificity of the PCR reaction has to be proven independently of the previous hybridization experiments. After this, the hybridization and PCR assays can be applied separately or in combination in order to improve the reliability and sensitivity of identification.

\section{Example}

Rhizobium galegae, a symbiotic nitrogenfixing bacterium, is peculiar in that it nodulates only a special legume host [5]. Therefore, a $R$. galegae species-specific probe was searched for in the region determining host specificity [15]. We note that any gene region with specific interest can be used in a similar way. In our experiments, a cosmid clone (pRg10 carrying a $28 \mathrm{~kb}$ insert) from the genomic library of $R$. galegae HAMBI 1174 was identified to carry the host specificity genes of the bacteria. The insert of the cosmid was digested with EcoRI and the resulting eight subfragments were cloned into a plasmid vector. All eight subfragments were tested in numerous hybridization experiments in order to find a $R$. galegae species-specific probe. A 2.4-kb EcoRI fragment was chosen. It was highly conserved among $R$. galegae strains as was shown in dot blot experiments. 
Smaller subfragments generated from this 2.4-kb EcoRI fragment with different restriction endonucleases were also studied. A 0.9-kb EcoRI-Sall fragment was also species-specific and was chosen for further studies. The fragment was sequenced and specific PCR primers were designed to amplify it (forward primer: $5^{\prime}$ CTG GGG CGA TGG GCG ATA ACT ACT G $3^{\prime}$ and reverse primer: $5^{\prime}$ TGC TTG GAG TCG GTG CAA GTT TGG T $3^{\prime}$ ). The primers were constructed to facilitate two-temperature PCR cycles $\left(94^{\circ} \mathrm{C}\right.$ denaturation and $72^{\circ} \mathrm{C}$ annealing and extension). The identity of the PCR products was confirmed by Southern hybridization with the EcoRI-SalI fragment. The fragment was amplified from genomic DNA from all $R$. galegae strains (33 strains studied) but not from DNA of any other bacteria studied (21 strains of 11 species) [16]. The probe was used for identification of $R$. galegae from peat containing R. galegae [17], and from nodules developed on roots of legumes inoculated with $R$. galegae [16] (see Figure 1). Recently, a native $R$. galegae strain and its marker gene-tagged derivatives were monitored by PCR in field-release experiments [9]. In these types of experiments intrinsic

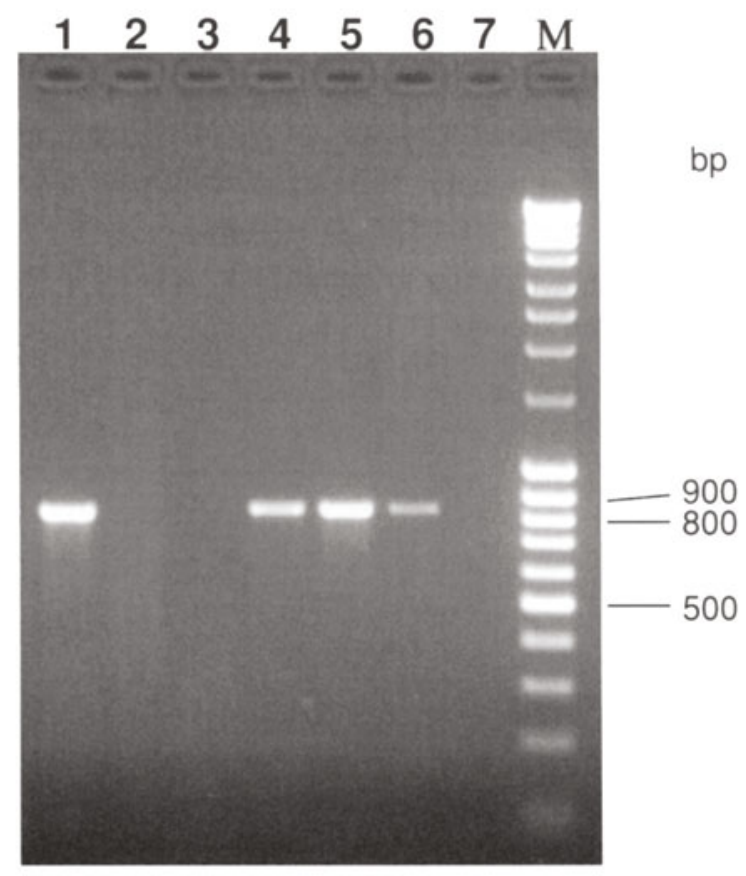

Figure 1. A R. galegae species-specific fragment (about $850 \mathrm{bp}$ ) is amplified from pure bacterial DNA of $R$. galegae (lane 1), from nodules developed on roots of a legume inoculated with $R$. galegae (lanes 4 and 5), and from DNA isolated from peat containing $R$. galegae (lane 6). However, the fragment was not amplified from pure bacterial DNA of R. leguminosarum (lane 2) and E. coli (lane 3), or in the negative control tube, which did not contain template DNA (lane 7). The sample in lane 4 contained nodule crude extract and the one in lane 5 contained the same nodule crude extract after purification on a MicroSpin ${ }^{\mathrm{TM}} \mathrm{S}-400 \mathrm{HR}$ Column (Pharmacia Biotech). Lane M is a molecular weight marker (MassRuler ${ }^{\mathrm{TM}}$ DNA Ladder, MBI Fermentas). 
markers provide important controls and their assays complement the use of introduced markers.

\section{Specificity of probes}

The specificity of each probe and primer pair has to be evaluated individually. The continuously growing nucleic acid sequence databases, including whole genomes, are of great help in this process. We can estimate how unique our selected probe is by comparing it with the sequences annotated in the databases. However, databases are never complete. They help to exclude sequences that are not unique but they do not prove the real specificity of a probe, which has to be investigated experimentally.

The probe should distinguish the target organism(s) from closely related nontarget groups or from other organisms inhabiting the same environment. Since most of the probes are isolated from organisms maintained in culture collections, we can never be sure that they recognise all possible target organisms from an environmental sample. For example, the probes or primers might not detect organisms of environmental importance which have never been previously cultured. In contrast, aspecificity may be revealed during the environmental application of new probes, although their specificity has been thoroughly tested in the laboratory. This is illustrated by the work of Cullen et al., who used PCR to monitor Rhizobium inoculants in the field [4]. One of their markers specifically detected the inoculated strain from soil samples, while DNA sequences of indigenous bacteria were not amplified. In contrast, with another set of primers they detected foreign sequences from the soil that were homologous to the target sequence. Some of these nonspecific products even comigrated in the gel with the targeted DNA bands, but finally they could be distinguished by DNA hybridization.

The specificity should always be defined in a given assay system, which includes the material to be tested and the whole procedure. Some of the problems with aspecificity could indeed be avoided by increasing the stringency of the reaction conditions.

In summary, we suggest that the specificity of the selected probes and primers is tested in the following steps:

1. Compare the selected sequences with accessible sequence databases.

2. Thoroughly test the specificity of the probes in numerous hybridization experiments (dot blots and Southern blots) and/or in PCR. All available related bacterial strains should be tested.

3. Before analysing environmental samples, build model experiments where you try to reproduce real assay conditions from sample collections throughout analysis. Amend pure DNA solutions or bacteria (pure and mixed cultures) to sediment or soil, inoculate plants with nodule-forming bacteria or find similar ways suitable for your experimental system. Analyse the samples by hybridization or PCR. 
4. If possible, also use alternative microbiological identification methods for the environmental samples to validate your results with probes. This is especially important in studies of complex samples containing diverse microbial communities. Examples are the BIOLOG ${ }^{\circledR}$ system, which colorimetrically detects the utilization of various carbon substrates, and analyses of phospholipid fatty acid (PLFA) profiles.

5. Combined use of several probes with different specificity is a good approach.

\section{Sensitivity of the assay}

These molecular methods (particularly PCR) theoretically allow the detection of a single cell from a sample. However, the sensitivity always depends on several factors. After recent development of non-radioactive labeling and detection techniques, the labeling method is no longer a limiting factor in sensitivity (see Chapter 2.6 in this manual). When studying environmental samples, the main problem is the purity of the extracted nucleic acid. Soil represents especially difficult material because of the presence of phenolic compounds. They lower the efficiency of binding of DNA to hybridization membranes and inhibit PCR. In contrast, it is relatively easy to access bacteria in plant nodules (see example), which do not contain so many inhibiting compounds. Therefore, the DNA extraction method should be optimized separately for each assay.

Use of nested PCR not only confirms the identity of the PCR products but also increases the sensitivity of detection by increasing the number of PCR cycles (see Chapter 2.12). Similarly, the combined use of PCR and hybridization increases the sensitivity while it confirms the identity of the PCR products. Improvements in quantitative PCR methods now allow very sensitive detection (see Chapter 2.13).

In conclusion, after optimizing the DNA extraction method and selecting the right assay conditions, hybridization and PCR are usually sensitive enough to answer questions about the presence or absence of a target organism in a sample. The methods for quantitative analysis are not discussed here, since other chapters of this manual give excellent examples for that: Hybridization signals can be quantified by using radioactive probes and a phosphoimager as shown in Chapter 2.8; Quantitative PCR is discussed in Chapter 2.13; while examples for the combined use of PCR and hybridization are given in Chapter 2.11.

\section{Procedures}

\section{Preparing the probes}

1. Isolate DNA from the cosmid clone by standard procedure [6] or with a commercially available kit (e.g. Promega, cat. no. A1330 or Qiagen cat. no. 12123 or 12462). Good yield and purity of the sample are important. 
2. Digest the DNA with EcoRI or another restriction enzyme and clone the restriction fragments into a suitable vector.

3. Prepare hybridization probes from the inserts of each clone in a PCR reaction: Use 1-50 $\mathrm{ng}$ of purified plasmid DNA as template, $50 \mathrm{pM}$ of vector-specific primers, $100 \mu \mathrm{M}$ of dATP, dCTP and dGTP, $65 \mu \mathrm{M}$ of dTTP and $35 \mu \mathrm{M}$ of digoxigenin-dUTP (Roche Applied Science). Add Taq polymerase or another suitable polymerase and reaction buffer according to the recommendations of the manufacturer. After an initial denaturation step $\left(94^{\circ} \mathrm{C}, 5\right.$ minutes), each PCR cycle consists of denaturation at $94^{\circ} \mathrm{C}(30 \mathrm{~s})$, annealing at $55^{\circ} \mathrm{C}$ (30 seconds) and DNA polymerization at $72{ }^{\circ} \mathrm{C}$ ( 2 minutes). $30-35$ cycles are recommended.

4. Test the specificity of each probe in dot blot hybridization (see the protocol below).

5. If necessary, continue subcloning with different enzymes and test the specificity of the new probes as before.

Notes

1. Restriction enzymes other than EcoRI can also be used if they produce fragments of convenient size (e.g. $0.5-5 \mathrm{~kb}$ ).

2. It is advised to use a vector with binding sites for sequencing and PCR primers.

3. Either isotopic or non-isotopic labelling methods are suitable. PCR is a convenient method for labelling fragments shorter than $2 \mathrm{~kb}$. Primers binding to the vector can be used in the PCR reaction. Longer fragments have to be labelled by random primer labelling or nick translation. See protocols in Chapters 2.5 and 2.6. In this case, we recommend to purifying the plasmid, cutting out the insert with the appropriate restriction enzyme(s), and separate it from the vector in an agarose gel. Use the purified fragment as the template in the labelling reaction.

4. The PCR conditions are only recommendations and they should be optimised according to ones own primers.

\section{Dot blot hybridization}

1. Purify bacterial genomic DNA from $100 \mathrm{ml}$ pure culture suspensions. We suggest the use of the CTAB method [1], but other purification methods suitable for the organisms under study are acceptable. Prepare DNA from all the available bacterial strains which are closely related to the target group and a few representatives from more distantly related taxons. 
2. Check the purity and yield of DNA on agarose gel and by a UVspectrophotometer.

3. Aliquot the samples and store them at $-20^{\circ} \mathrm{C}$. The aliquots in current use can be kept at $4{ }^{\circ} \mathrm{C}$.

4. Denature $50 \mathrm{ng}$ DNA of each sample (10 minutes in boiling water, then chill on ice) and transfer to a nylon membrane (e.g. of Roche Applied Science). A vacume-driven apparatus (VacuGene ${ }^{\mathrm{TM}}$, Amersham Biosciences, cat. no. 80-1266-24) helps to apply the samples in uniform dots. Use $20 \times$ SSC as a solvent for transfer. Prepare identical blots for each individual probe to be tested.

5. Prehybridization (1-2 hours) and hybridization ( 3 hours to overnight) are carried out at $68{ }^{\circ} \mathrm{C}$ in a hybridization oven. The hybridization solution is prepared according to standard protocols. In our experiments it contained $5 \times$ SSC, $1 \%$ blocking reagent (DNA labelling and detection kit, Roche Applied Science) and $0.02 \%$ SDS. $5 \mu \mathrm{l}$ of a $25-\mu \mathrm{l}$ PCR labelling mixture were typically used in $5 \mathrm{ml} \mathrm{hy}-$ bridization solution.

6. Wash the membranes twice for 5 minutes with $2 \times$ SSC, $0.1 \%$ SDS at room temperature and twice for 30 minutes with $0.1 \times$ SSC, $0.1 \%$ SDS at $68^{\circ} \mathrm{C}$.

7. Detect hybridization signals by autoradiography or color detection according to your labelling system.

8. Decide the specificity of each probe.

\section{Design of PCR primers and set up of a PCR-based assay}

1. Based on the results of the dot blot hybridization experiments, select a probe with the appropriate specificity.

2. Sequence the probe.

3. Check the DNA databases to assess whether the sequence is really unique.

4. Design PCR primers, possibly at the ends of the fragment; the primers are often synthesized in a service laboratory.

5. Set up PCR reactions as in standard protocols. Amplify the fragment from $10 \mathrm{ng}$ purified genomic DNA of the target organism(s).

6. Run a small aliquot (5-10 $\mu$ l) of the PCR products by electrophoresis in a $1 \%$ agarose gel. Run an appropriate size marker along your samples to check proper fragment size. 
7. Optimize the reaction conditions, if necessary (see protocols in [1]).

8. Test the specificity of the primers by running PCR reactions using genomic DNAs from closely and distantly related strains as templates. (All the strains used in the dot blot experiments have to be tested again in this system.)

\section{Notes}

1. Computer programs are available for selecting PCR primers (e.g. Primer, Whitehead Institute for Biomedical Research, MIT Center for Genome Research, USA). Try to find primers with high melting temperature, ideally close to $72{ }^{\circ} \mathrm{C}$, the optimal annealing temperature for most polymerases used in PCR. This allows the use of $72^{\circ} \mathrm{C}$ annealing temperature, which provides high specificity and shortens the PCR reaction time.

2. Designing two sets of primers for each fragment allows nested PCR, another possibility to improve specificity of the test [8].

3. Determine the optimal reaction conditions individually for each application. If necessary, use special additives in the reaction mixture, such as formamide, BSA or betaine. The addition of single-strand DNA-binding protein into the reaction mixture may help to amplify difficult sequences with a stable secondary structure [3]. Hot start is always recommended.

4. The optimal percentage of the agarose gel depends on the fragment length.

5. To facilitate the testing of a large number of samples, 96- and 384-well PCR blocks and serial pipettes as well as pipetting robots are now available. Using the REDTaq DNA polymerase (Sigma-Aldrich) or a similar system allows direct loading of the PCR products onto the gel, which saves time.

6. When using PCR for diagnostic purposes, it is particularly important to avoid crosscontamination and use a number of negative and positive controls.

\section{Applications for environmental samples}

After analysing the specificity of the probes and PCR primers for pure cultures, we can set up the assays for environmental samples. For each application, suitable model experiments should be carried out. In this manual, you find several protocols for extraction and purification of DNA and RNA from aquatic and soil samples as well as from plant material (see Section 1). Specific nucleic acid sequences can then be detected from these samples by hybridization or PCR. However, the sensitivity of PCR allows direct analysis of many raw materials. Here, we show a simple protocol for amplification of DNA from crude nodules of legumes. 
1. Collect nodules from the roots of plants. They can be used directly or stored at $-20^{\circ} \mathrm{C}$.

2. Crush a nodule with sterile glass rod in an Eppendorf tube and suspend it in $200 \mu$ l of TE buffer ( $\mathrm{pH} 8.5$ ).

3. Vortex the suspension for 2 minutes and centrifuge it in an Eppendorf centrifuge ( 1 minute at full speed).

4. Collect the supernatant. Use 1- $\mu$ l aliquots immediately for PCR. Keep the remaining samples in aliquots at $-20^{\circ} \mathrm{C}$.

5. Optionally, the nodule crude extract can be purified on a column (e.g. MicroSpin ${ }^{\mathrm{TM}}$ S-400 HR Column; Amersham Biosciences).

\section{Solutions}

$20 \times$ SSC

- $3 \mathrm{M}$ sodium chloride

- $0.3 \mathrm{M}$ sodium citrate

- Adjust $\mathrm{pH}$ to 7.0

TE buffer ( $\mathrm{pH}$ 8.5)

- $10 \mathrm{mM}$ Tris- $\mathrm{HCl}(\mathrm{pH} 8.5)$

- 1 mM EDTA

\section{Acknowledgments}

The authors thank Katriina Jyrkiäinen, Kaisa Wallenius and Zewdu Terefework for technical assistance. This work was supported by the Maj and Tor Nessling Foundation, Finland and by the Academy of Finland.

\section{References}

1. Ausubel FM, Brent R, Kingston RE, Moore DD, Seidman JG, Smith JA, Struhl K (Eds) (1989) Current protocols in molecular biology. New York: John Wiley \& Sons, Inc.

2. Brockman FJ (1995) Nucleic-acid-based methods for monitoring the performance of in situ bioremediation. Mol Ecol 4:567-578.

3. Chou Q (1992) Minimizing deletion mutagenesis artifact during Taq DNA polymerase PCR by E. coli SSB. Nucleic Acids Res 20:4371.

4. Cullen DW, Nicholson PS, Mendum TA, Hirsch PR (1998) Monitoring genetically modified rhizobia in field soils using the polymerase chain reaction. J Appl Microbiol 84:1025-1034. 
5. Lindström K (1989) Rhizobium galegae, a new species of legume root nodule bacteria. Int J Syst Bacteriol 39:365-367.

6. Maniatis T, Fritsch EF, Sambrook J (1982) Molecular cloning: a laboratory manual. New York: Cold Spring Harbor Laboratory, Cold Spring Harbor.

7. Mäntynen V, Lindström K (1998) A rapid PCR-based DNA test for enterotoxic Bacillus cereus. Appl Environ Microbiol 64:1634-1639.

8. Mullis KB, Faloona FA (1987) Specific synthesis of DNA in vitro via a polymerase-catalyzed chain reaction. Meth Enzymol 155:335-350.

9. Pitkäjärvi J, Räsänen LA, Langenskiöld J, Wallenius K, Niemi M, Lindström K (2003) Persistance, population dynamics and competitiveness for nodulation of marker gene-tagged Rhizobium galegae strains in field lysimeters in the boreal climatic zone. FEMS Microbiol Ecol 46:91-104.

10. Richardson AE, Viccars LA, Watson JM, Gibson AH (1995) Differentiation of Rhizobium strains using the polymerase chain reaction with random and directed primers. Soil Biol Biochem 27:515524 .

11. Rome S, Brunel B, Normand P, Fernandez M, Cleyet-Marel J-C (1996) Evidence that two genomic species of Rhizobium are associated with Medicago truncatula. Arch Microbiol 165:285-288.

12. Sayler GS, Layton AC (1990) Environmental application of nucleic acid hybridization. Annu Rev Microbiol 44:625-648.

13. Sebat JL, Colwell FS, Crawford RL (2003) Metanogenomic Profiling: Microarray Analysis of an Environmental Genomic Library. Appl Environ Microbiol 69:4927-4934.

14. Steffan RJ, Atlas RM (1991) Polymerase chain reaction: applications in environmental microbiology. Annu Rev Microbiol 45:137-161.

15. Suominen L, Paulin L, Saano A, Saren A-M, Tas E, Lindström K (1999) Identification of nodulation promoter (nod-box) regions of Rhizobium galegae. FEMS Microbiol Lett 177:217-223.

16. Tas É, Leinonen P, Saano A, Räsänen LA, Kaijalainen S, Piippola S, Hakola S, Lindström K (1996) Assessment of competitiveness of rhizobia infecting Galega orientalis on the basis of plant yield, nodulation and strain identification by antibiotic resistance and PCR. Appl Environ Microbiol 62:529-535.

17. Tas É, Saano A, Leinonen P, Lindström K (1995) Identification of Rhizobium spp. in peat-based inoculants by DNA hybridization and PCR and its application in inoculant quality control. Appl Environ Microbiol 61:1822-1827. 


\title{
Subtraction hybridization for the production of high specificity DNA probes
}

\author{
AJ BJOURSON $^{1}$, W STREIT ${ }^{2}$ and JE COOPER ${ }^{1 *}$ \\ ${ }^{1}$ Department of Applied Plant Science, Queen's University Belfast, Newforge Lane, Belfast \\ BT9 5PX, Northern Ireland, UK ${ }^{2}$ Institut für Mikrobiologie und Genetik, \\ Georg-August-Universität, Grisebachstr. 8, D-37077 Göttingen, Germany \\ *Corresponding author: Professor JE Cooper Department of Applied Plant Science Queen's \\ University Belfast Newforge Lane Belfast BT9 5PX Northern Ireland, UK Phone: +44 2890 \\ 255351 Fax: +44 2890255007 Email: j.e.cooper@qub.ac.uk
}

\section{Introduction}

Microorganisms can be exploited in the environment in many ways. In agriculture, for example, they can be used as symbiotic nitrogen fixers to improve crop yields, as plant growth promoting rhizobacteria or as biological control agents against pests and diseases. It is frequently necessary to monitor the fate of introduced microorganisms in order to evaluate their survival, the success of inoculation, or their effect on other organisms. In epidemiological and ecological studies also, it is important to identify species and strains of organisms accurately.

Nucleic acid-based techniques have been used successfully to track microorganisms in various environments [4]. Nucleic acid sequences can be labelled and used as probes to identify organisms at various levels of taxonomic organization by colony hybridization, hybridization to DNA extracted from environmental samples and in situ hybridization formats that allow the visualisation of individual microbial cells by microscopy. As a more sensitive alternative to such direct hybridization methodologies, oligonucleotide primer sequences can be designed to precisely anneal to each strand of a section of nucleic acid (target) whose base sequence has already been established. Primer pairs can then be used to detect the presence of minute quantities of this target sequence in DNA extracted from a wide range of natural samples through the amplifying power of PCR. Of course, this mode of detection also involves repeated hybridization of primers to their target nucleic acid template in the reaction mixture and in this sense the primers themselves are acting as "probes".

A fundamental requirement of all these techniques is the availability of short DNA sequences that are exclusive to the organism (or group of organisms) under study. How then are these definitive nucleic acid sequences obtained? One option is to generate a genomic library from the organism for which a probe is required, 
and screen random clones against colony or DNA dot blots from other organisms found in the same environment, in the hope of discovering a clone that fails to hybridize to any but its own organism's DNA. This is extremely time consuming and not always successful.

To overcome such difficulties we devised an alternative approach based on subtraction hybridization [2]. The principle underlying all subtraction hybridization protocols is the removal (ie subtraction) from one cell type, termed here the probe strain, of nucleic acid sequences that are shared with other cell types (sources of subtracter sequences), to leave only sequences that are unique to the probe strain. Subtracter sequences may be from one or more organisms that share some degree of homology with the probe strain. They can be modified in a variety of ways to permit separation of unwanted hybrids from the probe strain-specific sequences in the hybridization mixture. These include immobilisation on solid supports to facilitate removal from the mobile phase by centrifugation $[1,6]$ and biotinylation to allow removal of hybrids by affinity chromatography with streptavidin [1], binding to avidin-coated beads $[8,10]$ or streptavidin-phenol-chloroform extraction [7]. Such techniques are limited in their capacities to generate a pool of highly enriched cell-specific sequences, either by reliance on a single, partially efficient subtraction/separation system, or by an inability to amplify the small quantities of cell-specific nucleic acid generated by each round of subtraction.

The combined subtraction hybridization and PCR amplification procedure described here overcomes these problems. It is applicable to any group of bacteria for the generation of DNA sequences which may be used as hybridizing probes or PCR templates that allow discrimination between organisms at various levels of taxonomic organisation, including inter strain differentiation within a single bacterial species or biovar.

\section{Experimental Approach}

A combination of four distinct separation strategies is used to isolate unique DNA sequences from the genome of cell type "A" after its hybridization with total genomic DNA from cell type "B". The steps involved are shown diagramatically in Fig. 1. Cell type "A" in this scheme is the organism for which a DNA probe is to be constructed (the probe strain) and cell type " $\mathrm{B}$ " refers to a group of more or less related strains or species of bacteria (subtracter strains) which collectively provide the source of subtracter DNA.

Sau3A-digested DNA from cell type "A" is ligated to a non-biotinylated linker, denatured to single stranded form and hybridized in solution with a vast excess of subtracter DNA from cell type(s) "B", which has also been digested with Sau3A, ligated to a subtracter-specific biotinylated linker, amplified by PCR to incorporate dUTP and similarly denatured. Subtracter DNA ( both single stranded and reannealed double stranded "B" fragments) and "A-B" hybrids are then removed by phenol-chloroform extraction of a streptavidin-biotin-DNA complex. NENSORB chromatography of the sequences remaining in the aqueous layer captures 


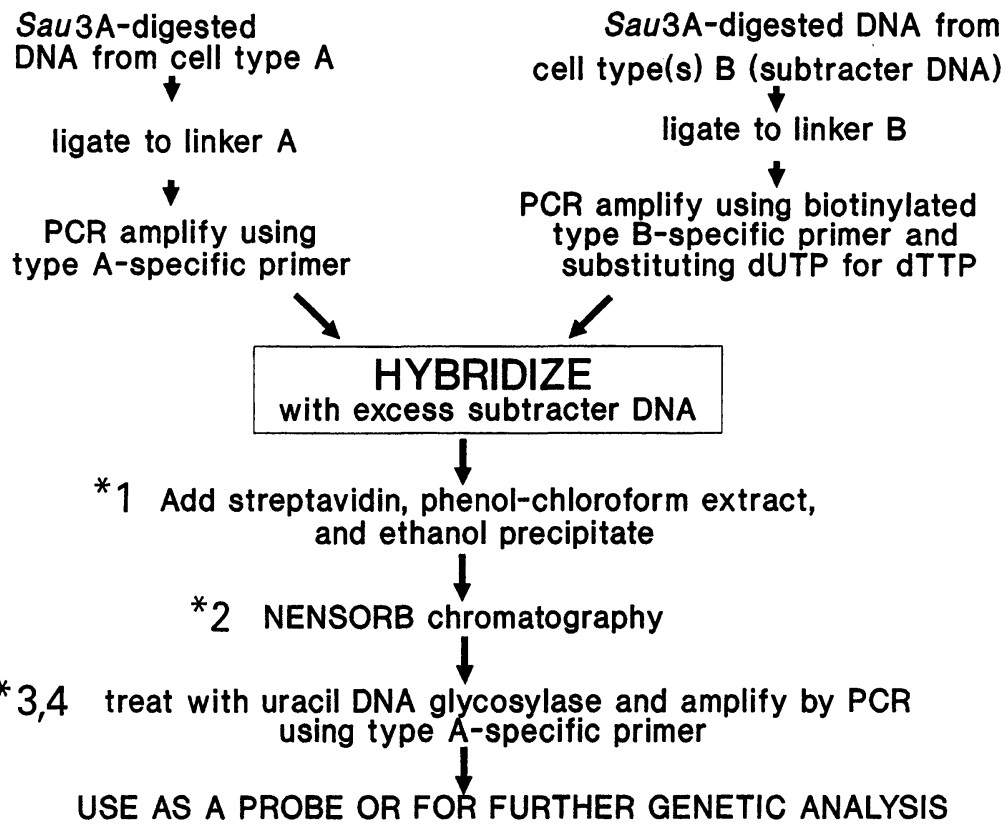

Figure 1. Scheme for isolating unique nucleic acid sequences from cell type "A" by combined subtraction hybridization and PCR amplification showing the four* separation strategies employed.

biotinylated subtracter DNA which may have escaped removal by the phenolchloroform treatment (NENSORB matrix irreversibly binds protein). Any more traces of contaminating subtracter DNA are removed by digestion with uracil DNA glycosylase. Finally, remaining sequences are amplified by PCR with the type "A"specific primer, labelled and tested for specificity in dot blot hybridizations against total genomic target DNA from cell type(s) "B". Removal of cross-hybridizing sequences is normally achieved after 1 or 2 rounds of subtraction/amplification. The information given below is generally applicable to probe generation in bacteria.

\section{Procedures}

Isolation of DNA

Any method of DNA isolation can be used provided that it yields pure undegraded DNA. Since the method only requires $\mu \mathrm{g}$ amounts of DNA any small scale method is applicable, including an array of commercial kits. Alternatively the following protocol may be used.

1. Grow pure cultures of bacteria in $50 \mathrm{ml}$ conical flasks containing $25 \mathrm{ml}$ of appropriate growth medium. 
2. Pellet $5 \mathrm{ml}$ of each culture in a bench centrifuge and resuspend the pellets in $50 \mu \mathrm{l} \mathrm{TE}$ buffer in $1.5 \mathrm{ml}$ centrifuge tubes. Wash the pellet with $500 \mu \mathrm{l} \mathrm{TE}$ buffer. Resuspend the final pellet in $100 \mu \mathrm{l}$ of resuspension buffer and incubate at $37{ }^{\circ} \mathrm{C}$ for 15 minutes.

3. Lyse the cells by adding $200 \mu$ lysis solution. Mix gently, and add $150 \mu \mathrm{l}$ of $7.5 \mathrm{~mol} / \mathrm{l}$ ammonium acetate and extract the mixture with $500 \mu \mathrm{l}$ chloroform/isoamyl alcohol by mixing and centrifuging in a microcentrifuge for 10 minutes.

4. Transfer the aqueous phase to a clean $1.5 \mathrm{ml}$ centrifuge tube and precipitate the DNA by adding 0.54 vol 2-propanol. Pellet the DNA by spinning at maximum speed in a microcentrifuge, remove the ethanol and wash the pellet twice with $100 \mu \mathrm{l}$ aliquots of $80 \%$ ethanol. Dry the pellet under vacuum and resuspend it in $20 \mu \mathrm{l}$ TE buffer.

5. Estimate the DNA concentration by gel electrophoresis against DNA standards of known concentration.

6. Digest approximately $1 \mu \mathrm{g}$ DNA from each strain with restriction endonuclease Sau3A, and purify the restriction fragments with Wizard DNA clean-up columns or PREP-A-GENE matrix (other DNA micro-purification systems can also be used) as described by the manufacturer and elute the DNA in $20 \mu \mathrm{l}$ TE buffer.

\section{Notes}

1. The restriction digestion reaction can be purified by phenol/chloroform extraction. However, the use of the commercial kits has the added advantage of removing small molecular weight products. For example, the Wizard Clean-up kit removes products smaller than $180 \mathrm{bp}$.

2. Modification of probe and subtracter DNA by the addition of specific linkers permits the unbiased amplification of fragments in the $100-2,500$ bp size range and it is important that the restriction enzyme chosen for the DNA digestion yields fragments within this size range.

\section{Addition of primer/linkers}

The addition of the primer-linkers described below to both ends of the Sau3A restriction fragments permits them to be amplified by PCR, thus providing a readily renewable supply. Oligonucleotides with the following base sequences are synthesised or obtained from commercial sources. 
TB7006 5' NH $_{2}$-AGCGGATAACAATTTCACACAGGA-OH 3' TB7007 5' BIOTIN-CGCCAGGGUUUUCCCAGUCACGAC -OH 3'

TB7008 5' P-GATCTCCTGTGTGAAATTGTTATCCGCT-NH ${ }_{2} 3^{\prime}$

TB7009 5' P-GAUCGUCGUGACUGGGAAAACCCUGGCG-NH ${ }_{2} 3^{\prime}$

Oligonucleotides are resuspended in sterile TE buffer at a final concentration of $200 \mu \mathrm{M}$ and stored in aliquots at $-20^{\circ} \mathrm{C}$.

1. Mix $5 \mu \mathrm{g}$ of the appropriate oligonucleotides to produce the linkers L-P (TB7006 and TB7008) and L-S (TB7007 and TB7009). L-P corresponds to linker $A$ for probe strain Sau $3 A$ digest fragments in Fig. 1 and L-S to linker B for subtracter strain Sau3A digest fragments.

2. Heat the mixtures to $65{ }^{\circ} \mathrm{C}$ and cool slowly to room temperature to produce double stranded linkers containing 5 '-phosphorylated Sau3A-compatible overhangs at one end.

3. Ligate linker L-P to Sau3A-digested probe strain DNA and linker L-S to similarly digested individual subtracter DNAs. In each case, mix $200 \mathrm{ng}$ of Sau3A-digested genomic DNA with $600 \mathrm{ng}$ of the appropriate linker and ligate the mixture with DNA ligase using standard procedures. Remove excess linkers using a Wizard DNA Clean-up kit as described by the manufacturer. Elute the DNA in $20 \mu \mathrm{l}$ sterile deionized water.

Notes

1. It is important that TB7008 and TB7009 are phosphorylated at the $5^{\prime}$-end. The user can design his/her own sequences provided that a Sau3A-compatible $5^{\prime}$ overhang results after they are annealed (e.g. annealing TB7006 and TB7008 generates a linker with a Sau3A-compatible $5^{\prime}$-GATC- overhang).

2. The primers used for ligation to the subtracter DNA (TB7007 and TB7009) contain dUTP instead of dTTP. This enables them to be subsequently destroyed by uracil DNA glycosylase after each subtraction cycle. Primer TB7007 contains biotin at the 5 '-end to facilitate biotinylation of the amplified fragments. The use of PHOTOPROBE Biotin (long arm) is also recommended for biotinylation of the subtracter DNA.

3. An $\mathrm{NH}_{2}$ group is included at the $3^{\prime}$-end of primers TB7008 and TB7009 and the $5^{\prime}$ end of primer TB7006. This prevents concatomerization of ligated products during subsequent amplifications.

4. It is important to have a large molar excess of linker over Sau3A digested fragments to prevent the latter ligating to each other. For example, if a unique DNA fragment becomes ligated to a non-unique fragment, the unique sequence will be inadvertently subtracted together with the non-unique sequence. To avoid this 
problem the cohesive termini are partially filled-in by one base which renders the termini of the digested DNA incompatible. Linkers are designed to be compatible with the partially filled-in termini. This modification will also prevent self ligation of linkers, making their removal after ligation less critical.

5. The use of the Wizard Clean-up kit or similar commercial kits has the added advantage of removing excess primer-linkers since products $<180 \mathrm{bp}$ are not efficiently bound by the matrices used in this kit.

6. Different primers and linkers should be designed for each separate subtraction experiment to eliminate the build-up of potential contaminating sequences.

\section{Amplification of probe DNA}

1. Amplify $50 \mathrm{ng}$ of the probe strain DNA, which has been modified by ligation to linker L-P, for 45 cycles of PCR. Each cycle should consist of denaturation at $94{ }^{\circ} \mathrm{C}$ ( 1 minute 20 seconds), annealing at $55{ }^{\circ} \mathrm{C}$ ( 1 minute) and DNA polymerisation at $72{ }^{\circ} \mathrm{C}$ ( 2 minutes) in an automated thermal cycler. Perform the reactions in sterile $0.5 \mathrm{ml}$ tubes with $100 \mu \mathrm{l}$ final reaction volumes containing Tris, $\mathrm{pH} 8.3,10 \mathrm{mmol} / \mathrm{l} ; \mathrm{KCl}, 50 \mathrm{mmol} / \mathrm{l} ; \mathrm{MgCl}_{2}, 1.5 \mathrm{mmol} / \mathrm{l} ;$ gelatin, 0.01 $\%(\mathrm{w} / \mathrm{v})$; dNTP's, $200 \mu \mathrm{mol} / \mathrm{l} ;$ primer TB7006, $1 \mu \mathrm{mol} / / ; 0.5$ units of AmpliTaq DNA polymerase (Perkin Elmer Cetus). Evaporation from the tubes can be prevented by addition of a $50 \mu \mathrm{l}$ mineral oil overlay (alternatively, oil-free PCR tubes can be used and the removal of oil by chloroform extraction is subsequently avoided).

2. After amplification, analyse $15 \mu$ aliquots of the PCR products by electrophoresis in a $1.5 \%$ agarose gel with size markers. Electrophorese the samples until they have run 1/4-way into the gel. A smear of PCR products ranging in size from 3.5-0.2 kb should be produced.

3. Extract the remaining PCR products with an equal volume of phenol/chloroform.

4. Extract the aqueous phase with chloroform, add $0.1 \mathrm{vol}$ of $3 \mathrm{~mol} / \mathrm{l}$ sodium acetate and $2.5 \mathrm{vol}$ of absolute ethanol and incubate at $70{ }^{\circ} \mathrm{C}$ for 30 minutes to precipitate the DNA. Collect the pellet by centrifugation and remove the ethanol.

5. Wash the pellet in $500 \mu$ of $80 \%$ ethanol, dry the pellet and resuspend it in $20 \mu$ sterile water.

6. Estimate the DNA concentration. 


\section{Notes}

1. At all stages in this procedure, but in particular after subtraction is complete, it is essential that the subtracted material does not become contaminated by unsubtracted probe sequences. Even a small amount of contamination from this source will be subsequently amplified by PCR. While contamination with subtracter DNA can be eliminated by uracil glycosylase treatment prior to amplification, contamination involving unsubtracted probe sequences can only be removed by additional subtraction cycles. For this reason PCR reagents and master mixes must be prepared in a sequestered laboratory. Separate pipettes should be reserved for this purpose and filtered sterile pipette tips should be used. Control PCR reactions devoid of template should be employed to check for contamination of reagents at all PCR amplification steps. Microcentrifuges and centrifugal evaporators should be kept clean. Tubes should not be left open during centrifugal evaporation. Instead, pierce the tube lid with a sterile hypodermic needle. This practice will prevent contamination of the evaporator bowl by the sample and vice versa.

2. In step 2 above, if the samples are run the full length of the gel, the products, which appear as a smear, will be more difficult to visualise because they are distributed over a large area of the gel. It is therefore recommended that they are initially run $1 / 4$ way into a minigel, and examined under long wave UV. If the products are clearly visible electrophoresis can be continued to determine a more accurate size distribution of the products.

\section{Amplification and preparation of subtracter DNA}

Amplify the subtracter DNA, modified by ligation to linker L-S, from the required number of subtracter strains. If more than one organism is used as subtracter, the PCR amplifications should be performed independently for the DNA from each organism. If only one organism is used as subtracter, set up $10 \times 100 \mu \mathrm{l}$ PCR reactions to serve as a source of subtracter DNA.

1. Amplify the individual subtracter DNAs using the amplification conditions described above for probe strain DNA, except use primer TB7007 instead of TB7006. Use dUTP instead of dTTP to give a final dUTP concentration of $300 \mu \mathrm{mol} / \mathrm{l}$.

2. Check the efficiency of amplification by submitting $15 \mu \mathrm{l}$ volumes of each reaction to electrophoresis in 1.5\% agarose gels (or $3 \%$ NuSieve agarose, $1 \%$ SeaKem agarose $(w / v))$.

3. Pool the amplified subtracter DNA reactions, remove the mineral oil and extract with an equal volume of chloroform/isoamyl alcohol (if oil-free PCR tubes are employed this extraction can be omitted). 
4. Transfer the aqueous phase to a Centricon-30 microconcentrator and make the volume up to $2 \mathrm{ml}$ with water. Concentrate the mixture by spin dialysis at a speed of $1,500-2,000 \mathrm{~g}$ to yield a final volume of $25-50 \mu l$ as described by the manufacturer. Again make the volume up to $2 \mathrm{ml}$ with sterile water and repeat the spin dialysis step until the residual volume of the mixture is approximately $25 \mu \mathrm{l}$.

5. Estimate the concentration of the subtracter DNA and adjust the concentration to approximately $1 \mu \mathrm{g} / \mu \mathrm{l}$ or less in a $1.5 \mathrm{ml}$ microcentrifuge tube.

6. Add an equal volume of PHOTOPROBE Biotin and place the tube on ice. Place a $500 \mathrm{~W}$ sunlamp (Mercury Vapour Bulb) $10 \mathrm{~cm}$ above the tube and irradiate for 15 minutes.

7. Add $0.1 \mathrm{vol}$ of $0.1 \mathrm{~mol} / \mathrm{l}$ Tris. $\mathrm{Cl}(\mathrm{pH} 9.5)$ to deprotonate the unreacted PHOTOPROBE Biotin.

8. Add an equal volume of 2-butanol and mix gently, centrifuge for 3 minutes in a bench centrifuge and discard the upper organic phase (repeat this extraction using the original volume of 2-butanol).

9. Measure the volume of the aqueous phase and add $\mathrm{NaCl}$ to a final concentration of $100 \mathrm{mmol} / \mathrm{l}$ (from a $5 \mathrm{~mol} / / \mathrm{NaCl}$ stock). Add $2.5 \mathrm{vol}$ of absolute ethanol and precipitate at $70{ }^{\circ} \mathrm{C}$ for 60 minutes. Collect the pellet by centrifugation at maximum speed in a microcentrifuge for 15 minutes.

Notes

1. dUTP is less efficiently incorporated than dTTP in PCR reactions. If the yield of subtracter DNA is poor, a 60:40 ratio of dUTP to dTTP may be used instead of dUTP alone.

2. Despite the need for the large molar excess of subtracter over probe strain DNA, the actual amount required for each subtraction cycle is in the 20-30 $\mu \mathrm{g}$ range. Additionally, the subtracter DNA is in an easily replenishable form and this feature would assume special significance for organisms that are difficult to grow or whose DNA is difficult to extract.

\section{Subtraction hybridization}

1. Mix $1-5 \mathrm{ng}$ (in a volume of $2 \mu \mathrm{l}$ ) of amplified probe strain DNA and $20-30 \mu \mathrm{g}$ (in a volume of $10 \mu \mathrm{l}$ ) of subtracter DNA in a $0.5 \mathrm{ml}$ microcentrifuge tube, add $2 \mu \mathrm{l}$ of $500 \mathrm{mM} / \mathrm{HEPES}(\mathrm{pH} 7.5), 2 \mu \mathrm{l}$ 
of $20 \mathrm{mM} / \mathrm{EDTA}, 2 \mu \mathrm{l}$ of $1 \%$ SDS and overlay the mixture with mineral oil.

2. Heat the mixture to $98{ }^{\circ} \mathrm{C}$ for $3-5$ minutes, cool on ice and add $2 \mu \mathrm{l}$ of $5 \mathrm{~mol} / \mathrm{l} \mathrm{NaCl}$.

3. Incubate the mixture at $65{ }^{\circ} \mathrm{C}$ for $24-48$ hours.

Note

The stringency at which the subtraction is performed in step 3 is an important factor when considering the intended use of the final sequences. Low stringency conditions will remove some probe strain sequences that have a relatively low base sequence homology with the subtracter DNA, whereas high stringency subtraction will remove only perfectly matched sequences.

Isolation of probe strain-specific DNA sequences from the subtraction mixture

1. Add $100 \mu \mathrm{l}$ of extraction buffer to the subtraction mixture and remove excess mineral oil. Add $5 \mu \mathrm{l}$ of streptavidin $(2 \mu \mathrm{g} / \mu \mathrm{l})$ and mix gently at room temperature for 10 minutes; add a further $20 \mu \mathrm{l}$ of streptavidin and mix gently for 5 minutes at room temperature.

2. Extract the mixture with an equal volume of phenol/chloroform $(50: 50, v / v)$ and centrifuge in a microcentrifuge for 5 minutes at $15,000 \times \mathrm{g}$. Transfer the aqueous phase to a fresh tube, avoiding the interface. Add $1 \mu$ of $1 \%$ SDS and extract three more times with phenol/chloroform, and once with chloroform.

3. Precipitate the DNA remaining in the aqueous phase by adding 10 $\mu \mathrm{l}(0.1 \mathrm{vol})$ of $3 \mathrm{~mol} / \mathrm{l}$ sodium acetate and $2 \mathrm{vol} 99 \%$ ethanol. Wash the pellet with $100 \mu \mathrm{l} 70 \%$ ethanol and redissolve the pellet in $20 \mu \mathrm{l}$ of sterile water. The deproteinized DNA can be desalted with a NENSORB 20 purification cartridge as described by the manufacturers, and finally resuspended in $20 \mu \mathrm{l}$ water.

4. Use $9 \mu$ of this subtracted material as probe strain DNA in a second subtraction cycle.

Notes

1. The efficiency of the phenol/chloroform extractions can be greatly improved by the use of phase lock gel (CP Laboratories, UK), which forms a barrier between the organic and aqueous phases. This permits total recovery of the aqueous phase without contamination from the interface. While other methods for removing biotinylated nucleic acids are available, such as streptavidin coated magnetic beads, the procedure described here appears to be the most efficient. 
2. For a second subtraction cycle the subtracted probe DNA (from step 4 above) and subtracter DNA can be mixed together, ethanol precipitated and resuspended in 10 $\mu l$ water. This will enable the second subtraction cycle to be performed in a $20 \mu \mathrm{l}$ reaction as described above. The NENSORB column chromatography in step 3 is optional. This matrix irreversibly binds protein, therefore it is useful for removing any remaining strepavidin-DNA complexes. As an alternative to NENSORB chromatography the Qiagen purification kit (Qiagen, Hilden, Germany) is also effective [9].

\section{Amplification of subtracted probe DNA}

The subtracted probe DNA from each subtraction cycle is amplified by PCR. It is recommended that a dilution series of the subtracted material from each cycle is prepared and amplified. It is normal to obtain a smear of products from undiluted subtracted material while the more extensively diluted samples can give rise to discrete bands which can be unique to the probe organism.

1. Prepare $10 \mu \mathrm{l}$ logarithmic dilutions $\left(10^{-1}-10^{-9}\right)$ of the subtracted probe DNA, e.g. mixing $1 \mu \mathrm{l}$ of subtracted material with a $9 \mu \mathrm{l}$ aliquot of water will give a $10^{-1}$ dilution, and mixing $1 \mu$ of this dilution with $9 \mu$ of water will give a $10^{-2}$ dilution.

2. Mix $9 \mu$ l of each dilution with PCR mix, omitting the primer and Taq polymerase (95 $\mu$ vol; Tris, $\mathrm{pH} 8.3,10 \mathrm{mmol} / / ; \mathrm{KCl}, 50 \mathrm{mmol} / / ; \mathrm{MgCl}_{2}$, $1.5 \mathrm{mmol} / \mathrm{l} ;$ gelatin, $0.01 \%(\mathrm{w} / \mathrm{v})$; dNTP's, $200 \mu \mathrm{mol} / \mathrm{l}$, containing 5 units of uracil DNA glycosylase) and incubate at $37{ }^{\circ} \mathrm{C}$ for 15 minutes followed by $98{ }^{\circ} \mathrm{C}$ for 3 minutes to destroy all traces of dUTP-containing subtracter DNA.

3. Add primer TB7006 (5 $\mu$ l of $200 \mu \mathrm{M} / \mathrm{l}$, probe strain-specific) and 0.5 units of Taq polymerase to give a final volume of $100 \mu \mathrm{l}$. Amplify for 45 cycles under the temperature conditions described above to prepare amplified subtracted probe DNA. Analyse a $15 \mu \mathrm{l}$ aliquot of each PCR reaction in a $1.5 \%$ agarose gel.

\section{Specificity of the subtracted probe strain DNA}

If the subtraction has been driven to completion, the subtracted material will contain DNA sequences that are exclusive to the organism of origin. This can be checked after each subtraction cycle by labelling the subtracted probe DNA and using it to probe dot blots containing total genomic DNA from each organism used for preparation of the 
subtracter DNA, as described below. If complete enrichment has occurred, the probe should only hybridize to the DNA from the probe strain. If the subtracted material is shown to hybridize exclusively with the probe strain, a batch should be digested with Sau3A and cloned into a suitable cloning vector. Even if there is slight hybridization to DNA from some of the subtracter organisms, it is still worth cloning the subtracted material, since it will be highly enriched for sequences exclusive to the probe strain.

Once cloned, the individual fragments can be labelled, checked once more for hybridization specificity and used as probes. Alternatively, clones with the required degree of hybridization specificity can be sequenced to permit the design of primers for use in PCR-based detection protocols.

\section{Preparation of DNA dot blots}

Denature $1 \mu \mathrm{g}$ (in $4 \mu \mathrm{l}$ of water) of total genomic target DNA from each subtracter strain at $100{ }^{\circ} \mathrm{C}$ for 3 minutes, snap cool on ice and add $4 \mu$ of $20 \times$ SSC. Manually spot the denatured DNA on to Hybond$\mathrm{N}+$ membranes using $2 \mu \mathrm{l}$ aliquots at a time. Place the membranes on filter paper soaked in denaturing solution for 5 minutes and then transfer them to another filter paper containing neutralising solution for 1 minute. Fix the DNA to the membranes by placing them on filter paper soaked in $0.4 \mathrm{M} \mathrm{NaOH}$ (20 minutes), immerse briefly in $6 \times \mathrm{SSC}$ and air dry. Membranes can be stored at $4{ }^{\circ} \mathrm{C}$ until used.

\section{Labelling procedure}

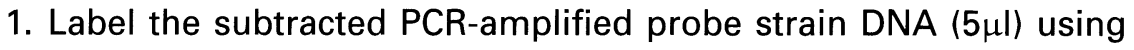
three cycles of PCR amplification. Each cycle should consist of denaturation at $95{ }^{\circ} \mathrm{C}$ ( 2 minutes), renaturation at $55^{\circ} \mathrm{C}$ ( 2 minutes), and polymerization at $72{ }^{\circ} \mathrm{C}$ (10 minutes). Perform the reactions in $50 \mu \mathrm{l}$ final volumes containing Tris, $\mathrm{pH} 8.3,10 \mathrm{mmol} / \mathrm{l} ; \mathrm{KCl}, 50$ $\mathrm{mmol} / \mathrm{l} ; \mathrm{MgCl}_{2}, 1.5 \mathrm{mmol} / \mathrm{l}$; gelatin, $0.01 \%(\mathrm{w} / \mathrm{v})$; dATP, dTTP, dGTP, $200 \mu \mathrm{mol} / \mathrm{l}$ each; $5 \mu \mathrm{l}\left[{ }^{32} \mathrm{P}\right] \mathrm{dCTP}\left(400 \mathrm{ci} \mathrm{mM}^{-1}\right)$; primer TB7006, 1 $\mu \mathrm{mol} / \mathrm{l}$ and 0.5 units of AmpliTaq DNA polymerase.

2. Remove unincorporated nucleotides using push columns as described by the manufacturer. 


\section{Filter hybridizations}

Prehybridize the filters for 5 hours at $68^{\circ} \mathrm{C}$ in bags or hybdridizationoven bottles containing prehybridization solution. Hybridization is performed at the same temperature in the same solution with $2.5 \times$ $10^{6} \mathrm{cpm} / \mathrm{ml}$ of ${ }^{32} \mathrm{P}$-labelled subtracted probe strain DNA for 18 hours. Wash the filters in $1 \times$ SSC, $0.5 \%$ SDS for 1 hour ( $4 \times 15$ minutes), and in $0.1 \times \mathrm{SSC}, 0.5 \%$ SDS at $68{ }^{\circ} \mathrm{C}$ for 1 hour ( $4 \times 15$ minutes $)$. Filters are subjected to autoradiography as previously described [1].

\section{Note}

Non-radioactive labelling systems may be used if preferred. A suitable alternative is the DIG labelling and detection kit (Roche Diagnostics, Mannheim, Germany) which permits labelling of probe strain-specific sequences with digoxigenin-11-dUTP [9].

\section{Materials}

TE buffer: $10 \mathrm{mM}$ Tris. $\mathrm{HCl}, 1 \mathrm{mM}$ EDTA, pH 8.0.

Resuspension buffer: $25 \%$ sucrose, $1 \mathrm{mg} / \mathrm{ml}$ lysosyme, $10 \mathrm{mmol} / \mathrm{l}$

Tris. $\mathrm{HCl}, \mathrm{pH} 8.0$ (freshly prepared).

Lysis solution: $5 \mathrm{~mol} / \mathrm{l}$ guanidine isothiocyanate, $0.1 \mathrm{~mol} / / \mathrm{EDTA}, \mathrm{pH}$

7.0 (stored refrigerated, heated to $37^{\circ} \mathrm{C}$ prior to use).

Phenol: molecular biology grade (Sigma Chemicals).

Chloroform/isoamyl alcohol: $24: 1 \mathrm{v} / \mathrm{v}$.

$7.5 \mathrm{~mol} / \mathrm{l}$ ammonium acetate (sterilized by autoclaving).

$3 \mathrm{~mol} / \mathrm{l}$ sodium acetate, $\mathrm{pH} 5.5$.

2-propanol.

$70 \%$ ethanol (store in a spark-proof freezer at $-20^{\circ} \mathrm{C}$ ).

Restriction endonuclease Sau3A (Amersham plc, UK).

DNA ligase (Amersham plc, UK).

Oligonucleotides (purified by HPLC or PAGE, synthesis and purification is available commercially).

PREP-A-GENE matrix (BIORAD Laboratories, UK). Alternatives such as Wizard DNA clean-up columns (Promega Corporation, UK) or equivalent DNA micro-purification systems are also acceptable.

Phase lock gel (CP laboratories, UK).

Centricon 30 microconcentrators (Amicon Ltd., UK).

PHOTOPROBE Biotin, long arm (Vector Laboratories, UK). 
Taq polymerase, uracil DNA glycosylase, and all PCR reagents available from Perkin Elmer, UK.

NuSieve agarose, SeaKem agarose (FMC BioProducts, Sittingbourne, UK).

NENSORB 20 purification cartridges (Du Pont Ltd., UK) or Qiagen purification kit (Qiagen, Hilden, Germany).

$20 \times \mathrm{SSC}(1 \times \mathrm{SSC}$ is $0.15 \mathrm{~mol} / \mathrm{l}$ sodium chloride, $0.015 \mathrm{~mol} / \mathrm{l}$ sodium citrate), sterilize by autoclaving.

Extraction buffer: $500 \mathrm{mmol} / / \mathrm{NaCl}, 1 \mathrm{mmol} / \mathrm{l}$ EDTA and $50 \mathrm{mmol} / \mathrm{l}$ HEPES.

Streptavidin (Sigma Chemicals).

Chromatography columns (push columns, Stratagene Ltd., UK).

Denaturing buffer: $1.5 \mathrm{~mol} / \mathrm{l} \mathrm{NaCl}, 0.5 \mathrm{~mol} / \mathrm{l} \mathrm{NaOH}$.

Neutralizing solution: $1.5 \mathrm{~mol} / \mathrm{I} \mathrm{NaCl}, 0.5 \mathrm{~mol} / \mathrm{l}$ Tris- $\mathrm{HCl} \mathrm{pH} 7.2,1 \mathrm{mmol} / \mathrm{I}$ EDTA.

Hybond-N+ membranes (Amersham plc, UK).

Prehybridization solution: $4 \times$ SSC, $10 \times$ Denhardt's solution, 100 $\mu \mathrm{g} / \mathrm{ml}$ sonicated denatured salmon sperm DNA, $10 \mathrm{mmol} / \mathrm{l}$ Tris- $\mathrm{HCl}$ $\mathrm{pH} 8.0,0.1 \%$ SDS.

\section{Application of the method}

This procedure has been used successfully in several applications. These include the detection of legume root nodule bacteria (rhizobia) at various taxonomic levels and the identification of differences between pairs of organisms with highly homologous genomes. In the initial development of the technique a probe which distinguished one strain of Rhizobium leguminosarum biovar trifolii from seven other strains of the same biovar was isolated [2]. This probe was suitable for determining the nodulating competitiveness of its parent strain against any of the seven subtracter strains under controlled conditions. Subsequently, a probe which hybridized to DNA from root nodule bacteria in the Rhizobium leguminosarum biovar phaseoli and Rhizobium tropici group was generated [9]. In this case the probe was used to estimate the numbers of rhizobia from this group in various soil samples. As well as being of value in ecological studies the method can be used to identify small differences between pairs of bacteria whose genomes are largely homologous. For example, 
Rhizobium sp. NGR234 and Sinorhizobium fredii are tropical rhizobia with a very close phylogenetic relationship and a broad, but not identical, legume host range. Symbiotic genes possessed by NGR234 but not by $S$. fredii were isolated by a combination of subtractive DNA hybridization, competitive RNA hybridization and shot-gun sequencing $[3,5]$. As an extension of this application subtractive DNA hybridization, as described in this article, could provide a useful tool for the comparative genome sequencing of any two closely related microbes.

\section{References}

1. Bjourson AJ, Cooper JE (1988) Isolation of Rhizobium loti strain-specific DNA sequences by subtraction hybridization. Appl Environ Microbiol 53: 1705-1707.

2. Bjourson AJ, Stone CE, Cooper JE (1992) Combined subtraction hybridization and polymerase chain reaction amplification procedure for the isolation of strain specific Rhizobium DNA sequences. Appl Environ Microbiol 58: 2296-2301.

3. Cooper JE, Bjourson AJ, Streit W, Werner D (1998) Isolation of unique nucleic acid sequences from rhizobia by genomic subtraction: applications in microbial ecology and symbiotic gene analysis. Plant Soil 204: 47-55.

4. Drahos DJ (1991) Methods for the detection, identification and enumeration of microbes. In Andrews JH, Hirano SS, eds. Microbial Ecology of Leaves pp. 135-158. Springer Publishers, New York.

5. Perret X, Fellay R, Bjourson AJ, Cooper JE, Brenner S, Broughton WJ (1994) Subtraction hybridization and shot-gun sequencing: a new approach to identify symbiotic loci. Nucl Acids Res 22: 1335-1341.

6. Scott MRD, Westphal K-W, Rigby PWC (1983) Activation of mouse genes in transformed cells. Cell 34: 557-567.

7. Sive HL, St John T (1988) A simple subtractive hybridization technique employing photoactive biotin and phenol extraction. Nucl Acids Res 16: 10937.

8. Straus D, Ausubel FM (1990) Genomic subtraction for cloning DNA corresponding to deletion mutants. Proc Nat Acad Sci USA 87: 1889-1892.

9. Streit W, Bjourson AJ, Cooper JE, Werner D (1993) Application of subtraction hybridization for the development of a Rhizobium leguminosarum biovar phaseoli and Rhizobium tropici groupspecific DNA probe. FEMS Microbiol Ecol 13: 59-68.

10. Sun T-P, Goodman HM, Ausubel FM (1992) Cloning of the Arabidopsis GA1 locus by genomic subtraction. Plant Cell 4: 119-128. 


\title{
Considerations for the use of functional markers and field release of genetically engineered microorganisms to soils and plants
}

\author{
MARK J. BAILEY*, TRACEY. M. TIMMS-WILSON and \\ ANDREW K. LILLEY. \\ Molecular Microbial Ecology Laboratory, Natural Environment Research Council, Centre for \\ Ecology and Hydrology (Virology and Environmental Microbiology), Mansfield Road, Oxford, \\ OX1 3SR.
}

\section{Introduction}

Over the last decade there have been major advances in the study of microbes in the environment. These investigations have been enhanced through developments in molecular biology that facilitate the detection of populations, cells and functional genes $[1,2,35]$. The modification of bacterial isolates by the introduction of novel traits not only provides the basis for improved understanding of the ecology of inocula, but also the means by which strains can be modified to express biologically useful functions. These practical modifications have a variety of biotechnological applications including those for bioremediation and in particular their use in agriculture for disease suppression, insect pest control and plant growth promotion. Despite the obvious commercial potential of these variants, concerns remain with the efficacy and function of derived inocula and with the potential environmental risks that might arise inadvertently with the field release of GMMs. Clearly defined procedures would be of benefit in the evaluation of selected strains. This is not always practical as assessments made in the laboratory or in microcosms, where better simulations of the field are possible, do not always reliably predict the eventual performance of introduced strains.

A large number of reviews and articles have been published which discuss the availability, suitability and sensitivity of marker genes for the detection and enumeration bacteria in environmental samples [27]. The essentials are that the released bacteria can be specifically detected and differentiated from the indigenous background of approaching $10^{9}$ cells per gram of soil. Traditional approaches have been based on the enumeration of isolates on bacteriological agars, the culturable component. Effective measures for inocula detection have included the use of spontaneous antibiotic resistances (rifampicin is a common choice) or selection based on the expression of a specific antibiotic resistance gene introduced by molecular techniques (kanamycin resistance is a favoured selectable marker). 
With these approaches viable bacteria at densities as low as $100 \mathrm{cfu} / \mathrm{g}$ soil can be readily detected and with modified methods we have been able to routinely detect $20 \mathrm{cfu} / \mathrm{g}$ against a background of $<10^{12} \mathrm{cfu} / \mathrm{g}$ decaying leaf tissue or $1 \mathrm{cfu} / \mathrm{g}$ soil by MPN [5]. These evaluations prove more reliable for the screening of a large collection of soil/phytosphere samples and provide greater sensitivities than commonly attained with PCR methodologies [7] when high quality DNA and RNA can be isolated from soils [17].

\section{The choice of marker genes}

The choice of marker does depend on the objectives of the experiment. If the direct monitoring of viable cells following release is required then simple antibiotic selection may suffice. To achieve sensitivity of detection and unequivocal identification the adoption of two or more unique markers may be necessary. Two markers provide confirmation of the identity of isolates, for example introduced antibiotic resistances can be supplemented by markers that allow detection based on calorimetric detection due to the enzymatic activity (lacZ, $x y l \mathrm{E})$, bioluminescence $(l u x, l u c)$ or fluorescence (gfp) $[3,13,26,34]$. One main advantage with the use of green fluorescent protein (gfp) is that excitation is mediated by incident blue light and not the addition of substrate as required for the effective use of the other markers [34]. Alone and in combination with antibiotic resistance and other selectable expressed phenotypes, i.e. lacZY, the use of these markers has found considerable favour as they are widely used as marker or reporter gene systems. A variety of substrates are available for direct detection of isolated colonies modified to express lacZ. Following the conversion of the substrate X-gal by $B$-galactosidase to a blue colour, or the use of other substrates for this enzyme that are available that fluoresce (MUG), or more significantly the additional presence of $l a c \mathrm{Y}$ provides lactose permease that allows pseudomonads to grow on lactose as a sole carbon source [6]. Mono-specific antisera have also been applied to the detection and isolation of bacteria from environmental samples. Agglutination by the use of beads coated with antisera against the flagella of Pseudomonas putida was described for water samples [24]. Antisera has also been used to confirm the in situ expression of selected reporter B-gene phenotypes, for example catechol 2,3, dioxygenase and $\beta$-galactosidase is commercially available, and we have raised low affinity sera to lactose permease expressed in the pseudomonad periplasm. These sera specific to the $l a c \mathrm{Z}$ or $l a c \mathrm{Y}$ encoded proteins have proved useful for the detection of reporter genes expressed in the rhizosphere of infected plants by pseudomonads with potential for the biological control of seed borne fungal infections [32]. The value of reporter systems to resolve ecological interactions have been highlighted recently in the description of rhizosphere microbial community signalling between the phytopathogen Pythium ultimum. In the first study a transposon mutation library was made in the 2,4-diacetylphloroglucinol (DAPG) producing fungal antagonist $P$. fluorescens $\mathrm{F} 113$ using a promoterless lacZ. Five 
variants were identified which were down regulated, repressed, for lacZ expression in the presence of Pythium and showed impaired fitness for rhizosphere colonisation, but not biocontrol activity [12]. We have undertaken similar investigations using a promoterless lacZY mini-Tn5 system (pUTTKZY) [32] to screen transposon mutagenesis libraries of $P$. fluorescens SBW25, that suppresses damping off [11], to detect induction or repression of reporter gene expression in the spermosphere or in the presence of Pythium ultimum var Trow. The reporter system lacZY was favoured as it allows the rapid screening of a greater number of fluorescent pseudomonad mutants by selection on minimal agars containing lactose as the sole carbon source and $\mathrm{X}$-gal as an indicator following induction in P. fluorescens SBW25 following exposure to infected seed or Pythium extracts. Similarly we have demonstrated with this approach that a number of genes in P. fluorescens are also repressed by exposure to Pythium [32]. These observations serve to illustrate the complex interactions that take place in the rhizosphere as the bacterium perceives and responds to its environment by sensing abiotic an biotic cues which result in the regulation of bacterial gene expression. The ecological relevance of these molecular signals should not be underestimated when developing strategies for field experimentation. Unless considerable care is taken in the design of laboratory and mesocosm based evaluations, inappropriate data may be collected for the prediction of activity and persistence following the open release of GMMs or any other inocula.

Substrate utilisation is not the only approach to the monitoring of bacteria. The potential for the use of antisera as an additional agent for detection has also been demonstrated where antisera to a coronavirus epitope was used to detect a recombinant variant of Pseudomonas fluorescens modified to express a lamBvirus chaemera on the cell surface [8]. These marker genes, and their associated substrates and reagents, have also been widely used a promoter probes for the detection of environmentally regulated gene expression. Examples of this include the construction of gene or operon fusion vectors based on the disarmed transposon system, miniTn5 originally described by Herrero et al. 1990 [18]. This delivery system has been widely applied for the mutagenesis of Gram-negative bacteria and is a valuable source of reagents for the rapid marking and genetic analysis of bacteria. Another approach we adopted used a combination of marker genes, targeted by site directed homologous recombination at different locations in a bacteria's chromosome, to study the autecology of a natural field isolate, Pseudomonas fluorescens SBW25 in microcosm and field studies [31] the assessment of gene transfer both from [5] and to [20] inocula introduced to the phytosphere of field grown crop plants. These investigations were based on the optimised experimental design for assessing the ecology and evaluating risk assessment guidelines for GMMs [19].

For the most part assessments of the performance and fitness of selected inocula remain experimental and broth grown monocultures are typical subjects used in laboratory situations or in simple constructed microcosms. However, for studies of the relevance of microbial function, more appropriately designed 
investigations are required that either simulate the natural world or which are actually undertaken in the field. Field investigations are demanding in terms of establishing and maintaining an experimental site, and the number of replicates needed for statistical analysis to offset biological variation which can often stretch the resources of most laboratories. The scale and complexity of the possible interactions between inocula and other components must, by definition, reduce field studies to a practically constrained number of factors. This has, until recently, meant that the microbial ecology of the natural environment has often been described in the context of a poorly defined black box where only a few practical measures of function, relative diversity and distribution can be made to predict fundamental processes and potential microbial activity. To better understand our surroundings and study the complexity of microbial interactions we have to build models. These models develop through simple observations of cause and effect, initially in defined conditions in the test tube, through bi-, tri, and multi-partite conditions until soil and plants are introduced to simulated the natural environment.

We have structured this chapter to discuss how experiments can be designed to study microbiology in the open field situation. Recent theoretical and practical advances in molecular and population genetics have progressed the discipline from the observational to a more precise science allowing predictive intervention. To date most releases, particularly in Europe, consist of small scale, controlled studies where the fate of inocula and its impact on the indigenous microflora has been assessed in the context of risk assessment [4, 36, 37]. As microorganisms multiply and are subject to selection pressures, including the exchange of genetic information, the uncertainty of the fate and effect that novel genetic traits have on the environment cannot be accurately predicted. It is therefore necessary to differentiate the real from perceived risks. These considerations precede the commercialisation of engineered microbial inocula, but should equally apply to the use of any exotic strain. To date, environmental releases with prototype strains are undertaken that have been purposely constructed to optimise detection but which avoid the use of traits that represent any known or perceived risk. Understandably the activity of these vector bacteria provides a base line against which the effect of novel expressed traits might be determined. Consents for environmental (field) releases are only granted by the national competent authority on a case-by-case basis. This position has not changed in the last decade despite the lack of direct evidence, with the analytical methods used, of unintentional harm resulting from deliberate releases of GMMs and GMOs. This situation may be the result of the cautious approaches used in the construction of GMMs, and the fact that fully competent inocula expressing introduced and/or over expressed biologically active molecules have not been widely released in the field situation. Indeed even studies using fluorescent pseudomonads chromosomally modified for the de novo expression of an introduced antifungal compound, such as phenazine-1-carboxylic acid (PCA) [33] had no observable adverse impact on the indigenous soil and rhizosphere microflora in mesocosm studies with $P$. fluorescens SBW25::phz [33] or in field release experiments where PCA producing Pseudomonas putida WCS358r were inoculated on wheat plants [16]. 


\section{Impact assessment}

When considering impact, perturbation and risk associated with the release of GMMs, it is not possible to provide all encompassing guidelines. One significant obstacle to providing a generalised method for assessing the risk (potential) is the diversity of microbes themselves. Non-the-less it remains incumbent upon those who wish to release genetically modified organisms to provide a risk assessment, which in general requires the following information:

1. The characteristics of donor and recipient organisms, vector DNA and GMM

2. The conditions of the release and of the receiving environment

3. The interaction with the environment, namely survival, multiplication, dissemination and environmental impact of the GMM

4. The sensitivity, specificity and practicality of monitoring techniques, waste treatment and emergency responses

We have based the following experimental approach on our own investigations. For further details of experimental outcome the reader is referred to more recent overviews of the studies [4] and reviews of pertinent statistical tools for field microbiology $[14,22,23]$.

\section{Procedures}

\section{Experimental approach}

The aims of the studies we undertook in 1993 and 1994 were to demonstrate the ability of the GMM to survive and colonise a sugar beet crop following seed inoculation and to determine whether any adverse impact on the microbial community diversity and function could be detected. The bacteria, $P$. fluorescens SBW25 was originally isolated from the sugar beet phytosphere as it was considered that an indigenous isolate would be more appropriate for ecological studies of population dynamics and gene flow. The wild type isolate was kept in laboratory culture for the minimum period possible to avoid adaptation, and by site directed homologous recombination two markers gene cassettes were introduced each at a separate site in the chromosome. The markers were chosen to facilitate detection on selective and indicator medium. Two separate locations in the chromosome were identified, which were presumably non-essential, to allow evaluations of the rate of marker gene transfer in situ. The markers cassettes were: aphl-xy/E (kanamycin resistance and catechol 2,3 dioxygenase expression) and lacZY (lactose utilisation as a sole carbon source 
by pseudomonads including $\beta$-galactosidase expression). Therefore the recombinant bacterium, $P$ fluorescens SBW25EeZY6KX, could be specifically selected as isolated blue colonies growing on minimal media supplemented with $100 \mu \mathrm{g} \mathrm{ml}-1$ kanamycin, lactose as the carbon source and X-gal. Identity was confirmed by the direct application of $1 \%(\mathrm{w} / \mathrm{v})$ catechol where colonies turn from blue to green due to the reduction of catechol by $\mathrm{C}-230$ to a yellow semi-aldehyde.

Three treatments, uninoculated, wild type inoculated and GMM inoculated, were compared. Studies intended to calculate population parameters (e.g. mean values and variances), to test hypotheses (e.g. compare means between treatments) or to test the fit of mathematical models, require careful design. Such designs must take into account the nature of the habitat and the presumed performance of inocula, and are dependent on the availability of resources, which dictate realistic and practical sampling methods to provide data suitable for statistical analyses. Treatment effects must be distinguished from natural variation. Factors which must be taken into account included the design of the field plots to meet the demands of sampling, monitoring and detection methods, the need for controls, replicates and reproducibility must not be overlooked; and appropriate methods for the introduction of bacterial inocula must have been determined in pilot investigations.

\section{Design and sampling of the release site}

The design must provide randomisation, replication and the use of 'treatment blocks' which account for natural variation or subdivisions of the material. We routinely prefer to adopt a multi plot randomised Latin square arrangement. Three main considerations are made in choosing this arrangement:

1. Evaluate the topography of the selected site, for example a gradient or slope may influence experimental conditions due to drainage, incident sunlight, prevailing wind etc. [to avoid bias the Latin square should be laid out perpendicular to any slope so that all treatments can be applied to all pre-determined positions on and across the gradient]. 
2. The use of sample "blocking" facilitates the use of statistical methods which increases precision when comparing treatment effects when estimating differences between blocks.

3. The use of several plots per treatment is essential to provide statistical power for the tests applied.

One important consideration must be the practical limitations imposed by the number of samples that can be collected, processed and accurately analysed with the resources available. To resolve this it is necessary to determine whether it is more valid to increase the numbers of replicates (plots) at the expense of the number of individual samples (plants) or vice versa. Many statistical texts address this problem. Some offer formulae for estimating the number of plots and samples needed to achieve specific levels of precision. For meaningful comparison all samples must collected at the same time of day, i.e., early morning, on every sampling occasion to avoid adverse diurnal influences [30] and to normalise as much as possible the procedure.

The rapid processing of samples is desirable to minimise postsampling change in the microbiology or decay on the material. It is similarly important to minimise physical differences between samples and the rate at which different samples are processed. It may be necessary to bulk samples. For example we have compared the outcome of collecting and pooling the tissues of three plants collected from each of three replicate plots with nine individual plants from the three plots. The bulking of the plants may aid in the reduction of variance but it can also result in an overestimate of mean values (e.g., GMM counts and other bacterial counts) and reduce the power of the statistical tests performed. Individually sampled plants increased the power of the statistical tests applied and allowed assessments of plant to plant variation and plot to plot variation to be determined. Where practical we advise that the pooling of samples be avoided.

Statistical analysis of data sets can be applied to estimate population parameters, to calculate the confidence of these estimates and distinguish significant from non-significant differences. Populations with normal distributions are most commonly described by a measure of central tendency (mean) and a measure of variability such as standard deviation, standard error, or coefficient of variation. Because estimates of the population size of epiphytic bacteria are 
often strongly skewed, where counts vary by several orders of magnitude, data can be normalised by logarithmic transformation where the mean of $\log _{10}$ data is expressed as the arithmetical mean. Furthermore, sample data should be standardised and expressed as a function of the colony forming units per gram dry weight of sample, this approach minimises soil or plant wet weight variation.

\section{Preparation and release of inocula to field}

The method of inocula preparation, broth conditions, liquid culture verses agar derived bacteria must be considered [38]. The age of the culture is also important. Stationary phase bacteria survive better in soils, though they may be less fit for establishing communities than mid-exponential grown bacteria. Similarly the method of inoculation needs to be resolved. For example is seed or soil drenching always adequate when the colonisation of both root and leaf habitats is required? Spray application can also be effective for targeting the phyllosphere. Essentially the most effective measures for activity, persistence and delivery are needed to enhance survival and ability to colonise. The impact and consequences of the possibility of inocula dispersal to the wider environment should also be considered. Wider environmental distribution may result following spray application of drenching [9] compared to release by direct seed dressing [20]. In studies of the efficacy of the biocontrol of damping-off disease we have determined that soil pre-treatment, prior to seed planting, is considerably more effective that seed inoculation or soil drenching at the time of planting [33].

\section{Sampling}

The collection of samples, the dispersal of bacteria from those samples, their dilution and plating on suitable media are all part of the experimental design. In our own studies sugar beet plants were divided into 6 identifiable and ecologically appropriate habitats based on previous experience with this crop [28]. At sampling 3 leaf types were taken (immature, mature and senescent leaves) and the roots dug up and shaken leaving closely adhering soil which was taken as the rhizosphere soil sample. The roots were then rinsed with sterile distilled 
water and peeled to give the rhizoplane sample and the root cortex (inner storage tissue) removed using sterile knives. Randomisation in the selection of plants was used to avoid bias in sampling. In almost all instances destructive sampling methods are employed, so plot size should be dictated by the numbers of samples needed to undertake the investigation without compromising the biology of the study (edge effects etc.). Many methods for the extraction and suspension of bacteria from environmental samples have been described [25]. Due to the interactions of the surface charges of bacteria and soil particles, bacteria are released from different soils and plant tissues under different ionic conditions. As soils and other samples vary substantially in their composition, a range of dispersants may be tested to improve the efficiency of bacterial extraction. Similarly if environmental DNA is to be extracted, standard methods should be tested and where necessary optimised for the material sampled.

Enumeration of bacteria by isolation on selective agars (population dynamics)

The benefits of agar based systems and colorimetric markers are that no specialised equipment is generally required and investigations can be undertaken in basic microbiology laboratories. Even the location of the GMM may be determined by the use of novel substrates or overlay methods where selective indicator agars can be used to suspend extorted leaves or roots and colony development followed. Indicator markers, bioluminescence and gfp, also prove very effective for evaluating spatial distribution and cellular activity both in situ and $e x$ situ.

Assessment of ecological impact through changes in carbon source utilization (BIOLOG) and relative species richness of identified bacterial groups (FAME-MIS)

Considerable improvements have been made in recent years with respect to characterising community diversity. Evidence has been acquired from plant and other environments that there is discernible community structure and succession of associated bacterial populations. This evidence has particularly come from isolation studies 
which applied high throughput bacterial identification systems such as fatty acid methyl ester (FAME) analysis, PAGE and substrate utilisation patterns to identify a broad range of taxa and more recently from the application of genomic fingerprint analysis and PCR based DGGE methods $[1,17,35]$. When considering the ecological impact of various experimental conditions, these methods may be applied to monitor changes in bacterial diversity, community structure, succession and short-term community dynamics [15]. Our own studies have shown that different plant habitats carry distinct communities and that the structure and taxonomic profiles of these communities change with the season and plant development [10, 21, 29]. Despite the naturally high diversity of these habitats, recurring populations have been detected in separate years, and an impact of released bacteria on community structure has been detected compared with control plants.

\section{Statistical tests}

An important test for distinguishing significant from non-significant differences in these and many other studies was the analysis of variance (ANOVA). We recommend Fry 1993 [14] to provide readers with a general understanding of statistics.

Data for ANOVA, as with the requirements for the many other statistical tests, has to be initially evaluated ensure it complied with the assumptions implicit in the test. The 3 main preconditions for applying the test are:

- 1. Unbiased collection of data. This can be fulfilled by the random assigning of treatments to plots in a Latin square design and the randomised selection of plants for sampling.

- 2. That data are normally distributed.

- 3. That the variances of the samples are similar.

Conditions 2 and 3 are tested using standard procedures and are usually achieved after Log transformation of the data. ANOVA tests the null hypothesis $\left(\mathrm{H}_{0}\right)$, that samples are drawn from populations with very similar means and may typically be applied to comparing bacterial counts. The null hypothesis determines that there are no significant differences in the sample means from treatments. This is 
a 'two tailed' test because if $\mathrm{H}_{0}$ should fail then the 'alternative hypothesis' is only that they are different and not that one treatment or other is greater. One-tailed tests are less stringent, but require prior predictions of 'greater than' and are not so common in microbiology and ecology.

ANOVA compares two or more sample means by dividing up or partitioning the variability of the samples into its components. This variability is calculated and partitioned as the sums of squares (SS) using standard formulae and is depicted here for one of our own experiments as the equation:

$$
\mathrm{SS}_{\text {total }}=\mathrm{SS}_{\text {treatment }}+\mathrm{SS}_{\text {plots across slope }}+\mathrm{SS}_{\text {plots up the slope }}+\mathrm{SS}_{\text {residual }}
$$

The reader may have seen similar equations for one and two-way ANOVA. This ANOVA examined whether the total bacterial counts on immature leaves were significantly different and if so the influence of the treatments and the position in the field on the count.

\section{Summary of considerations}

\section{Establishment of field experiment; checklist}

- Choice of bacteria (preferably natural to the release habitat) and markers.

- Piloting the experiment in a greenhouse or similar simulated field environment (mesocosm).

- Risk assessment.

- Application for consent for release.

- Experimental design incorporating statistical and practical considerations.

- Independent replicates with appropriate controls.

- Method of application of bacteria.

- Monitoring for affects on plant growth.

- Monitoring for affects on microbial community.

- Field site management (weeding, pesticides, fertilizer, watering etc.).

- Plot or plant markers. 
- Sampling at consistent time of day.

- Individual labelled bags or similar for samples.

- Storage container for transport (avoiding temperature change).

- Random co-ordinates for sampling.

- Extra samples for dry weights.

- Additional samples to avoid 'missing data' problems in data analysis.

- Take appropriate meteorological records associated with the sampling.

- Supply of spades, forks, cutters etc. (avoid cross-contamination between treatments).

- Minimise sampling to processing times and minimise differences between samples.

- Laboratory ready for return with samples to minimise handling time.

- Prepared sterile dispersant and dilution series.

- Homogeniser/shaker/stomacher.

- Media.

- Incubator temperature.

\section{Acknowledgements}

The authors wish to thank the Natural Environment Research Council, Department of the Environment, Ministry of Agriculture Fisheries and Food, Defra UK and the European Commission for their support.

\section{References}

1. Akkermans, DL, Van Elsas, JD, De Bruijn, FJ (1996) Molecular Microbial Ecology Manual, Kluwer Academic Press, Netherlands.

2. Ammann, RI, Ludwig, W, Schleifer, K-H. (1995) Phylogenetic identification and in situ detection if individual microbial cells without cultivation. Microbiol Rev 59: 143-169.

3. Bailey, MJ, Lilley, AK, Thompson, IP, Rainey, PB, Ellis, RJ (1995) Site directed chromosomal marking of a fluorescent pseudomonad isolated from the phytosphere of sugar beet; stability and potential for marker gene transfer. Mol Ecol 4: 755-764;

4. Bailey, MJ, Lilley, AK, Ellis, RJ, Bramwell, PA, Thompson, IP (1997) Microbial ecology, inoculant distribution, and gene flux within populations of bacteria colonising the surface of plants: Case study of a GMM field release in the United Kingdom. In: Van Elsas, JD, Trevors JT \& Wellington EM (eds). Modern Soil Microbiology pp 479-500, Marcel Dekker, New York. 
5. Bailey, MJ, Lilley, AK, Thompson, IP, Whipps, JM, De Leij, FAAM, Lynch, JM (1999). Deliberate release of Recombinant Micro-organisms. In: Demain, AL \& Davies, JE (eds), Manual of Industrial Microbiology and Biotechnology 2nd edition pp 693-703. ASM Washington.

6. Barry, GF (1988) A broad host range shuttle system for gene insertion into the chromosome of Gram-negative bacteria. Gene 71: 75-84.

7. Bramwell, PA, Barallon, RV, Rogers, HJ, Bailey, MJ (1995) Extraction and PCR amplification of DNA from the rhizoplane. In: Akkermans, ADL, Van Elsas, JD, DeBruijn, FJ (eds.). Molecular Microbial Ecology Manual pp 1.4.2, 1-20, Kluwer Academic Press, Netherlands.

8. Cebolla, A, Guzman, C, de Lorenzo, V. (1996) Non-disruptive detection of activity of catabolic promoters of Pseudomonas putida with an antigenic surface reporter system. Appl Environ Microbiol 62: 214-220.

9. DeLeij, FAAM, Sutton, EJ, Whipps, JM, Fenlon, JS, Lynch, JM (1995) Field release of a genetically modified Pseudomonas fluorescens on wheat: Establishment, survival and dissemination. Nature Bio/Technology 13: 1488-1992.

10. Ellis RJ, Thompson, IP, Bailey, MJ (1995) Metabolic profiling as a means of characterising plant-associated microbial communities. FEMS Microbiol Ecol 16: 9-18.

11. Ellis, RJ, Timms-Wilson, TM, Bailey, MJ (2000). Identification of conserved traits in fluorescent pseudomonads with anti-fungal activity. Environ Microbiol 2: 274-284.

12. Fedi, S, Tola, E, Moenne-Loccoz, Y, Dowling, DN, Smith, LM, O'Gara F (1997) Evidence for signalling between phytopathogenic fungus Pythium ultimum and Pseudomonas fluorescens F113: $P$. ultimum represses the expression of genes in and $P$. fluorescens $\mathrm{F} 113$, resulting in altered ecological fitness. Appl Environ Microbiol 63: 4261-4266.

13. Flemming, CA, Leung, KT, Lee, H, Trevors, JT, Greer, GW. (1994) Survival of lux-lac marked biosurfactant producing Pseudomonas aeruginosa UG21 in soil monitored by non-selective plating and PCR. Appl Environ Microbiol 60: 1606-1613.

14. Fry, JC (1993) Biological data analysis: a practical approach. Oxford: Oxford University Press.

15. Gilbert, GS, Parke, JL, Clayton, MK, Handelsman, J (1993) Effects of an introduced bacterium on bacterial communities on roots. Ecology 74: 840-854.

16. Glandorf, DCM, Verheggen, P, Jansen, T, Jorritsma, LS, Thomashow, LS, Leeflang, P, Smit, E, Wernars, K, Lauerijs, E, Thomas-Oates, JE, Bakker, PAHM, van Loon, LC (2001) Effect of genetically modified Pseudomonas putida WCS358r on the fungal rhizosphere microflora of field-grown wheat. Appl Environ Microbiol 67: 3371-3378.

17. Griffiths, RI, Whiteley, AS, O'Donnell, AG\& Bailey, MJ (2000). A rapid method for the coextraction of DNA and RNA from natural environments for the analysis of rDNA and rRNA based microbial community composition. Appl Environ Microbiol 66: 5488-5491.

18. Herrero, M, de Lorenzo, V, Timmis, KN (1990) Transposon vectors containing non-antibiotic resistance selection markers for cloning and stable chromosomal insertion of foreign genes in gram negative bacteria. J Bacteriol 172: 6557-6567.

19. Jansson, JJ, Van Elsas, JD, Bailey, MJ (2000) Tracking Genetically Engineered Micro-organisms. Landes Bioscience, Georgetown, Texas.

20. Lilley, AK, Bailey, MJ (1997) The acquisition of indigenous plasmids by a genetically marked pseudomonad population colonising the phytosphere of sugar beet is related to local environmental conditions. Appl Environ Microbiol 63: 1577-1583.

21. Lilley, AK, Fry, JC, Bailey, MJ, Day, MJ (1996) Comparison of aerobic heterotrophic taxa isolated from four root domains of mature sugar beet (Beta vulgaris). FEMS Microbiol Ecol 21: 231242.

22. MacIntosh, M (1991) Statistical for field testing of genetically engineered micro-organisms. In: Levin, MA \& Strauss, H (eds) Risk assessment in genetic engineering pp 219-239, McGraw Hill, New York.

23. McSpadden-Gardener, B, Lilley, AK (1997) Application of common statistical tools. In: Van Elsas JD, Trevors JT, Wellington EM (eds). Modern soil microbiology pp 501-523, Marcel Dekker, New York. 
24. Morgan, JAW, Winstanley, C, Pickup, RW, Saunders, JR (1991) Rapid immunocapture of Pseudomonas putida cells from lake water by using bacterial flagella. Appl Environ Microbiol 57: 503-509.

25. Olsen, RA, Bakken, LR (1987) Viability of soil bacteria-optimization of plate counting technique and comparison between total counts and plate counts within different size groups. Microb Ecol 13: 59-74.

26. Shaw, JJ, Dane, F, Geiger, D, Kloepper, JW. (1992) Use of bioluminescence for detection of genetically engineered micro-organisms released into the environment. Appl Environ Microbiol 58: 267-273.

27. Smit, E, Wernards, K, Van Elsas, JD (1996) Antibiotic resistance as a marker for tracking bacteria in the soil ecosystem. In: Akkermans, DL, Van Elsas, JD, De Bruijn, FJ (eds) Molecular Microbial Ecology Manual pp 6.1.6, 1-15, Kluwer Academic Press, Netherlands.

28. Thompson, IP, Bailey, MJ, Fenlon, JS, Fermor, TR, Lilley, AK, Lynch, JM, McCormack, PJ, McQuilken, M, Purdy, KJ, Rainey, PB, Whipps, JM (1993) Quantitative and qualitative seasonal changes in the microbial community from the phyllosphere of sugar beet (Beta vulgaris). Plant and Soil 150: 177-191.

29. Thompson, IP, Bailey, MJ, Ellis, RJ, Purdy, KJ (1993) Sub-grouping of bacterial populations by cellular fatty acid composition. FEMS Microbiol Ecol 12: 75-84.

30. Thompson, IP, Bailey, MJ, Ellis, RJ, Lilley, AK, McCormack, PJ, Purdy, KJ \& Rainey, PB (1995) Short term community dynamics in the phyllosphere microbiology of field grown sugar beet. FEMS Microbiol Ecol 16: 205-211.

31. Thompson, IP, Lilley, AK, Ellis, RJ, Bramwell, PA, Bailey MJ. (1995) Survival, colonisation and dispersal of genetically modified Pseudomonas fluorescens SBW25 in the phytosphere of field grown sugar beet. Nature Bio/Technology 13: 1493-1497.

32. Timms-Wilson, TM, Ellis, RJ, Bailey, MJ (2000). Immuno-capture differential display method (IDDM) for the detection of environmentally induced promoters in rhizobacteria. J Microbiol Methods 41: 77-84.

33. Timms-Wilson, TM, Ellis, RJ, Renwick, A, Rhodes, DJ, Weller, DM, Mavrodi, DV, Thomashow, LS, Bailey, MJ (2000) Chromosomal insertion of the phenazine biosynthetic pathway (phz$A B C D E F G$ ) enhances the efficacy of damping off disease control by Pseudomonas fluorescens. Mol Plant Micro Interact 13: 1293-1300.

34. Tombolini, R, Unge, A, Davey, ME, de Bruijn, FJ, Jansson, JK. (1997) Flow cytometric and microscopic analysis of GFP-tagged Pseudomonas fluorescens bacteria. FEMS Microbiol Ecol 22: $17-28$.

35. van Elsas, JD, Trevors, JT, Wellington, EMH (1997) Modern Soil Microbiology. Marcel Dekker, New York.

36. van Veen, JA, van Overbeek, LS, Van Elsas, JD (1997) Fate and activity of micro-organisms introduced to soil. Microbiol Molec Biol Rev 61: 121-325.

37. Wilson, M, Lindow, SE (1993) Release of recombinant micro-organisms. Ann Rev Microbiol 47: 913-944.

38. Wilson, M, Lindow, SE (1993). Effect of phenotypic plasticity on epiphytic survival and colonisation by pseudomonas syringae. Appl Environ Microbiol 59: 410-416. 